\title{
EFEITO DO NITROGÊNIO E POTÁSSIO NA PRODUÇÃO E NUTRIÇÃO DO PIMENTÃO EM AMBIENTE PROTEGIDO
}

\author{
MARIA ANITA GONÇALVES DA SILVA \\ Engenheira Agrônoma
}

Orientador: Prof. Dr. Antônio Enedi Boaretto

Tese apresentada à Escola Superior de Agricultura

"Luiz de Queiroz", Universidade de São Paulo, para obtenção do título de Doutor em Agronomia, Área de concentração:Solos e Nutrição de Plantas.

\author{
PIRACICABA \\ Estado de São Paulo - Brasil \\ Julho - 1998
}


Dados Internacionais de Catalogação na Publicação (CIP) DIVISÃo DE BIBLIOTECA E DOCUMENTAÇÃO - Campus "Luiz de Queiroz"/USP

Silva, Maria Anita Gonçalves da

Efeito do nitrogênio e potássio na produção e nutrição do pimentão em ambiente protegido / María Anita Gonçalves da Silva. - - Piracicaba, 1998.

86 p. : il.

Tese (doutorado) - - Escola Superior de Agricultura Luiz de Queiroz, 1998.

Bibliografia.

1. Crescimento vegetal 2. Nitrogênio 3. Nutrição vegetal 4. Pimentão 5. Potássio 6. Produtividade agrícola I. Título 


\section{ERRATA}

\begin{tabular}{|c|c|c|c|c|}
\hline Página & Parágrafo & Linha & onde se lê: & leia-se: \\
\hline vi & - & 5 & nitroênio & nitrogênio \\
\hline vii & - & - & página 57,58 e 59 & página 56,57 e 58 \\
\hline$x i$ & 1 & 12 & nutrientes & macronutrientes \\
\hline xii & 1 & 11 & nutrients & macronutrients \\
\hline$x i i$ & 1 & 15 & $3.0 \mathrm{mmo}_{\mathrm{c}} \mathrm{dm}^{-3}$ & $3.0 \mathrm{mmol}_{c} \mathrm{dm}^{-3}$ \\
\hline 4 & 3 & 5 & 469 a $737 \mathrm{mg} \mathrm{planta}^{-1}$ & 469 a $737 \mathrm{mg}$ por planta \\
\hline 9 & 4 & 3 & 5,44 e 6,86 & 54,4 e $68,6 \mathrm{~g} \mathrm{~kg}^{-1}$ \\
\hline 10 & 2 & 2 & 4,$24 ; 0,37$ e 4,02 & 42,$4 ; 3,7$ e $40,2 \mathrm{~g} \mathrm{~kg}^{-1}$ \\
\hline $15 / 37$ & 1 & $7 e 8 / 8$ e 9 & $26,4 \mathrm{~g} \mathrm{~m}^{-2}$ & $26,6 \mathrm{~g} \mathrm{~m}^{-2}$ \\
\hline $\begin{array}{c}21 e \\
43\end{array}$ & 2 & 2 e $3 / 1$ e 2 & $\begin{array}{l}333 \mathrm{~g} \mathrm{~kg}^{-1} \text { de argila, } \\
590 \mathrm{~g} \mathrm{~kg}^{-1} \text { de areia }\end{array}$ & $\begin{array}{l}330 \mathrm{~g} \mathrm{~kg}^{-1} \text { de areia, } \\
590 \mathrm{~g} \mathrm{~kg}^{-1} \text { de argila }\end{array}$ \\
\hline $21 / 43$ & 2 & 4 e $5 / 3$ e 4 & $\begin{array}{c}370 \mathrm{~g} \mathrm{~kg}^{-1} \text { de argila e } \\
530 \mathrm{~g} \mathrm{~kg}^{-1} \text { de areia }\end{array}$ & $\begin{array}{l}370 \mathrm{~g} \mathrm{~kg}^{-1} \text { de areia e } \\
530 \mathrm{~g} \mathrm{~kg}^{-1} \text { de argila }\end{array}$ \\
\hline 21 & 2 & 7 e 11 & $P($ Mehlich 1$)$ & $P($ Resina $)$ \\
\hline 21 & 2 & 8 e 14 & $\mathrm{~N}=0,18$ e $\mathrm{N}=0,17 \mathrm{~g} \mathrm{~kg}^{-1}$ & $\mathrm{~N}=1,8 \in \mathrm{N}=1,7 \mathrm{~g} \mathrm{~kg}^{-1}$ \\
\hline $21 / 44$ & $6 / 1$ & $2 / 4$ & 1 tha $a^{-1}$ & 20 tha $a^{-1}$ \\
\hline $22 / 44$ & 4 & 5 & área de $2,75 \mathrm{~m}^{2}$ & área de $0,30 \mathrm{~m}^{2}$ \\
\hline 23 & 2 & 1 & $30 / 06 / 97,39$ semanas & $30 / 08 / 97,34$ semanas \\
\hline 28 & 3 & 2 & $0,25 \mathrm{~cm}$ & $0,25 \mathrm{~m}$ \\
\hline 31 & 1 & 5 e 6 & $\begin{array}{l}\text { ON melhorou } \\
\text { (tabela 7) }\end{array}$ & $\begin{array}{c}\text { O N não melhorou } \\
\text { (tabelas } 7 \text { e } 8 \text { ) }\end{array}$ \\
\hline 35 & $2 / 4$ & $2 e 1$ & $\mathrm{~K}$ aplicado como $\mathrm{KCl}$ & $\mathrm{K}_{2} \mathrm{O}$ aplicado como $\mathrm{KCl}$ \\
\hline 47 & - & 6 & $(1),(1) e(1)$ & $(1),(2)$ e (3) \\
\hline 51 & tabela & 3 & $\mathrm{~g} \mathrm{~m}^{-2}$ & $\mathrm{~g} \mathrm{~kg}^{-1}$ \\
\hline 59 & 4 & 1 & $6,83 \mathrm{~g} \mathrm{~m}^{-2}$ & $6,83 \mathrm{~kg} \mathrm{~m}^{-2}$ \\
\hline 60 & 2 & 2 & 24,22 e $11 \%$ & $7,22 \odot 11 \%$ \\
\hline
\end{tabular}




\section{À Deus}

dedico

Ao meu pai querido (em memória), pelo exemplo de coragem, À minha mãe querida, pela confiança, força e convicção da vitória,

Aos meus irmãos Mônica e Marco, pelo imenso amor,

Aos meus cunhados Márcio e Jussara e a minha tia Bila, pelo apoio e carinho,

Ao Sérgio, pela admiração e afeto,

Ao Rafael, pela meiguice, ternura e bondade, 


\section{AGRADECIMENTOS}

À Universidade Estadual de Maringá, pela oportunidade de realização deste curso de pós-graduação.

À Escola Superior de Agronomia "Luiz de Queiroz" (ESALQ/USP), ao Centro de Energia Nuclear na Agricultura, da Universidade de São Paulo (CENA/USP) e ao Instituto Agronômico de Campinas (IAC), da Secretaria de Agricultura e Abastecimento do Estado de São Paulo, que possibilitaram a realização do curso.

Ao Prof. Dr. Antonio Enedi Boaretto, pela orientação, apoio e incentivo no planejamento e execução desta pesquisa.

Ao Prof. Dr. Takashi Muraoka pela amizade e ensinamentos.

À Dr'. Walkyria Bueno Scivittaro e Dr'. Arlete Marchi Tavares de Melo e Dr. Paulo Espíndola Trani, pelas facilidades oferecidas à realização do experimento em campo.

Ao funcionário Assis Lopes dos Santos pela dedicação e empenho nos trabalhos de campo.

Aos funcionários da seção de Hortaliças da Fazenda Santa Eliza, Instituto Agronômico de Campinas, pela colaboração e amizade.

À funcionária Henriqueta M. Gimenes Fernandes pela dedicação, amizade, eficiência e seriedade na realização das atividades de laboratório no CENAUSP.

Aos estagiários Felipe, Margarete e Rodrigo, do laboratório de Nutrição Mineral de Plantas do CENA-USP, pela amizade, alegre convivência e auxílio na realização das atividades de laboratório.

Às funcionárias Marileusa A. Bassi e Sandra Tereza Pereira pela amizade e colaboração nas análises de laboratório. 
À funcionária Maria Aparecida Callegaro pelo apoio na digitação.

Ao colega Cássio Hamilton Abreu Júnior, pelo apoio às determinações de nutrientes no solo.

À professora Gláucia M. Bovi Ambrosano, da Faculdade de Odontologia de Piracicaba da UNICAMP, pelas sugestões e colaboração na realização da análise estatística.

Ao Engenheiro Agrônomo Flávio Pagani de Castro, pela presteza e boa vontade no trabalho de campo.

Ao Sr. Luiz Carlos Lúcio, agricultor, produtor de pimentão em cultivo protegido, pela força, fé e dedicação ao trabalho

À bibliotecária Marilia R.G. Henyei, pela colaboração a normatização das referências bibliográficas.

Aos funcionários da Seção de Circulação, Empréstimo e Reprografia, do CENA-USP e ESALQ-USP, pela amizade e bom atendimento.

companheirismo.

Aos colegas do curso de pós-graduação pela amizade e

À Fundação de Amparo à Pesquisa do Estado de São Paulo - FAPESP, pelo financiamento da pesquisa.

À Fundação Coordenação de Aperfeiçoamento de Pessoal de Nível Superior (CAPES), pela concessão de bolsa de estudo.

Aos amigos Arlete, Bete, Gisele, Henriqueta, Marcos, Ozinaldo, Sérgio Gaspar e Walkyria, pelo carinho e incentivo nos momentos mais difíceis.

A todos os demais que de alguma forma auxiliaram e incentivaram a realização deste trabalho. 


\section{SUMÁRIO}

LISTA DE FIGURAS.................................................................................... vii

LISTA DE TABELAS.....................................................................................

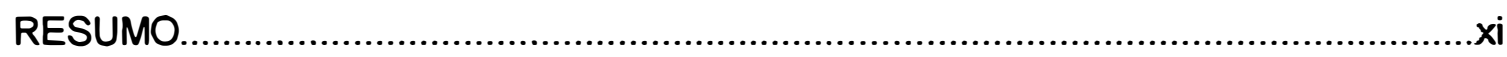

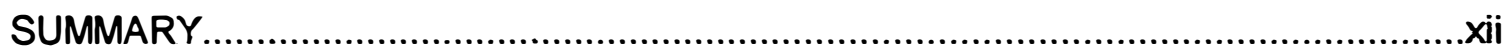

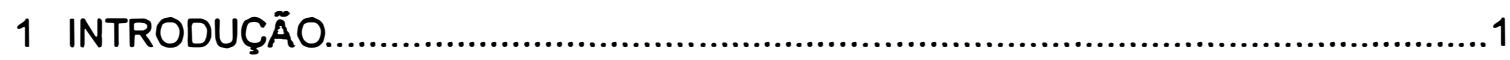

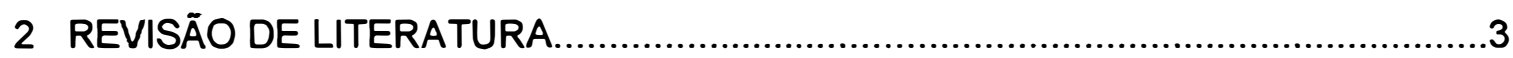

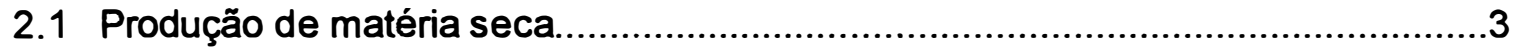

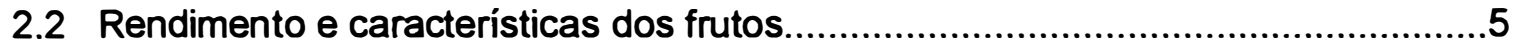

2.2.1 Produtividade de frutos de pimentão......................................................... 5

2.2.2 Características dos frutos....................................................................

2.3 Nutrição das plantas de pimentão...........................................................

2.3.1 Concentração de nutrientes em folhas........................................................8

2.3.2 Extração de nutrientes por plantas de pimentão........................................10

2.4 Adubação com $\mathrm{N}$ e $\mathrm{K}$ e teores de nutrientes no solo........................................12

3 EFEITO DO NITROGÊNIO E POTÁSSIO NO CRESCIMENTO E PRODUÇÃO DO PIMENTÃO CULTIVADO EM AMBIENTE PROTEGIDO.................................. 15

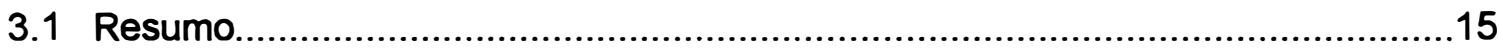

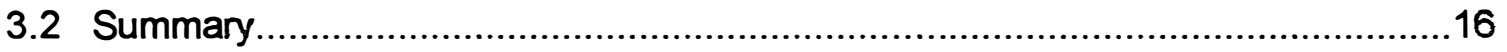

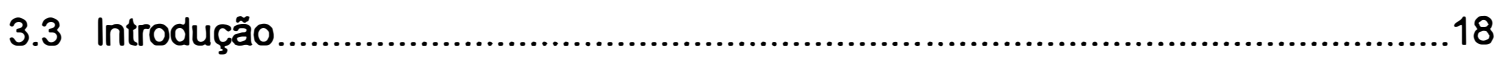

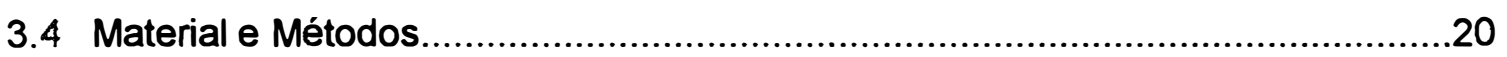




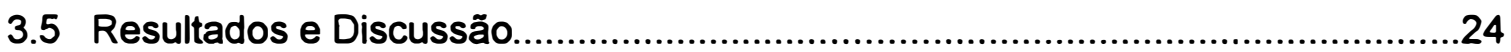

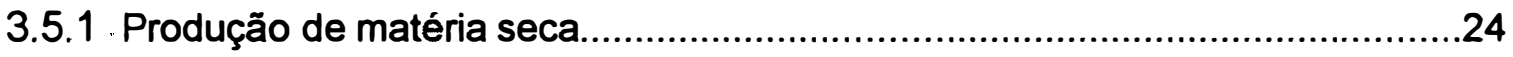

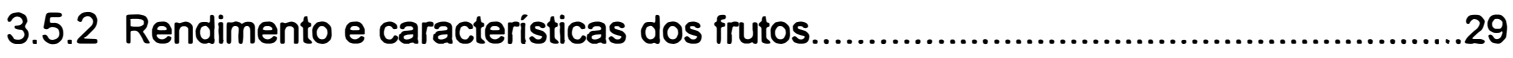

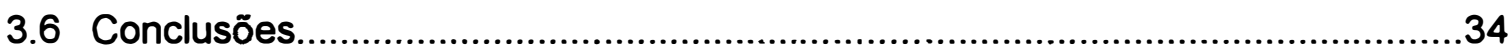

4.0 EFEITO DO NITROÊNIO E POTÁSSIO NA NUTRIÇÃO DO PIMENTÃO

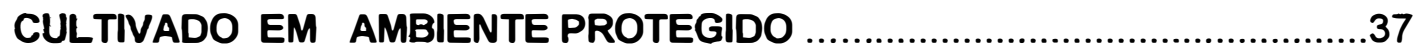

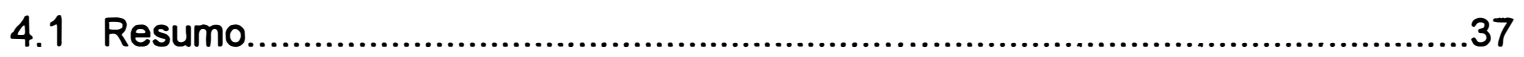

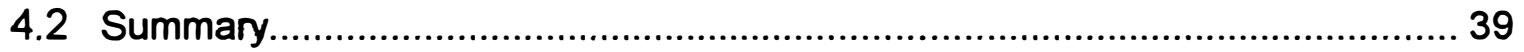

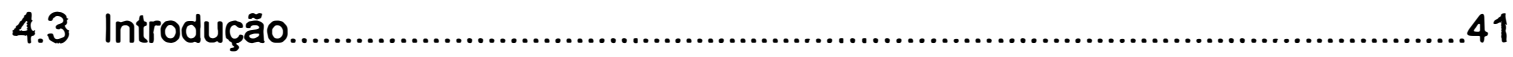

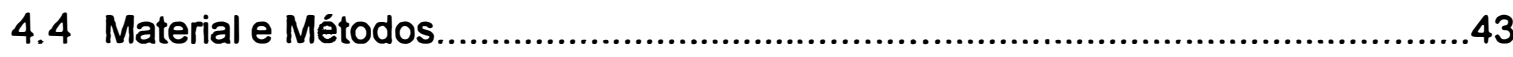

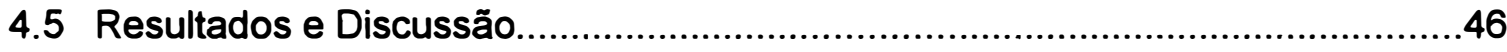

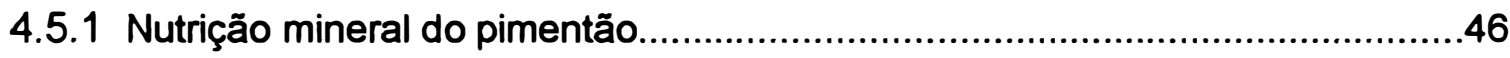

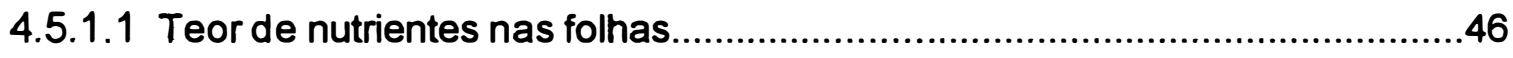

4.5.1.2 Acúmulo de nutrientes nos órgãos da planta.......................................... .53

4.5.2 Efeito da adubação nitrogenada e potássica nas características químicas

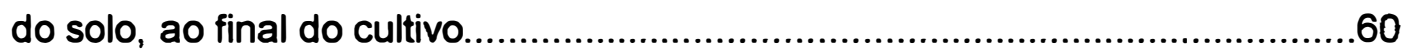

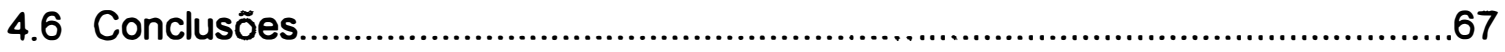

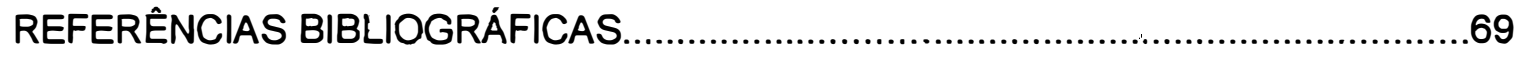

APÊNDICE 


\section{LISTA DAS FIGURAS}

Figura

Página

1 Acúmulo de nutrientes pelos frutos de pimentão, em função da aplicação de $\mathrm{N}$ no solo, na dose de $\mathrm{K}_{2} \mathrm{O}$ de $13,3 \mathrm{~g} \mathrm{~m}^{-2}$

2 Acúmulo de nutrientes pela parte aérea do pimentão, em função da aplicação de $\mathrm{N}$ no solo, na dose de $\mathrm{K}_{2} \mathrm{O}$ de $13,3 \mathrm{~g} \mathrm{~m}^{-2}$

3 Acúmulo de nutrientes pelos frutos de pimentão, em função da aplicação de $\mathrm{K}_{2} \mathrm{O}$ no solo, na dose de $\mathrm{N}$ de $26,6 \mathrm{~g} \mathrm{~m}^{-2}$

4 Acúmulo de nutrientes pela parte aérea do pimentão, em função da aplicação de $\mathrm{K}_{2} \mathrm{O}$ no solo, na dose de $\mathrm{N}$ de $26,6 \mathrm{~g} \mathrm{~m}^{-2}$

5 Distribuição percentual dos nutrientes na planta de pimentão, ao final do cultivo. 


\section{LISTA DE TABELAS}

Tabela

Página

1 Produção de matéria seca da parte vegetativa e dos frutos em relação à testemunha.

2 Tipos de equações de melhor ajuste para produção de matéria seca. .26

3 Peso de matéria seca de raízes em relação à testemunha

4 Peso de matéria seca de raízes em diferentes profundidades.

5 Produtividade e características de crescimento dos frutos de pimentão.

6 Produtividade e características de crescimento dos frutos de pimentão classificados como comercial.

$7 \quad$ Número total de frutos por planta.

8 Número total de frutos por área.

9 Características químicas do solo coletado antes e após calagem. 
10 Teores de nutrientes em folhas recém maduras de pimentão em diferentes estádios de desenvolvimento...

11 Teores de nutrientes em folhas e caules de pimentão

12 Concentração de nutrientes nas folhas em função da época de amostragem, comparado à testemunha.

13 Concentração de nutrientes em folhas recém maduras

14 Concentração de enxofre nas folhas, aos 83 dias após transplante......

15 Acúmulo de nutrientes pelo pimentão ao final do ciclo de cultivo, após 39 semanas.

16 Quantidades de nutrientes acumulados por plantas de pimentão, citadas na literatura...

17 Caracteristicas quimicas do solo ao final do cultivo.

18 Efeito das adubações nitrogenadas e potássicas sobre as características químicas do solo, em difere tes profundidades $(\mathrm{cm})$, ao final do cultivo

19 Concentração de $\mathrm{N}$ no solo (amoniacal e nitrico), em duas profundidades $(\mathrm{cm})$ ao final do cultivo.

20 Concentração de P Ca e Mg no solo, ao final do cultivo, em relação à testemunha.

21 Efeito das adubações nitrogenada e potássica sobre a concentração de P Ca e Mg, ao final do cultivo. 


\section{APRESENTAÇÃO}

A presente tese foi redigida em "Forma de Publicação ", de acordo com as normas para Elaboração de Teses da ESALQ (1997) e consta dos seguintes trabalhos cientificos:

- Efeito do nitrogênio e potássio no crescimento e produção de pimentão cultivado em ambiente protegido.

- Efeito do nitrogênio e potássio na nutrição de pimentão cultivado em ambiente protegido.

Antecedendo a apresentação dos referidos trabalhos encontramse um Resumo, Summary, Introdução e Revisão Bibliográfica. 


\title{
EFEITO DO NITROGÊNIO E POTÁSSIO NA PRODUÇÃO E NUTRIÇÃO DO PIMENTÃO CULTIVADO EM AMBIENTE PROTEGIDO
}

\author{
Autora : MARIA ANITA GONÇALVES DA SILVA \\ Orientador: Prof. Dr. ANTONIO ENEDI BOARETTO
}

\section{RESUMO}

Doses crescentes de $\mathrm{N}$ e $\mathrm{K}_{2} \mathrm{O}$ foram aplicadas em cobertura na cultura do pimentão, cultivado em ambiente protegido. Avaliou-se produção de matéria seca total, características de crescimento e produção dos frutos (peso, número de frutos por planta e por área, comprimento, diâmetro e rendimento), concentração foliar de nutrientes, no início do florescimento e frutificação, acúmulo de nutrientes e concentração de nutrientes remanescentes no solo, ao final do ciclo de cultivo. As doses de $\mathrm{N}$ de $26,6 \mathrm{~g} \mathrm{~m}^{-2}$ e $\mathrm{K}_{2} \mathrm{O}$ de $13,3 \mathrm{~g} \mathrm{~m}^{-2}$ proporcionaram melhor desenvolvimento vegetativo e produção de matéria seca da planta, maior número de frutos totais, assim como maior absorção de nutrientes pela planta. $\mathrm{O} \mathrm{N}$ e $\mathrm{K}_{2} \mathrm{O}$ aplicados ao solo não influenciaram o número, o peso e o rendimento de frutos comerciais, assim como o seu comprimento e o diâmetro. Ao final do cultivo, após 39 semanas, os nutrientes mais absorvidos pela planta foram $\mathrm{K}, \mathrm{N}$ e Ca e os nutrientes menos absorvidos foram $\mathrm{Mg}, \mathrm{P}$ e $\mathrm{S}$. A movimentação de cátions no solo, como o $\mathrm{NH}_{4}{ }^{+}, \mathrm{K}^{+}, \mathrm{Ca}^{2+} \mathrm{e} \mathrm{Mg}^{2+}$, ocorreu junto com a água de irrigação, embora concentraramse mais até a profundidade de $20 \mathrm{~cm} . \mathrm{O} \mathrm{N}-\mathrm{NO}_{3}{ }_{3}$, por outro lado, concentrou-se mais de 20 a $40 \mathrm{~cm}$ no solo. $O \mathrm{~K}_{2} \mathrm{O}$, aplicado como $\mathrm{KCl}$, em doses maiores que $13,3 \mathrm{~g} \mathrm{~m}^{-2}$, resultou em teor de $\mathrm{K}$ trocável maior que $3,0 \mathrm{mmol}_{\mathrm{c}} \mathrm{dm}^{-3}$, e foi prejudicial à produção de raízes, desenvolvimento da planta, absorção de nutrientes, produção, crescimento e rendimento dos frutos, provavelmente devido a um efeito salino do cloreto. 


\section{EFFECT OF NITROGEN AND POTASSIUM ON THE PRODUCTION AND NUTRITION OF SWEET PEPPER GROWN AT A PROTECTED ENVIRONMENT}

Author: MARIA ANITA GONÇALVES DA SILVA

Adviser: Prof. Dr. ANTONIO ENEDI BOARETTO

\section{SUMMARY}

Increasing rates of $\mathrm{N}$ and $\mathrm{K}_{2} \mathrm{O}$ were applied on the top of a sweet pepper crop grown at a protected environment submitted to trickle irrigation. The total dry matter production, yielding and growth characteristics of fruits (length and diameter), leaf concentration at early blooming and fructification, nutrient absorption, and nutrients remaining in the soil at the end of the crop cycle were evaluated. The $26.6 \mathrm{~g} \mathrm{~m}^{-2}$ rate for $\mathrm{N}$ and $13.3 \mathrm{~g} \mathrm{~m}^{-2}$ for $\mathrm{K}_{2} \mathrm{O}$ were the best for the production of total dry matter, number of total fruits per plant and per area as well as for a higher absorption of nutrients by the plant. Both $\mathrm{N}$ and $\mathrm{K}_{2} \mathrm{O}$ were applied onto the soil; however, neither affected the number, weight (production), and yield of commercial fruits, as well as the length and diameter of fruits. At the end of the cultivation, $\mathrm{K}, \mathrm{N}$, and $\mathrm{Ca}$ were the nutrients most absorbed by the plant, and $\mathrm{Mg}, \mathrm{P}$, and $\mathrm{S}$ were the least absorbed ones. $\mathrm{N}-\mathrm{NH}_{4}^{+}, \mathrm{K}^{+}, \mathrm{Ca}^{2+}$, and $\mathrm{Mg}^{2+}$ moved within the soil along with the irrigation water, although in higher concentrations at a $20-\mathrm{cm}$ depth. $\mathrm{N}-\mathrm{NO}_{3}$, on the other hand, was concentrated especially in 20 - to $40-\mathrm{cm}$ depths. The potassium, applied as $\mathrm{KCl}$, at rates higher than $13.3 \mathrm{~g} \mathrm{~m}^{-2}$ at concentrations in the soil over $3.0 \mathrm{mmo}_{\mathrm{c}} \mathrm{dm}^{-3}$ was harmful to root production, plant development, absorption, fruit production and yielding, probably because of a saline effect of the chloride. 


\section{INTRODUÇÃO}

Atualmente, o pimentão está entre as hortaliças mais importantes do Brasil, tanto em valor como em volume comercializado. É plantado em todo o país, sendo que as maiores áreas se localizam na região sudeste (Nascimento \& Borteux, 1992). O consumo pode ser sob a forma de frutos verdes ou maduros (vermelho, laranja, amarelo e até lilás), ou os frutos são utilizados sob a forma de pó, como condimentos.

O consumo de produtos hortícolas, escassos em determinadas épocas do ano, fora da estação, tem levado os agricultores a melhorarem e renovarem os sistemas de cultivo, de modo a obterem colheitas em períodos de baixas ofertas destes produtos no mercado interno. $\mathrm{O}$ cultivo em ambiente protegido possibilita uma produção contínua e certa, abastecendo o mercado o ano todo. Neste sistema tem-se conseguido colheitas com alto rendimento e qualidade dos produtos, em épocas do ano em que as condições normalmente são desfavoráveis no campo. Desse modo, é possivel abastecer e alcançar mercado nas estações de meses relativos a inverno e primavera. Várias hortaliças estão sendo produzidas nesse ambiente em túneis de plástico, entre elas o pimentão. Nesse ambiente, o comportamento da planta e sua necessidade nutricional é diferente da mesma planta cultivada no campo. Apesar disso, as mesmas doses de fertilizantes são indicadas para os dois sistemas de cultivo, enfatizando a necessidade de pesquisas sobre este assunto, que servirão de base para que os fertilizantes sejam usados pelos produtores de forma mais racional e econômica, além de evitar problemas ao solo, como o excesso de sais. Esse tem sido o maior problema nos cultivos em ambiente protegido pois nessas condições, mesmo com a quantidade de água controlada, tem-se uma a evaporação maior que a quantidade de água percolada, fazendo com os sais se acumulem à superfície do 
solo. Outro agravante são os cultivos sucessivos no mesmo local, o que torna ainda mais importante o conhecimento das necessidades nutricionais das cultura e 0 manejo correto dos fertilizantes aplicados. Os objetivos dos trabalhos são avaliar os efeitos de doses de $\mathrm{N}$ (uréia) e $\mathrm{K}_{2} \mathrm{O}$ (cloreto de potássio), aplicados parceladamente, durante o desenvolvimento da cultura, sobre o crescimento das plantas, crescimento, produção e rendimento de frutos e nutrição da cultura do pimentão. A tese está dividida em duas partes a saber:

1. Efeito do nitrogênio e potássio no crescimento e produção de pimentão cultivado em ambiente protegido.

2. Efeito do nitrogênio e potássio na nutrição do pimentão cultivado em ambiente protegido. 


\section{REVISÃO DE LITERATURA}

$\mathrm{Na}$ literatura encontraram-se trabalhos em que doses de $\mathrm{N}$ e $\mathrm{K}$ e seus efeitos em diferentes parâmetros da cultura do pimentão, como produção de matéria seca, rendimento de frutos, teor de nutrientes extraídos do solo, foram estudados isoladamente ou em conjunto. Na revisão de literatura esta mesma ordem foi obedecida, pois se fossem discutidos os efeitos das doses de $\mathrm{N}$ e K de maneira isolada, o que facilitaria a compreensão, haveria, por outro lado repetição de muitas citações comuns para o $\mathrm{N}$ e K.

\subsection{Produção de matéria seca}

O crescimento da planta depende da disponibilidade dos nutrientes no solo e de sua eficiência de utilização, e determina a produção de biomassa. Vários trabalhos mostram essa interrelação. Locascio \& Fiskell (1979) obtiveram aumentos significativos nas produções de matéria seca de folhas e caule de 32 para $45 \mathrm{~g} \mathrm{pl}^{-1}$ (primeiro experimento) e de 59 para $78 \mathrm{~g} \mathrm{pl}^{-1}$ (segundo experimento), quando as plantas tinham 12 semanas de desenvolvimento; as produções estavam relacionadas à 56 e $224 \mathrm{~kg} \mathrm{ha}^{-1}$ de $\mathrm{N}$ no solo. Vários outros autores, como Locascio et al. (1985), Hochmuth et al. (1987), Crespo Ruiz et al. (1988), Sing \& Srivastava (1988) obtiveram resultados semelhantes aos relatados acima. Porém, Locascio et al. (1981) não encontraram aumento na produção de matéria seca da parte aérea, relacionado ao $\mathrm{N}$.

Abdel Maksoud et al. (1975), Hochmuth et al. (1988) e Gollifer (1993) relacionaram a produção de matéria seca do pimentão com a dose de $\mathrm{K}$ aplicada no solo. Hochmuth et al. (1988) estudaram, em dois locais da Flórida, a relação entre os níveis de $\mathrm{K}$ no solo e o peso de matéria seca da planta e obtiveram 
resultados diferentes em cada localidade. Num dos locais, constataram que havia uma relação linear entre peso de matéria seca da planta, que aumentou de 57 a $77 \mathrm{~g}$ planta $^{-1}$ e os níveis de $\mathrm{K}$ aplicado ao solo, que esteve entre 35 a $255 \mathrm{~kg} \mathrm{ha}^{-1}$. Entretanto, em outros locais de experimentação, a mesma relação não foi constatada, não havendo efeito do nutriente na produção de matéria seca da planta e fruto e, as doses mais baixas foram suficientes para o máximo crescimento da planta. Em geral, o aumento do $\mathrm{K}$, resultou em plantas maiores, devido ao consumo de luxo, que absorveu mais o nutriente, porém não resultou no aumento de peso de matéria seca ou tamanho dos frutos.

O efeito conjunto do $\mathrm{N}$ e $\mathrm{K}$ na produção de matéria seca de plantas de pimentão foi estudado por Chougule \& Mahajan (1979), Graifenberg et al. (1985), Olsen et al. (1993) e Johnson \& Decoteau (1996).

Olsen et al. (1993) aplicaram ao solo $280 \mathrm{~kg} \mathrm{ha}^{-1}$ de $\mathrm{N}$ e $200 \mathrm{~kg} \mathrm{ha}^{-1} \mathrm{de}$ $\mathrm{K}$ e obtiveram, após 14 semanas do transplante, $7532 \mathrm{~kg} \mathrm{ha}^{-1}$ de matéria seca total distribuidos para os seguintes órgãos da planta: $2664 \mathrm{~kg} \mathrm{ha}^{-1}$ nos caules, $1528 \mathrm{~kg} \mathrm{ha}^{-1}$ nas folhas, $2747 \mathrm{~kg} \mathrm{ha}^{-1}$ nos frutos, e $594 \mathrm{~kg} \mathrm{ha}^{-1}$ nas raízes, durante o cultivo na primavera. A relação entre a massa de matéria seca e absorção de $\mathrm{N}$ foi linear. Exceto para os frutos, a matéria seca da planta foi maior no cultivo da primavera que no outono. Da mesma forma, Johnson \& Decouteau (1996) observaram um maior crescimento das plantas de pimentão cultivadas em ambiente protegido, em solução nutritiva contendo $\mathrm{N}$ e $\mathrm{K}$.

A aplicação de $\mathbf{N}$ também influenciou o desenvolvimento do sistema radicular das plantas de pimentão. Por exemplo, Leskovar et al. (1989), em ambiente protegido, relataram que o nutriente aumentou linearmente o número e comprimento de raízes basais e laterais de pimentão crescido em areia. Aos 60 dias do transplante, a matéria seca das raizes esteve entre 469 a $737 \mathrm{mg} \mathrm{planta}^{-1}$, quando as doses de $\mathrm{N}$ aumentaram de 112 a $224 \mathrm{~kg} \mathrm{ha}^{-1}$. Entretanto Goyal et al. (1988) não encontraram efeito do $\mathrm{N}$ no crescimento das raízes, para as mesmas profundidades de amostragem. Porém, o peso, densidade e percentagem de distribuição de raízes foram maiores até a profundidade de $22 \mathrm{~cm}$, onde a concentração radicular foi de $80 \%$. Uma pequena quantidade de raizes atingiu $44 \mathrm{~cm}$ no solo. 
Além dos nutrientes, outro fator importante no crescimento das de raízes é a umidade do solo. Bar Yosef et al. (1980) estudaram o efeito da adubação e água em pimentão e observaram que as raízes da planta, extendiam-se até $0,50 \mathrm{~m}$, lateramente aos gotejadores e até uma profundidade de $0,60 \mathrm{~m}$, seguindo a área umidecida do solo. Um outro exemplo desta dependência pode ser encontrado em Goyal et al. (1988). Os autores observaram que mais de $80 \%$ das raizes estiveram concentradas entre 0 e $22 \mathrm{~cm}$ de profundidade do solo, principalmente onde havia a maior distribuição de água pelos gotejadores.

\subsection{Rendimento e características dos frutos}

\subsubsection{Produtividade de frutos de pimentão}

É bem conhecida a importância do nitrogênio no crescimento, desenvolvimento e produtividade de pimentão. Na literatura existem muitos trabalhos evidenciando o efeito favorável do $\mathrm{N}$ no rendimento de frutos de pimentão (O'Sullivan, 1979; Knavel, 1977; Stroehlein \& Oebker, 1979; Batal \& Smitlle, 1981; Wiedenfeld, 1986; Payero \& Bhangoo, 1990; Locascio \& Alligood, 1992). Ótimos rendimentos foram conseguidos com doses de $\mathrm{N}$ entre 134 e $224 \mathrm{~kg} \mathrm{ha}^{-1}$, havendo entretanto, maiores respostas quando o $\mathrm{N}$ variou de 56 a $134 \mathrm{~kg} \mathrm{ha}^{-1}$ e pequeno percentual de resposta ( 8 a $10 \%$ ), quando a aplicação do nutriente foi em doses maiores que 224 kg ha ${ }^{-1}$ (Locascio \& Fiskell, 1977; Locascio \& Fiskell, 1979). Em dois anos de estudo, o rendimento de frutos de pimentão aumentou linearmente no primeiro ano, até doses de $224 \mathrm{~kg} \mathrm{ha}^{-1}$ de $\mathrm{N}$ e em outro ano, até doses de $308 \mathrm{~kg} \mathrm{ha}^{-1}$ de $\mathrm{N}$ (Locascio et al., 1981). De acordo com Batal \& Smitlle (1981), maiores produtividades foram conseguidas cultivando pimentão durante a primavera, comparado ao outono. Stroehlein \& Oebker (1979) reportam altos rendimentos, obtidos com a aplicação de 100 a $150 \mathrm{~kg} \mathrm{ha}^{-1}$ de N. Entretanto, segundo Hochmuth et al. (1994), o pimentão não respondeu a doses de $\mathrm{N}$ maiores que $134 \mathrm{~kg} \mathrm{ha}^{-1} \mathrm{e}$ a partir da dose de $269 \mathrm{~kg} \mathrm{ha}^{-1}$, a adubação nitrogenada causou diminuição na produção de frutos. 
Alguns trabalhos relacionam o efeito do potássio sobre o rendimento de frutos de pimentão (Hortenstine, 1962; Gollifer, 1972; Abdel Maksoud, 1975; Gollifer, 1993; Hassan \& Ramlan, 1994; Hochmuth et al., 1994). Hortenstine (1962) avaliou K em solos orgânicos e turfosos da Flórida; o nutriente foi colocado em área total e em faixas, de forma localizada, em solo com teor médio do elemento. No primeiro experimento, realizado em época mais chuvosa, houve melhor rendimento de frutos. Em outro experimento, em ano menos chuvoso, o $\mathrm{K}$ teve um efeito depressivo sobre $\mathrm{o}$ mesmo parâmetro. Gollifer (1972) obteve aumento de produtividade de $72 \%$. O efeito do nutriente foi maior quando foi aplicado sem o N. Da mesma forma, Gollifer (1993) aplicou K, com e sem adubação orgânica e também observou a importância do nutriente na melhoria de produção de frutos de pimentão. Outros autores não encontraram respostas, quando as doses de $K$ eram maiores que $146 \mathrm{~kg} \mathrm{ha}^{-1} \mathrm{e}$ raramente ocorreram respostas à produção de frutos quando a dose era mais que 67 $\mathrm{kg} \mathrm{ha}^{-1}$, mesmo em solos com baixos teores do elemento. (Hochmuth et al., 1988; Hochmuth et al., 1994).

Vários trabalhos referem-se ao efeito conjunto do $\mathrm{N}$ e $\mathrm{K}$ sobre $\mathrm{o}$ - rendimento de frutos de pimentão (Ramanathan, 1965; lley \& Ozaki, 1966; Lal e Pundrik, 1971; Albregts, 1971; Ramirez et al., 1978; Jaworski et al., 1978; Sharma \& Prazad, 1992; Carballo et al., 1994; Olsen \& Lyons, 1994; Silvestri \& Siviero, 1994 ; Moreno et al., 1996).

Jaworski et al. (1978) aplicaram doses de 84, 168, 336, 504 e $672 \mathrm{~kg}$ $\mathrm{ha}^{-1}$ de $\mathrm{N}$, juntamente com 70,$5 ; 141 ; 279 ; 418$ e $558 \mathrm{~kg} \mathrm{ha}^{-1}$ de $\mathrm{K}$, numa relação $\mathrm{N}: \mathrm{K}$ de 1:0,83, através de fertirrigação. Após um perídodo de 21 semanas, obtiveram rendimentos crescentes de frutos de 60 a $96 \mathrm{t} \mathrm{ha}^{-1}$. Os rendimentos foram semelhantes, para todos os tratamentos, durante as três primeiras colheitas, de acordo com as doses aplicadas. Somente após esse período é que foi evidenciada diferença entre os tratamentos. 


\subsubsection{Características dos frutos}

O nitrogênio promove maior crescimento vegetativo, submetendo menos os frutos a injúrias pelo sol, facilitando um desenvolvimento mais uniforme e melhor qualidade dos frutos. Estudos têm sido direcionados visando melhorar o rendimento e características dos frutos, como o uso de variedades melhoradas e práticas de manejo da adubação.

$\mathrm{O}$ efeito do $\mathrm{N}$ no número e peso de frutos de pimentão é referido em vários trabalhos, como os de O' Sullivan (1979); González \& Beale (1987); Hegde (1988); Locascio \& Stall (1994); o efeito do N em características de crescimento dos frutos, como comprimento e diâmetro, é referido por Singh \& Srivastava (1988); Singh et al. (1988); Goyal et al. (1989).

Singh \& Srivastava (1988) avaliaram a produção do pimentão em função do número de frutos por planta, peso, comprimento e diâmetro de frutos e encontraram, respectivamente, a 11,$7 ; 153,9 \mathrm{~g} ; 6,1 \mathrm{~cm}$ e 9,2 cm. Estes valores estavam relacionados com a maior dose de $\mathrm{N}$ aplicada (120 $\mathrm{kg} \mathrm{ha}^{-1}$ ). Com a mesma dose de $\mathrm{N}$ foi possível aumentar, em relação à testemunha, em $245 \%$ mais o número de frutos, $177 \%$ mais no peso de frutos e $30 \%$ mais no comprimento de frutos. Singh et al. (1988) encontraram frutos maiores e mais pesados, quando avaliaram doses e forma de aplicação do nutriente. Da mesma forma, Goyal et al. (1989) avaliaram durante 16 semanas o peso, comprimento e diâmetro de frutos de pimentão em função do N. Considerando o tempo de transplantio, foi estabelecida uma relação sigmoidal entre peso e diâmetro e uma relação linear para o comprimento dos frutos. A testemunha produziu frutos significativamente menores e de menor peso. Todos estes parâmetros dos frutos foram menores após a quinta colheita, sendo que mais de $50 \%$ dos frutos pesavam entre 20 e $50 \mathrm{~g}$ e menos de $40 \%$ deles tinham peso entre 50 e $130 \mathrm{~g}$. Os autores observaram melhor produtividade quando foi utilizada a fertirrigação e o $\mathrm{N}$ foi aplicado como uréia.

$\mathrm{O}$ efeito do $\mathrm{N}$ e $\mathrm{K}$ no número e peso de frutos de pimentão são reportados por Albregs (1971); Covarelli (1974); Ramirez et al. (1976), Everett \& 
Subramanya (1983), Silvestre \& Siviero (1994), Olsen \& Lyons (1994), Johnson \& Decoteau (1996) e Moreno et al. (1996). Os relatos são bastante divergentes.

Covarelli (1974) e Moreno et al. (1996), os últimos em ambiente protegido, verificaram que somente $0 \mathrm{~N}$ afetou o número de frutos por planta $\mathrm{e}$, da mesma forma, Khan \& Suryanarayana (1977) relacionam o aumento do comprimento e diâmetro dos frutos à quantidade de $\mathrm{N}$ presente no solo. Por outro lado, efeitos favoráveis de $\mathrm{N}$ e $\mathrm{K}$ no comprimento e diâmetro dos frutos, foram constatados por Subhani et al. (1990), que atribuiram ao nitrogênio maior crescimento vegetativo das plantas e ao potássio, maior translocação de carboidratos e desenvolvimento dos frutos. O aumento no peso dos frutos foi atribuído ao maior tamanho e conteúdo de sementes. Os resultados concordam com Joseph \& Pillai (1985), porém com doses mais baixas dos nutrientes aplicadas no solo.

Miller (1961), trabalhando em solução nutritiva, observaram que altas concentraçōes de $\mathrm{N}$ são prejudiciais ao tamanho e formato dos frutos, diminuindo, principamente o seu comprimento. O potássio é importante na produtividade, havendo em sua deficiência extrema redução no comprimento e diâmetro dos frutos.

\subsection{Nutrição das plantas de pimentão.}

\subsubsection{Concentração de nutrientes em folhas}

A concentração mineral em pimentão varia durante todo o ciclo de cultivo, dependendo de cada nutriente e do órgão vegetativo analisado. Quando a concentração está abaixo de um nivel considerado crítico, a produção está comprometida e quando a concentração está acima desse nível, o seu aumento não corresponde mais a aumentos de crescimento e produção, representando um consumo de nutriente desnecessário ou de luxo.

Haag et al. (1970) trabalhando em solução nutritiva, observaram que a concentração de $\mathrm{N}$ e K aumentou até 81 dias, estabilizou-se até 95 dias, decrescendo em seguida até 116 dias. A concentração de $P$ decresceu e o Ca aumentou com o 
envelhecimento da planta. $\mathrm{OMg}$ sofreu pequena oscilação no seu teor percentual, comparado ao S, que aumentou na parte vegetativa até aos 95 dias, estabilizando-se em seguida.

De acordo com Zomoza \& Arozarena (1986), no início da frutificação, o conteúdo de $\mathrm{N}$ nas folhas de pimentão foi significativamente superior aos outros órgãos da planta. Pecíolos e frutos mostraram níveis médios similares, enquanto o caule teve concentrações mais baixas. $O$ niveis de $P$ são menores nos caules, $e$ maiores nas folhas, peciolos e frutos. $\mathrm{O}$, Ca e $\mathrm{Mg}$ oferecem a seguinte distribuição quanto a concentração: peciolos $\rightarrow$ folhas $>$ caules $\gtrsim$ frutos. O teor de $\mathrm{Ca}$ nas folhas teve uma evolução ascendente com a idade da planta, demostrando seu caráter cumulativo nesse órgão, relacionado à sua participação nos tecidos de sustentação das células. O teor de $\mathrm{Mg}$ nas folhas se comportou de forma oposta ao que ocorreu nos frutos, refletindo claramente o processo de maturação dos mesmos, com perda e degradação de clorofila e diminuição do nutriente.

Miller et al. (1979) citaram teores (\%) de nutrientes nas folhas + peciolos e caule, no início da frutificação, respectivamente de: $N=4,9$ e 3,0; $P=0,38$ e 0,29; $K=4,7$ e 4,3; $\mathrm{Ca}=1,6$ e 0,8 e $\mathrm{Mg}=0,9$ e 0,8. Concentrações de $\mathrm{N}$ nas folhas semelhantes às citadas, no mesmo estádio de desenvolvimento, foram encontradas por Thomas \& Heilman (1964), Locascio et al. (1981), Hartz et al. (1993), teores esses que corresponderam aos mais altos rendimentos de frutos. Por outro lado, Salinas et al. (1982) observaram, em folhas amostradas durante a época de florescimento, maiores concentrações de $\mathrm{N}$ e $\mathrm{P}$ e menores concentrações de $\mathrm{K}, \mathrm{Ca}$ e $\mathrm{Mg}$.

De acordo com Miller (1961), o nivel de $\mathrm{N}$ nas plantas e frutos está diretamente relacionado ao no rendimento e qualidade dos frutos. Da mesma forma, o conteúdo de $\mathrm{N}$ nas folhas, tem sido usado como um parâmetro relacionado à produtividade de pimentão (Thomas \& Heilman, 1964, Thomas \& Heilman, 1967; Stroehlein \& Oebker, 1979).

Olsen \& Lyons (1994) obtiveram 95\% da produtividade máxima de frutos quando os teores de $\mathrm{N}$ nas folhas, no início do florescimento encontravam-se entre 5,44 e 6,86 (faixa de teores críticos). Teores semelhantes foram reportados por 
Sundstrom et al. (1984), Hochmuth et al. (1987), Locascio \& Alligood (1992) e Locascio \& Stall (1994). Entretanto, valores menores do que os citados, foram encontrados por Maynard et al. (1962) e Thomas \& Heilman (1964), no início do florescimento, ambos cultivando pimentão em ambiente protegido.

Locascio \& Fiskell (1979) referem-se a concentrações de N P K nas folhas de plantas, em plena frutificação, respectivamente, de 4,24; 0,37 e 4,02, correspondentes a $200 \mathrm{~kg} \mathrm{ha}^{-1}$ de $\mathrm{N}$, como uréia. A concentração foliar de $\mathrm{N}$ e K aumentou linearmente em relação às doses de $N$, enquanto que o $P$ não apresentou relação com as doses do nutriente no solo. Hochmuth et al. (1994) determinaram teores semelhantes de $\mathrm{N}$ nas folhas e maiores teores de $\mathrm{K}$, para a mesma época de amostragem.

As concentrações foliares de $\mathrm{N}$ determinadas por Locascio \& Fiskell (1977) estiveram relacionadas à dose do nutriente aplicada ao solo. O aumento da quantidade de $\mathrm{N}$ no solo, diminuiu o teor foliar de $\mathrm{K}$. Por outro lado, Abdel Maksoud et al. (1975) não encontraram efeito do K, na concentração foliar de NPK, durante dois anos de experimentação.

\subsubsection{Extração de nutrientes por plantas de pimentão}

O conhecimento da exigência nutricional das plantas é importante para se estabelecer as quantidades de nutrientes a serem aplicadas através de fertilizantes obtendo assim, os melhores rendimentos. A absorção de nutrientes é diferente de acordo com o desenvolvimento da planta, intensificando-se com a floração, formação e crescimento dos frutos. Analisando a absorção de nutrientes na parte vegetativa, Haag et al. (1970), em cultivo protegido, observaram um aumento de $\mathrm{N}, \mathrm{Ca}$ e $\mathrm{S}$ até o início da frutificação. O P foi absorvido mais intensamente até o início da floração, estabilizando-se em seguida. O K e Mg são absorvidos ao longo de todo o ciclo, sem apresentarem uma época preferencial de absorção. 
Graifenberg et al. (1985), em cultivo protegido, relacionaram a curva de absorção de nutriente com a curva de crescimento da cultura, estabelecendo três períodos distintos de desenvolvimento. No primeiro, do tranplantio até 90 dias, houve baixo desenvolvimento e baixa absorção de nutrientes. No segundo, de 90 a 130 dias, houve grande desenvolvimento e máxima absorção, sendo que a planta utilizou percentagens relativas a $62,64,55,50$ e 53 de N, P, K, Ca e Mg, respectivamente. No terceiro periodo, de 130 a 170 dias, ocorreram diminuições de absorção e desenvolvimento das plantas de pimentão. Em dois cultivares estudados, o $\mathrm{K}$ foi mais absorvido, seguido do $\mathrm{N}$ e $\mathrm{Ca}$, enquanto que o $\mathrm{P}$ e $\mathrm{Mg}$ foram bem menos exigidos. Ao final do cultivo, quando as plantas estavam com 24 semanas, os dois cultivares acumularam ( $\left(\right.$ planta $^{-1}$ ) : $\mathrm{K}=8,0$ e 12,$5 ; \mathrm{N}=6,7$ e 10,0; $\mathrm{Ca}=6,0$ e 9,$0 ; \mathrm{P}=1,0$ e 1,5 e $M g=1,0$ e 1,3. A produção de $10 t$ de frutos resultou em uma exportação de nutrientes diferente para cada cultivar estudado. No cultivar menos exigente, $10 \mathrm{t}$ de frutos exportaram: $41,0 \mathrm{~kg}$ de $\mathrm{N} ; 5,2 \mathrm{~kg}$ de $\mathrm{P} ; 51,2 \mathrm{~kg}$ de $\mathrm{K} ; 38,5 \mathrm{~kg}$ de $\mathrm{Ca}$ e 4,6 kg de $\mathrm{Mg}$; o outro cultivar exigiu $25 \%$ a mais de nutrientes para a mesma quantidade de frutos produzidos. Do início ao fim do ciclo, houve maior conteúdo de $\mathrm{N}, \mathrm{K}, \mathrm{Ca}$ e $\mathrm{Mg}$ nas folhas, enquanto que o $P$ permaneceu mais nos frutos.

Uma relação proporcional entre $N$, crescimento e absorção de nutrientes foi estabelecida por Crespo Ruiz et al. (1988). Os nutrientes mais absorvidos foram $\mathrm{K}, \mathrm{N}, \mathrm{Ca}, \mathrm{Mg}$ e $\mathrm{P}$. Após 15 semanas do transplante, as quantidades máximas acumuladas de NPK, calculadas pelos autores, foram ligeiramente menores que os resultados obtidos por Graifenberg et al. (1985).

Olsen et al. (1993) constataram que uma população de 40 mil plantas $\mathrm{ha}^{-1}$, após 14 semanas de idade, contadas a partir do transplante e cultivadas na primavera, acumularam as seguintes quantidades $\left(\mathrm{kg} \mathrm{ha}^{-1}\right)$ de nutrientes: $\mathrm{K}=210 ; \mathrm{N}=$ 195; $\mathrm{Ca}=78 ; \mathrm{Mg}=46 ; \mathrm{S}=34 \mathrm{P}=20$. No cultivo do outono, as quantidades acumuladas foram ligeiramente menores. Os frutos acumularam percentagens de $\mathrm{K}$, $\mathrm{N}$ e P de 40, 40 e 49 (no cultivo da primavera) e 64, 64 e 76 (no cultivo de outono), valores considerados altos quando comparados a outras partes da planta. Por outro lado, os frutos continham baixa proporção de $\mathrm{Ca}$ total (6\%), devido principalmente a sua baixa mobilidade na planta. 
Rincon et al. (1995) referem-se ao acúmulo de nutrientes $\left(\mathrm{g} \mathrm{m}^{-2}\right)$ por plantas de pimentão, após 21 semanas do transplante: $N=29,30 ; P=3,30 ; K=38,33$; $\mathrm{Ca}=12,07 ; \mathrm{Mg}=6,31$. Os resultados foram maiores aos obtidos por Miller et al. (1979); Locascio et al. (1985) e Hegde (1988). Os nutrientes que mais se acumularam nos frutos foram $\mathrm{N}$ e P. As taxas mais elevadas de absorção de NPK foram verificadas no período de maior produção de frutos e de $\mathrm{Ca} \mathrm{e} \mathrm{Mg}$, no período de maior crescimento foliar. Do total de nutrientes acumulados, os frutos contribuíram com $63 \%$ do $\mathrm{N}$ e $77 \%$ do $\mathrm{P}$, enquanto que as folhas contribuíram com $79 \%$ do $\mathrm{Ca}$ e $52 \%$ do $\mathrm{Mg}$. O $\mathrm{K}$ foi distribuído em partes iguais para frutos e demais órgãos vegetativos.

\subsection{Adubação com $\mathrm{N}$ e $\mathrm{K}$ e os teores dos nutrientes no solo}

Os nutrientes estão em constante equilíbrio no sistema solo-planta, sofrem diversas transformações, que interferem em suas concentrações no solo e disponibilidade às plantas. Nesse sentido, os fertilizantes são aplicados para aumentar as concentrações dos nutrientes no solo e suprir as exigências das culturas. Entretanto, muitas vezes, por serem aplicados em doses acima das necessárias, como vem acontecendo nos cultivos de pimentão em ambiente protegido, podem causar efeitos indesejáveis, como por exemplo, diminuir a produtividade e impossiblitar que novos cultivos sejam feitos no mesmo local, causando o que se tem chamado de salinização do solo. Neste item, são relatados os trabalhos da literatura com adubação nitrogenada e potássica e disponibilidade desses nutrientes no solo, ao final do ciclo de cultivo.

Cultivando pimentão durante dois anos, Locascio \& Fiskell (1977) aplicaram doses de $\mathrm{N}$ entre 56 e $224 \mathrm{~kg} \mathrm{ha}^{-1}$, sem contudo encontrarem alteração nos teores de amônio no solo, os quais mantiveram-se em torno de 9 ppm. Entretanto, 14 semanas após o transplante das mudas de pimentão, verificaram que o teor de nitrato aumentou de 6 para 13 ppm. Em outros anos subsequentes, porém, em função da aplicação de maiores doses de fertilizante nitrogenado, os teores de amônio e nitrato foram bem maiores. Ao final do cultivo, Fiskell et al. (1978) avaliaram doses 
crescentes de $\mathrm{N}$ no solo e eficiência de extratores. A concentração de amônio (extraido com $\mathrm{KCl} 1 \mathrm{~N}$ ) foi de $39 \mu \mathrm{g} \mathrm{g}^{-1}$. O nitrato, aplicado de diversas fontes de fertilizantes, esteve entre 36 e 78 ppm. Hochmuth et al. (1994) referem-se a concentrações de nitrato, na linha de plantio, semelhantes aos últimos autores, em dois locais da Flórida, após 19 semanas. Por outro lado Hochmuth et al. (1994) determinaram concentrações de nitrato bem menores, no mesmo local amostrado.

Estudos sobre $\mathrm{o}$ efeito de doses e fontes de $\mathrm{N}$ de diferentes solubilidades, sobre nas concentrações do nutriente no solo foram feitos por Locascio et al. (1981). Os teores de amônio, nitrato e $\mathrm{N}$ total, quando se aplicou uréia, foram, respectivamente: 38,74 e 112 ppm. Teores bem menores foram citadas por Locascio \& Alligood (1992), para o mesmo período de cultivo.

Teores de K no solo, após cultivo do pimentão são reportados por Fiskell et al. (1978) e Hochmuth et al. (1994). Os primeiros autores avaliaram teores de 101 e $84 \mathrm{mg} \mathrm{g}^{-1}$ de $\mathrm{K}$, respectivamente, extraído por acetato de amônio e duplo ácido. 
EFEITO DO NITROGÊNIO E POTÁSSIO NO CRESCIMENTO E PRODUÇÃO DO PIMENTÃO CULTIVADO EM AMBIENTE PROTEGIDO 


\section{EFEITO DO NITROGÊNIO E POTÁSSIO NO CRESCIMENTO E PRODUÇÃO DO PIMENTÃO CULTIVADO EM AMBIENTE PROTEGIDO}

\subsection{Resumo}

O trabalho teve por objetivos : (a) avaliar o efeito do $\mathrm{N}$ e $\mathrm{K}_{2} \mathrm{O}$, aplicados em cobertura, sobre o crescimento e produção de matéria seca de plantas de pimentão, cultivado em ambiente protegido; (b) relacionar doses de $\mathrm{N}$ e $\mathrm{K}_{2} \mathrm{O}$, à caracteristicas de crescimento, produção e rendimento de frutos. $O$ experimento foi conduzido no Centro experimental de Campinas do Instituto Agronômico (IAC), Fazenda Santa Elisa, de novembro/96 a agosto/97 e constou dos seguintes tratamentos: controle e as combinações de 3 doses de $\mathrm{N}\left(13,3 ; 26,4\right.$ e $\left.39,9 \mathrm{~g} \mathrm{~m}^{-2}\right)$ e 3 doses de $\mathrm{K}_{2} \mathrm{O}\left(13,3 ; 26,4\right.$ e $\left.39,9 \mathrm{~g} \mathrm{~m}^{-2}\right)$. O delineamento experimental adotado foi o de blocos ao acaso, em esquema fatorial $(3 \times 3+1)$, com 4 repetições, totalizando 40 parcelas. Cada parcela foi composta de 11 plantas, num total de 444 plantas. 0 cultivo foi feito em tunel de plástico. Durante todo o periodo de crescimento da cultura foram realizados tratos culturais, incluindo irrigação por gotejamento. Os frutos foram colhidos recém maduros, após atingirem ponto de consumo. Foram avaliados a produção de matéria seca total (parte vegetativa, frutos e raizes), características de produção e crescimento (peso, número de frutos por planta, comprimento e diâmetro) além do rendimento dos frutos. Com base nos resultados, foram obtidas as seguintes conclusões : 
1. $\mathrm{ON}$ aumentou a produção de matéria seca do caule, folhas, parte aérea e raízes, não tendo efeito na produção de matéria seca dos frutos. Comparativamente à testemunha, a melhor dose de $\mathrm{N}$ foi de $26,6 \mathrm{~g} \mathrm{~m}^{-2}$.

2. A contribuição do peso de matéria seca do caule, folhas, caule + folhas e frutos foi de 31,$5 ; 15,7 ; 47,2$ e $53,1 \%$, respectivamente, em relação ao peso de matéria seca total da parte aérea.

3. O efeito favorável do $\mathrm{N}$ na produção de matéria seca total ocorreu somente em baixas concentraçōes de $\mathrm{K}_{2} \mathrm{O}$ no solo $\left(13,3 \mathrm{~g} \mathrm{~m}^{-2}\right)$.

4. $\mathrm{ON}$ aumentou $\mathrm{O}$ número total de frutos produzidos por planta e por área, embora não tenha afetado o número de frutos comerciais e as características de crescimento dos frutos comerciais, como peso, comprimento e diâmetro, e consequentemente não afetou também $o$ rendimento de frutos comerciais.

5. $\mathrm{O} \mathrm{K}_{2} \mathrm{O}$, aplicado como $\mathrm{KCl}$, em doses maiores que $13,3 \mathrm{~g} \mathrm{~m}^{-2}$, teve efeito depressivo no crescimento da planta, crescimento, produção e rendimento de frutos, como consequência de um menor crescimento de raízes.

\section{EFFECT OF NITROGEN AND POTASSIUM ON GROWTH AND PRODUCTION OF SWEET PEPPER GROWN AT A PROTECTED ENVIRONMENT}

\subsection{Summary}

The goals of this work were to evaluate the effect of top application of nitrogen and potassium on the growth and production of dry matter of sweet pepper plants grown at a protected environment, relate $\mathrm{N}$ and $\mathrm{K}_{2} \mathrm{O}$ rates to the characteristics of growth, production, and yield of fruits, and relate the production of dry matter to fruit yielding. 
The experiment was conducted at the Centro Experimental de Campinas, of the Instituto Agronômico (IAC), Santa Elisa farm, from November/96 through Augusv97, with the following treatments: control and combination of three rates of $N(13.3,26.4$, and $\left.39.9 \mathrm{~g} \mathrm{~m}^{-2}\right)$ and three rates of $\mathrm{K}_{2} \mathrm{O}\left(13.3,26.4\right.$ and $\left.39.9 \mathrm{~g} \mathrm{~m}^{-2}\right)$. The experimental block design was randomized, in a factorial scheme $(3 \times 3+1)$, with four replications in a total of 40 plots. Each plot comprised 11 plants in a total of 444 plants. Cultural handling was performed including trickle irrigation along the entire development period of the crop. The fruits were collected just as they ripened, when ready for consumption. The production of total dry matter (plant part, fruits, and roots), growth characteristics (weight, length, and diameter), and yield of fruits were evaluated. The results led to the following conclusions:

1. The nitrogen increased the production of dry matter of the stem, leaves and top part, with no effects on the production of fruit and roots dry matter. Comparatively to the control plant, the best rate of $\mathrm{N}$ was $26.6 \mathrm{~g} \mathrm{~m}^{-2}$.

2. The contribution of the weight of the dry matter of the stem, leaves, stem + leaves, and fruits was $31.5,15.7$, and $53.1 \%$ in relation to the weight of the top parts total dry matter.

3. The favorable effect of the nitrogen on the production of total dry matter occurred only at low concentrations of potassium in soil $\left(13.3 \mathrm{~g} \mathrm{~m}^{-2}\right)$.

4. The nitrogen increased the total number of fruits produced per plant and per area, although not affecting the number of commercial fruits and the growth characteristics of commercial fruits such as weight, length, and diameter, accordingly not affecting the yield of commercial fruits either.

5. The potassium had a depressive, suppied $\mathrm{KCl}$ to upper $13.3 \mathrm{~g} \mathrm{~m}^{-2}$, effect on growth production, and yield of fruits as a consequence of a lower roots growth and nutrient absorption. 


\subsection{Introdução}

O pimentão destaca-se entre as solanaceas por ter alto consumo e grande importância econômica, no Brasil e exterior, principalmente nos Estados Unidos, México, Itália, Japão e Índia.

No mercado é comercializado como frutos verdes e vermelhos, principalmente, sendo produzidos também frutos laranja, amarelo e até lilás, mais exóticos, que alcançam preços mais pela excentricidade. A pigmentação influencia no sabor e aroma e os frutos vermelhos são mais saborosos, porque têm $50 \%$ mais substância picante, a capsaína (Fonseca, 1986). O valor nutritivo dos frutos deve-se à presença de vitaminas, em especial a vitamina $\mathrm{C}$, essencial à nutrição humana, cujo teor pode chegar até $1,5 \mathrm{~g}\left(100 \mathrm{~g}^{-1}\right.$ de peso seco, além de $10 \%$ de proteinas (El Saied, 1995). Contém ainda outras vitaminas (A, B1, B2) e minerais como Ca, Fe e P (Poblete, 1971).

O pimentão tem uma larga adaptabilidade de cultivo, crescendo em condições tropicais e subtropicais, sob os mais variados tipos de solo e fertilidade, sendo porém bem exigente em nutrientes. $O$ uso de fertilizantes deve ser feito criteriosamente, principalmente com relação ao $\mathrm{N}$, o qual concentra-se no solo na forma nítrica, que apresenta alta mobilidade vertical, podendo atingir o lençol freático e contaminar os mananciais aquiferos, próximos a áreas agrícolas, causando poluição ambiental (Jones \& Schwab, 1993). Em cultivo protegido, esse problema é menor porque os nutrientes são fornecidos de forma controlada, junto com a água, através de irrigação por gotejo ou através de fertiirrigação.

Atualmente o cultivo de hortaliças, em ambiente protegido, entre as quais o pimentão, assume cada vez mais importância, porque permite a produção em diferentes época, alcançando maiores preços no mercado. Porém, há escassez de informações sobre o comportamento e as exigências nutricionais da cultura nesse ambiente, sendo que, em geral, as recomendações de adubação se baseiam em trabalhos realizados com o pimentão, cultivado em condições de campo. 
O nitrogênio é o principal nutriente que estimula o crescimento vegetativo e produção de biomassa, podendo, por esse motivo, quando fornecido em altas quantidades, atrasar o florescimento e frutificação. Stroehlein \& Oebker (1979) relatam que doses maiores que $280 \mathrm{~kg} \mathrm{ha}^{-1}$ são consideradas altas, mesmo quando aplicadas parceladamente, pois favorece produção de excessiva folhagem, prolongando o ciclo vegetativo da planta. Por outro lado, Hassan et al. (1993) verificaram que doses de $\mathrm{N}$ maiores que $224 \mathrm{~kg} \mathrm{ha}^{-1}$, aplicadas de uma só vez, após o transplante das mudas, resultaram em menor crescimento vegetativo da cultura, principalmente devido a alta solubilidade da uréia. Redução no peso seco das plantas foi evidenciada por Locascio et al. (1981) usando doses de $\mathrm{N}$ maiores que $308 \mathrm{~kg}$ $\mathrm{ha}^{-1}$, aplicado em área total. $\mathrm{O}$ excesso de sais solúveis no solo, devido ao uso de diferentes fontes de $\mathrm{N}$, foi a principal causa do menor crescimento das plantas de pimentão, verificado por Hochmuth et al. (1987).

Por outro lado, vários autores (Manchanda \& Singh, 1987; Shukla et al., 1987; Hochmuth et al., 1987; Manchanda \& Singh, 1988) referem-se ao efeito favorável de doses de $\mathrm{N}$ aplicadas ao solo, no crescimento e produção de matéria seca da planta e frutos de pimentão. Hochmuth et al. (1987) encontraram em Manatee, Flórida, uma produção de matéria seca de frutos de 80,7 e 101,7 g, respectivamente, para as doses de 160 e $222 \mathrm{~kg} \mathrm{ha}^{-1}$ de $\mathrm{N}$, enquanto que a produção de matéria seca da parte vegetativa da planta, para os mesmos niveis de $\mathrm{N}$ no solo, foi de 60,5 e 72,2 $\mathrm{g} \mathrm{pl}^{-1}$. Em Martin, foram encontrados valores de matéria seca menores, embora as doses de $\mathrm{N}$ aplicadas fossem mais altas.

Gollifer (1993), na Índia, observou influência do K, no crescimento de plantas de pimentão, em solos ricos em matéria orgânica e de boa fertilidade. A maior produção de matéria seca ( $\mathrm{g}$ planta ${ }^{-1}$ ), após 28 semanas do transplante foi de 102,9; 76,$3 ; 131,1$ e 24,1 ; respectivamente para caule, folhas, frutos e raizes. De forma contrária, Chougule \& Mahajan (1979 ) e Abdel Maksoud et al. (1975) não encontraram relação entre as doses de $\mathrm{K}$ e crescimento da planta.

A influência do $\mathrm{N}$ e $\mathrm{K}$ no rendimento de frutos de pimentão foi estudada por lley \& Ozaki, 1966; Everett, 1976; Everett \& Subramanya, 1983; Prince et al., 1988). Avaliando a proporção $N: K$ de 1:1,15, Everett (1976) encontrou melhores 
rendimentos quando altas quantidades dos nutrientes foram aplicadas no outono ( doses de 726 e $837 \mathrm{~kg} \mathrm{ha}^{-1}$, respectivamente para $\mathrm{N} \mathrm{e} \mathrm{K}$ ). Na primavera os melhores rendimentos exigiram a metade das doses utilizadas no outono. Segundo lley \& Ozaki (1966), altas quantidades de $K$, comparativamente ao $N$, em proporções de 1:1; $1: 3 ; 1: 6$, estiveram relacionadas às maiores produtividades de frutos. $O$ nível 1 correspondeu a $336 \mathrm{~kg} \mathrm{ha}^{-1}$ de $\mathrm{N}$.

Quando a produção do pimentão foi avaliada através do número e peso médio dos frutos por planta, Mishriky \& Alphonse (1994) observaram que o N favoreceu esses parâmetros. De forma semelhante, Chougule \& Mahajan (1979) referem-se a um maior crescimento dos frutos em comprimento e diâmetro devido ao N. O K não afetou nenhum dos parâmetros avaliados, embora Jeyaraman \& Balasubramanian (1988) evidenciaram a importância do nutriente, observando uma relação linear para o número de frutos por planta.

Os objetivos do trabalho foram :

1. Avaliar o efeito de doses de $\mathrm{N}$ e $\mathrm{K}_{2} \mathrm{O}$, aplicados em cobertura, sobre o crescimento e produção de matéria seca de plantas de pimentão.

2. Relacionar doses de $\mathrm{N}$ e $\mathrm{K}_{2} \mathrm{O}$, aplicados em cobertura, ao rendimento, produção e características de crescimento dos frutos (peso, número de frutos por planta e por área, comprimento e diâmetro).

\subsection{Material e Métodos}

Desenvolveu-se 0 presente experimento em tunel de plástico, com dimensões de $7,0 \times 30,0 \mathrm{~m}$, ou área de $210 \mathrm{~m}^{-2}$, seguindo-se as mesmas condições de plantio e condução da cultura, adotadas pelos agricultores. 
O experimento foi conduzido no Centro Experimental de Campinas, S.P., Fazenda Santa Elisa, Instituto Agronômico da Secretaria de Agricultura e Abastecimento do Estado de São Paulo.

O solo da área experimental foi classificado como latossolo vermelho escuro distrófico. A análise granulométrica apresentou, na camada de 0 a $20 \mathrm{~cm}: 333$ $\mathrm{g} \mathrm{kg}^{-1}$ de argila, $80 \mathrm{~g} \mathrm{~kg}^{-1}$ de silte e $590 \mathrm{~g} \mathrm{~kg}^{-1}$ de areia e densidade do solo de $1,12 \mathrm{~g}$ $\mathrm{cm}^{-3}$; na camada de 20 a $40 \mathrm{~cm}$, o solo apresentou $370 \mathrm{~g} \mathrm{~kg}^{-1}$ de argila, $100 \mathrm{~g} \mathrm{~kg}^{-1} \mathrm{de}$ silte, $530 \mathrm{~g} \mathrm{~kg}^{-1}$ de areia e densidade do solo de $1,37 \mathrm{~g} \mathrm{~cm}^{-3}$. A análise química, após calagem, adubação orgânica e fosfatada, apresentou na camada de 0 a $20 \mathrm{~cm}$ : pH $\left(\mathrm{CaCl}_{2}\right)=5,7 ;$ matéria orgânica $=24,0 \mathrm{~g} \mathrm{dm}^{-3} ; \mathrm{P}\left(\right.$ Mehlich-1) $=199,0 \mathrm{mg} \mathrm{dm}^{-3} ; \mathrm{S}^{-\mathrm{SO}_{4}}=$ $250,7 \mathrm{mg} \mathrm{dm}^{-3} ; \mathrm{N}=0,18 \mathrm{~g} \mathrm{~kg}^{-1} ; \mathrm{K}=3,2 \mathrm{mmol}_{\mathrm{c}} \mathrm{dm}^{-3} ; \mathrm{Ca}=52,0 \mathrm{mmol}_{\mathrm{c}} \mathrm{dm}^{-3} ; \mathrm{Mg}=19,0$ $\mathrm{mmol}_{\mathrm{c}} \mathrm{dm}^{-3} ; \mathrm{H}^{+}+\mathrm{Al}^{3+}=22,0 \mathrm{mmol}_{\mathrm{c}} \mathrm{dm}^{-3} ; \mathrm{S}=74,2 \mathrm{mmol}_{\mathrm{c}} \mathrm{dm}^{-3} ; \mathrm{T}=96,2 \mathrm{mmol}_{\mathrm{c}} \mathrm{dm}^{-3}$; $V=77 \%$. Para a camada de 20 a $40 \mathrm{~cm}$, os resultados foram: $\mathrm{pH}\left(\mathrm{CaCl}_{2}\right)=4,8$;

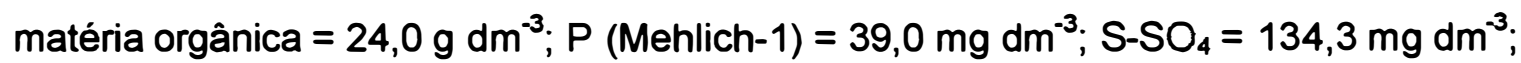
$\mathrm{N}=0,17 \mathrm{~g} \mathrm{~kg}^{-1} ; \mathrm{K}=3,5 \mathrm{mmol}_{\mathrm{c}} \mathrm{dm}^{-3} ; \mathrm{Ca}=27,0 \mathrm{mmol}_{\mathrm{c}} \mathrm{dm}^{-3} ; \mathrm{Mg}=14,0 \mathrm{mmol}_{\mathrm{c}} \mathrm{dm}^{-3} ;$ $\mathrm{H}^{+}+\mathrm{Al}^{3+}=34,0 \mathrm{mmol}_{\mathrm{c}} \mathrm{dm}^{-3} ; \mathrm{S}=45,0 \mathrm{mmol}_{\mathrm{c}} \mathrm{dm}^{-3} ; \mathrm{T}=79,0 \mathrm{mmol}_{\mathrm{c}} \mathrm{dm}^{-3} ; \quad \mathrm{V}=57 \%$.

O cultivar Mayata foi empregado no experimento por ser bastante plantado em ambiente protegido. As mudas foram produzidas em casa de vegetação e o substrato utilizado foi constituído por casca de pinus, vermiculita, turfa, macro e micronutrientes (Silva, 1994). A semeadura ocorreu em 10/09/96, através da colocação de 3 a 4 sementes por célula da bandeja. Duas semanas após a germinação foi feito um desbaste, mantendo duas plantas por célula. As mudas receberam tratamento fitossanitário através de pulverizações a cada 7 dias, com fungicidas e inseticidas. A irrigação foi constante.

O solo foi preparado com uma aração profunda, seguida de revolvimento com enxada rotativa e gradagem.

A calagem foi feita em área total, baseada no resultado da análise química do solo, visando atingir uma saturação por bases de $80 \%$ para a camada de 0-20 cm de solo superficial e aumentar o teor de magnésio a um mínimo de 9 $\mathrm{mmol}_{\mathrm{c}} \cdot \mathrm{dm}^{-3}$. Foram utilizadas 2,0 ton ha ${ }^{-1}$ de calcário dolomítico, com $100 \%$ de PRNT.

Seguindo-se recomendação de Nagai et al (1995), incorporou-se esterco curtido, em quantidades relativas a $1 \mathrm{tha}^{-1}$. 
Foram construídos quatro canteiros de $1,00 \mathrm{~m}$ de largura e $0,20 \mathrm{~m}$ de altura, abrangendo todo o comprimento a extensão da casa de vegetação. Em cada canteiro foram dispostas duas linhas de plantio, distanciadas de 0,60 $\mathrm{m}$, de tal forma que as plantas foram alinhadas a $20 \mathrm{~cm}$ das bordas laterais dos canteiros.

A adubação mineral foi feita 7 dias antes do transplante das mudas, colocando-se $60 \mathrm{~g} \mathrm{~m}^{-2}$ de $\mathrm{P}_{2} \mathrm{O}_{5}, 100 \mathrm{mg} \mathrm{m}^{-2}$ B e $240 \mathrm{mg} \mathrm{m}^{-2}$ de $\mathrm{Zn}$, nas formas de superfosfato simples, bórax e sulfato de zinco. Os fertilizantes foram aplicados no sulco de plantio, seguindo recomendação de Boaretto (1986) e Raij et al. (1996).

As mudas, com 50 dias de idade foram transplantadas para os locais definitivos em 01/11/96. As adubações nitrogenada (uréia) e potássica (cloreto de potássio) foram iniciadas 13 dias após o transplantio, em cobertura e parceladas em seis vezes, entre o período de 13/11/96 a 24/01/97. Os tratamentos compreenderam uma testemunha geral e as combinações de três doses de nitrogênio $(4,8$, e $12 \mathrm{~g}$ planta ${ }^{-1}$ ou 13,$3 ; 26,6$ e $39,9 \mathrm{~g} \mathrm{~m}^{-2}$ de $\mathrm{N}$ ), e três doses de potássio (4, 8 e $12 \mathrm{~g} \mathrm{planta}^{-1}$ ou 13,3; 26,6 e $39,9 \mathrm{~g} \mathrm{~m}^{-2}$ de $\mathrm{K}_{2} \mathrm{O}$ ). Os níveis de $\mathrm{N}$ e $\mathrm{K}_{2} \mathrm{O}$ forma escolhidos de acordo com resultados da análise do solo, seguindo recomendação de Boaretto (1986) e Raij et al. (1996). Os adubos foram aplicados ao lado das plantas, ou linha de plantio na forma de grânulos, logo abaixo dos gotejadores.

$O$ delineamento experimental adotado foi o de blocos ao acaso, em esquema fatorial $(3 \times 3+1)$, com 4 repetições, totalizando 40 parcelas. Cada parcela experimental foi composta de 11 plantas, dispostas em duas linhas, num total de 444 plantas. Foram consideradas úteis as sete plantas em posição central, ocupando, cada planta, uma área de $2,75 \mathrm{~m}^{2}$, para $0,50 \mathrm{~m}$ entre plantas e $0,60 \mathrm{~m}$ entre linhas.

Durante todo 0 periodo do experimento foram realizados tratos culturais, como irrigação por gotejamento, capinas, desbrotas, podas de ramo ladrão e galhos não produtivos, tutoramento e tratamento fitossanitário.

Para a irrigação utilizaram-se gotejadores colocados ao lado da linha das plantas mantendo-se o sistema radicular constantemente umidecido; o volume de água esteve entre a umidade mínima necessária para o pimentão e a umidade na capacidade de campo, considerando-se a área da parcela e a profundidade do sistema radicular. O volume de água mínimo limitante para o pimentão, correspondeu a um potencial matricial $(\psi)$ igual a $11 \mathrm{kPa}$ e foi calculado em função da curva de 
retenção de água pelo solo (Wosten \& van Genuchten, 1988). A capacidade máxima de retenção de água foi obtida experimentalmente, de acordo com Pereira (1995). O tempo de irrigação das parcelas foi calculado em função da vazão dos gotejadores por parcela e do volume de água necessário. O potencial matricial, correspondente às umidades, foi lido em tensiômetros instalados no solo, nas profundidades de 20 e 40 $\mathrm{cm}$, no início, meio e final do tunel de plástico a casa de vegetação. Os cálculos do potencial matricial, correspondente a umidade na capacidade de campo, seguiram orientação de Wosten \& van Genuchten (1988).

As desbrotas dos ramos ladrões foram mensais e o tutoramento das plantas dependeu do crescimento das plantas. $O$ tratamento fitossanitário preventivo com inseticidas (Confidor, Decis, Hortene, Sumidã, Tamaron), acaricida (Vertimec) e fungicidas (Cerconil, Dacobre, Manzate, Kumulus S, Afugan, Trifimine, Rubigan) foi executado semanalmente

No período entre 07/01/97 até 30/06/97, durante 39 semanas, colheram-se os frutos que atingiam o ponto de consumo, totalizando 18 colheitas.

Em cada colheita foram avaliadas as características de produção de cada fruto de pimentão, como peso de matéria fresca, comprimento e diâmetro em 3332 frutos. Em quatro épocas de colheita $\left(2^{\mathrm{a}}, 6^{\mathrm{a}}, 10^{\mathrm{a}}\right.$ e $\left.18^{\mathrm{a}}\right)$, foram separadas amostras de 3 a 5 frutos por parcela, para avaliação do conteúdo de água, determinação da matéria seca e extração de nutrientes. Os frutos foram cortados no sentido longitudinal, pesados e postos para secar em estufa com circulação forçada de ar, a $70^{\circ} \mathrm{C}$, até peso constante.

Ao final do experimento, 39 semanas após transplante, foram colhidas 7 plantas por parcela, num total de 280 plantas no experimento todo. As plantas foram separadas em folhas com peciolos, caules e frutos verdes, não comerciáveis. As partes da planta foram lavadas em água deionizada e secas em estufa a $65^{\circ} \mathrm{C}$ até peso constante, para a determinação da quantidade de matéria seca produzida. Os frutos não comerciáveis, ou seja, frutos verdes, com peso menor que $120 \mathrm{~g}$, queimados pelo sol, ou deformados foram separados e contados.

Para a coleta das raizes adotou-se a metodologia de Bohm (1979), porém, com algumas modificações introduzidas pela seções de Projetos e Materiais e de Irrigação e Drenagem do IAC. Utilizou-se trado específico para essa coleta, com 
volume de $407 \mathrm{~cm}^{3}$. O peso do solo úmido correspondeu em média a $500 \mathrm{~g}$, com umidade entre 25 a $30 \%$, dependendo do dia de coleta. As raizes foram coletadas logo abaixo da linha de gotejo, às profundidades de 0-10, 10-20 e 20-40 cm. Foram feitas 2 amostragens por planta, utilizando-se 3 plantas por parcela; o trado foi colocado a uma distância de $10 \mathrm{~cm}$ do centro da planta. Os tratamentos amostrados foram aqueles onde $\mathrm{o}$ menor nivel de $\mathrm{N}\left(13,3 \mathrm{~g} \mathrm{~m}^{-2}\right)$ estava combinado com o menor $\left(13,3 \mathrm{~g} \mathrm{~m}^{-2}\right)$ e com o maior nivel de $\mathrm{K}_{2} \mathrm{O}\left(39,9 \mathrm{~g} \mathrm{~m}^{-2}\right)$. O mesmo procedimento foi adotado para a escolha dos tratamentos com niveis de $\mathrm{K}_{2} \mathrm{O}$, além do controle. $A$ separação das raizes do solo foi feita por meio de dissolução em água e fracionamento do solo e pela suspensão e peneiramento das raizes (Fujimura et al.,1994). As raizes foram lavadas e colocadas para secar à sombra sobre papel toalha. Após a secagem fez-se a separação das impurezas, tais como raizes de ervas daninhas e material orgânico. A seguir, o material foi seco em estufa a $65^{\circ} \mathrm{C}$, por 48 horas, e determinou-se então o peso seco.

Foi utilizado o teste de Dunnett bilateral ao nivel de $5 \%$ de probabilidade para comparar a testemunha com os demais tratamentos. Para a análise da quantidade de raizes, utilizou-se fatorial $2 \times 2$ e para a análise da matéria seca da parte aérea, crescimento e rendimento dos frutos, utilizou-se fatorial $3 \times 3$. Os graus de liberdade referentes aos niveis de $\mathrm{N}$ e $\mathrm{K}$ foram decompostos em polinômios ortogonais para obtenção da melhor equação de ajuste dos dados (Gomes,1987).

\subsection{Resultados e Discussão}

\subsubsection{Produção de matéria seca}

Comparativamente à testemunha, foi observado efeito do $\mathrm{N}$ na produção de matéria seca de caules, folhas e parte aérea, havendo respostas para as 
quantidades intermediárias e altas de $\mathrm{N}\left(26,6\right.$ e $\left.39,9 \mathrm{~g} \mathrm{~m}^{-2}\right)$. Os resultados estão apresentados na tabela 1 . O peso da matéria seca dos frutos não foi influenciado pelos tratamentos. Em média, as contribuições do caule, folha, caule + folha e frutos foram de 32; 16; 47 e 53\%, respectivamente. Miller et al. (1979) atribuiram, para 511 $\mathrm{kg} \mathrm{ha}{ }^{-1}$ de matéria seca total produzida, um percentual de 30,27 e 43 , respectivamente para a produção da matéria seca do caule, folha e fruto. Proporçōes semelhantes são referidas por Graifenberg et al. (1985), em ambiente protegido, que conseguiram 230 e 332 g por planta, em dois cultivares, após 24 semanas de cultivo. Rinchon et al. (1995), em ambiente protegido, constataram ao final do ciclo da cultura, após 21 semanas do transplante das mudas uma produção de 1,17 $\mathrm{kg} \mathrm{m}^{-2}$ de matéria seca total (parte aérea), contribuindo os frutos em $67 \%$, as folhas em $19 \%$ e caules, em $14 \%$.

O efeito favorável do $N$ no crescimento vegetativo, ocorreu porém, somente com baixas quantidades de $\mathrm{K}_{2} \mathrm{O}$ no solo. Nesse sentido, o $\mathrm{K}_{2} \mathrm{O}$ diminuiu a produção de matéria seca do caule, folhas e parte aérea, de forma linear, para doses mais baixas de $\mathrm{N}\left(13,32 \mathrm{~g} \mathrm{~m}^{-2}\right)$ e quadrática, para doses intermediárias de $\mathrm{N}(26,64 \mathrm{~g}$ $\mathrm{m}^{-2}$ ), como pode ser verificado na tabela 2 .

$\mathrm{O}$ efeito negativo do $\mathrm{K}_{2} \mathrm{O}$, aplicado como $\mathrm{KCl}$, provavelmente deveu-se mais à presença do cloreto em solução, que apresenta toxidez, quando em alta concentração, porque aumenta a pressão osmótica e diminue o potencial de água no solo (Marschner, 1985). O efeito do cloreto, diminuindo a produção de matéria seca das plantas de pimentão, foi também relatado por Guines et al. (1996) e resultados em tomate são referidos por Feigin et al. (1987) e Al Rawahy et al. (1992). O último autor encontrou, após 20 dias do transplante, uma redução no peso seco das folhas, raizes e caules de 46,36 e $25 \%$ devido stress ao $\mathrm{NaCl}$.

De acordo com Malavolta et al. (1997) o $\mathrm{N}$ estimula a formação e o desenvolvimento de gemas floriferas e frutiferas, assim como a vegetação, porque faz parte da constituição de enzimas, coenzimas, vitaminas e proteinas que participam da absorção iônica, fotossintese, respiração, multiplicação e diferenciação celular. 
Tabela 1. Produção de matéria seca da parte vegetativa e dos frutos.

\begin{tabular}{|c|c|c|c|c|c|c|}
\hline$N$ & $\mathrm{~K}_{2} \mathrm{O}$ & Caule (C) & Folha $(F)$ & $C+F$ & Fruto & Parte aérea \\
\hline $\begin{array}{r}9 \\
0,0 \\
13,3 \\
13,3 \\
13,3 \\
26,6 \\
26,6 \\
26,6 \\
39,9 \\
39,9 \\
39,9 \\
\end{array}$ & $\begin{array}{r}n^{-2} \\
0,0 \\
13,3 \\
26,6 \\
39,9 \\
13,3 \\
26,6 \\
39,9 \\
13,3 \\
26,6 \\
39,9 \\
\end{array}$ & $\begin{array}{l}196 \\
281 *(1) \\
233 \mathrm{~ns}^{(2)} \\
216 \mathrm{~ns} \\
400^{\star} \\
197 \mathrm{~ns} \\
218 \mathrm{~ns} \\
276^{\star} \\
266 \mathrm{~ns} \\
265 \mathrm{~ns} \\
\end{array}$ & $\begin{array}{c}95 \\
147^{*} \\
107 \mathrm{~ns} \\
98 \mathrm{~ns} \\
205^{\star} \\
116 \mathrm{~ns} \\
97 \mathrm{~ns} \\
154^{\star} \\
138 \mathrm{~ns} \\
125 \mathrm{~ns} \\
\end{array}$ & $\begin{array}{l}9 \mathrm{~m}^{-2} \\
291 \\
425^{\star} \\
340 \mathrm{~ns} \\
315 \mathrm{~ns} \\
605^{\star} \\
314 \mathrm{~ns} \\
316 \mathrm{~ns} \\
447^{\star} \\
403 \mathrm{~ns} \\
390 \mathrm{~ns}\end{array}$ & $\begin{array}{l}399 \\
440 \mathrm{~ns} \\
393 \mathrm{~ns} \\
431 \mathrm{~ns} \\
467 \mathrm{~ns} \\
439 \mathrm{~ns} \\
424 \mathrm{~ns} \\
420 \mathrm{~ns} \\
465 \mathrm{~ns} \\
438 \mathrm{~ns}\end{array}$ & $\begin{array}{l}696 \\
880 \mathrm{~ns} \\
733 \mathrm{~ns} \\
745 \mathrm{~ns} \\
1072^{\star} \\
753 \mathrm{~ns} \\
740 \mathrm{~ns} \\
865 \mathrm{~ns} \\
844 \mathrm{~ns} \\
801 \mathrm{~ns}\end{array}$ \\
\hline \multicolumn{2}{|c|}{ Média } & 256 & 128 & 384 & 432 & 813 \\
\hline \multicolumn{2}{|c|}{ C V (\%) } & 16 & 19 & 15 & 16 & 13 \\
\hline
\end{tabular}

${ }^{(1)}$ Diferenças significativas ou ${ }^{(2)}$ nåo significativas a $5 \%$ de probabilidade, pelo teste de Dunnett, entre as médias do tratamento e a testemunha.

Tabela 2. Tipos de equações de melhor ajuste, para produção de matéria seca

\begin{tabular}{|c|c|c|c|c|c|}
\hline $\begin{array}{l}\text { Contraste } \\
\text { Doses de } \mathrm{N} \text { dentro de dose } \mathrm{I} \text { de } \mathrm{K}_{2} \mathrm{O}\end{array}$ & $\begin{array}{c}\text { Efeito } \\
\text { Quadrático } \\
\mathrm{R}^{2}\end{array}$ & $\begin{array}{c}\text { Caule C) } \\
{ }^{*} \\
1,00\end{array}$ & $\begin{array}{c}\text { Folha }(F) \\
* * \\
1,00\end{array}$ & $\begin{array}{l}\mathrm{C}+\mathrm{F} \\
* * \\
1,00\end{array}$ & $\begin{array}{c}\text { Parte aérea } \\
* * \\
1,00\end{array}$ \\
\hline Doses de $\mathrm{K}_{2} \mathrm{O}$ dentro de dose 1 de $\mathrm{N}$ & $\begin{array}{l}\text { linear } \\
R^{2}\end{array}$ & $\stackrel{*}{*}$ & $\stackrel{*}{*}$ & $\stackrel{*}{*}$ & $\dot{-}$ \\
\hline Doses de $\mathrm{K}_{2} \mathrm{O}$ dentro da dose 2 de $\mathrm{N}$ & $\begin{array}{l}\text { Quadrático } \\
\mathrm{R}^{2}\end{array}$ & $\begin{array}{l}* * \\
1.00\end{array}$ & $\begin{array}{c}* * \\
1.00\end{array}$ & $\begin{array}{l}* * \\
1.00\end{array}$ & $\begin{array}{c}* * \\
1.00\end{array}$ \\
\hline
\end{tabular}


Os relatos da literatura a respeito dos efeitos do $\mathrm{N}$ e $\mathrm{K}$ na produção de matéria seca de pimentão são contraditórios, como se pode verificar a seguir. Mishriki \& Alphounse (1994) constataram que as doses de $\mathrm{N}$ aumentaram a produção da parte vegetativa do pimentão, durante dois anos de experimentação, que aumentou de 75,9 a 89,4 $\mathrm{g}$ planta ${ }^{-1}$, enquanto que Singh \& Srivastava (1988) encontraram menor produção de matéria seca da parte aérea, quando o $\mathrm{N}$ aumentou de 60 até $120 \mathrm{~kg} \mathrm{ha}^{-1}$ e Locascio et al. (1981) não encontraram resposta ao $\mathrm{N}$ na produção de matéria seca da parte aérea, com quantidades maiores que $224 \mathrm{~kg} \mathrm{ha}^{-1}$.

Abdel Maksoud et al. (1975) trabalhando em solo franco argiloso, de alta fertilidade, não encontraram resposta à aplicação de K no crescimento da planta, não havendo diferença em relação à testemunha, sem o nutriente. Os mesmos autores, porém, em um segundo ano de experimentação, no mesmo local, afirmam que a matéria seca da parte aérea, aumentou, devido a aplicação do nutriente.

Trabalhando com $\mathrm{K}$ em solos da Flórida, Hochmuth et al. (1988) obtiveram em Martin, uma relação linear entre o crescimento da planta, e K aplicado ao solo: Níveis mais altos do nutriente aumentaram o tamanho da planta , mas não do fruto. Em outros 3 locais, não houve relação entre o $\mathrm{K}$ e matéria seca da planta $\mathrm{e}$ dos frutos.

O efeito favorável do $\mathrm{N}$ na produção de matéria seca de frutos foi reportado por Guillen et al. (1966), Knavel (1977) e Olsen et al. (1993). Os últimos autores constataram aumentos de 140 para $178 \mathrm{~g}^{\text {fruto }}{ }^{-1}$ e 162 para $219 \mathrm{~g}_{\text {fruto }}^{-1}$, repectivamente para o cultivo na primavera e outono, não concordando com os resultados obtidos por Locascio et al. (1981) e Hassan et al. (1993). De acordo com os últimos autores, resultados contraditórios podem ser devido a diferenças nas variedades e condições dos experimentos.

Os resultados de produção de matéria seca das raízes estão nas tabelas 3 e 4 . Em todas as profundidades amostradas, houve maior produção de raízes nos tratamentos com $\mathrm{N}$, sendo que $0 \mathrm{~K}_{2} \mathrm{O}$ diminui este efeito. Singh \& Srivastawa (1988), também encontraram efeito favorável do $\mathrm{N}$ na produção de raízes, que aumentou de $6,5 \mathrm{~g}$ planta $^{-1}$ para $10,1 \mathrm{~g} \mathrm{planta}^{-1}$. 
Richter et al. (1968) obtiveram meihor crescimento das raizes em baixas concentraçōes de $K$ no solo e Abdel Maksoud et al. (1975), trabalhando em solo franco argiloso, de alta fertilidade, não encontraram resposta à aplicação de $K$ para o mesmo parâmetro. Os mesmos autores, porém, em um segundo ano de experimentação, no mesmo local, afirmaram que a matéria seca das raízes, após 230 dias do transplante, aumentou de 3,02 (testemunha) para 5,05 g planta ${ }^{-1}$, devido ao nutriente.

Bar-Yosef et al. (1980) encontraram respostas favoráveis ao $\mathrm{N} \in \mathrm{K}$ na produção de raizes e relatam sua distribuição no solo, lateraimete à linha de gotejadores e em profundidade no perfil do solo. $O \mathrm{~N}$ também influenciou favoraveimente o número e comprimento de raizes basais e laterais (Leskovar et al., 1989), entretanto Goyal et al. (1988) referem-se apenas a profundidade de amostragem afetando a massa radicular.

Hulugalle \& Willatt (1987) encontraram $72 \%$ das raizes de pimentão irrigado, desenvolvido em coluna de areia, até $0,25 \mathrm{~cm}$ de profundidade, embora foram determinadas raizes até $1,0 \mathrm{~m}$ de profundidade na coluna. A melhor extração de água foi até $0,50 \mathrm{~m}$ de profundidade.

Tabela 3. Peso de matéria seca de raízes em relação à testemunha .

\begin{tabular}{|c|c|c|c|c|c|c|c|}
\hline \multirow[t]{2}{*}{$N$} & \multirow[t]{2}{*}{$\mathrm{K}_{2} \mathrm{O}$} & \multicolumn{6}{|c|}{ Profundidade da amostra do solo $(\mathrm{cm})$} \\
\hline & & \multicolumn{2}{|l|}{$0-10$} & \multicolumn{2}{|c|}{$10-20$} & \multicolumn{2}{|l|}{$20-40$} \\
\hline \multicolumn{2}{|c|}{$\mathrm{g} \mathrm{m}^{-2}$} & $\longrightarrow$ & - & g amostrag & $\mathrm{em}^{-1}$ & 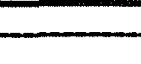 & - \\
\hline 0,0 & 0,0 & 0,37 & & 0,22 & & 0,04 & \\
\hline 13,3 & 13,3 & 0,59 & $\star \star(1)$ & 0,42 & $\star \star$ & 0,12 & $\star$ \\
\hline 13,3 & 39,9 & 0,45 & $n \mathbf{s}^{(2)}$ & 0,26 & ns & 0,05 & ns \\
\hline 39,9 & 13,3 & 0,54 & $\star(1)$ & 0,40 & $\#$ & 0,11 & * \\
\hline 39,9 & 39,9 & 0,49 & ns & 0,27 & ns & 0,09 & $*$ \\
\hline \multicolumn{2}{|c|}{ Média } & \multicolumn{2}{|l|}{0,49} & \multicolumn{2}{|l|}{0,31} & \multicolumn{2}{|l|}{0,08} \\
\hline \multicolumn{2}{|c|}{$C V(\%)$} & \multicolumn{2}{|l|}{17} & \multicolumn{2}{|l|}{17} & \multicolumn{2}{|l|}{31} \\
\hline
\end{tabular}

(9) Diferenças significativas (") a $5 \%$ e $\left(^{*}\right) 1 \%$ de probabilidade ou ${ }^{(2)}$ não significativas, pelo teste de Dunnett, entre as médias dos tratamentos em relação a testemunha, 
Tabela 4. Peso de matéria seca de raízes em diferentes profundidades.

\begin{tabular}{|c|c|c|c|}
\hline \multirow{2}{*}{$\begin{array}{c}\text { Dose de } \mathrm{Ne} \mathrm{K}_{2} \mathrm{O} \\
\mathrm{g} \mathrm{m}^{-2}\end{array}$} & \multicolumn{3}{|c|}{ Profundidade da amostra de solo $(\mathrm{cm})$} \\
\hline & $0-10$ & $10-20$ & $20-40$ \\
\hline & & $\mathrm{g}$ amostragem $^{-1}$ & 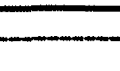 \\
\hline$N \quad 13,3$ & 0,52 & 0,34 & 0,08 \\
\hline$N \quad 39,9$ & 0,51 & 0,34 & 0,10 \\
\hline $\mathrm{K}_{2} \mathrm{O} \quad 13,3$ & 0,56 & 0,41 & 0,11 \\
\hline $\mathrm{K}_{2} \mathrm{O} 39,9$ & 0,47 & 0,27 & 0,07 \\
\hline Média & 0,52 & 0,34 & 0,09 \\
\hline \multicolumn{4}{|l|}{ Análise estatística } \\
\hline$F \quad(N)$ & $n s^{(2)}$ & ns & ns \\
\hline $\mathrm{F} \quad\left(\mathrm{K}_{2} \mathrm{O}\right)$ & $\star \star(1)$ & ** & ** \\
\hline $\mathrm{CV}(\%)$ & 7 & 17 & 25 \\
\hline
\end{tabular}

(1) Diferenças significativas (**) $1 \%$ de probabilidade ou ${ }^{(2)}$ não significativas.

\subsubsection{Rendimento e características dos frutos}

O cultivar utilizado, Mayata é bastante plantado, em cultivo protegido, devido ao seu formato e alto rendimento. No Brasil a preferência é por formato de fruto cônico, com coloração verde escura e vermelha, quando maduro. São frutos grandes, principalmente no comprimento e com peso de colheita (recém maduros) variável entre 120 a $170 \mathrm{~g}$ e 170 a $300 \mathrm{~g}$, alcançando, para os maiores pesos, melhor classificação comercial. O peso e tamanho dos frutos se mantém, mesmo após 1 ano de cultivo. O rendimento atingido por produtores, que utilizam cultivo protegido durante esse periodo está entre $70 \mathrm{tha}^{-1}$.

Verifica-se na Tabela 5 que o tratamento que recebeu a dose intermediária de $\mathrm{N}\left(26,6 \mathrm{~g} \mathrm{~m}^{-2}\right)$ e a menor de $\mathrm{K}_{2} \mathrm{O}\left(13,3 \mathrm{gm}^{-2}\right)$, diferiu significativamente, em relação à testemunha, quanto ao número total de frutos por planta ou por área, entretanto dentro da mesma dose de $\mathrm{N}, \circ \mathrm{K}_{2} \mathrm{O}$ causou um efeito depressivo sobre os citados parâmetros. 


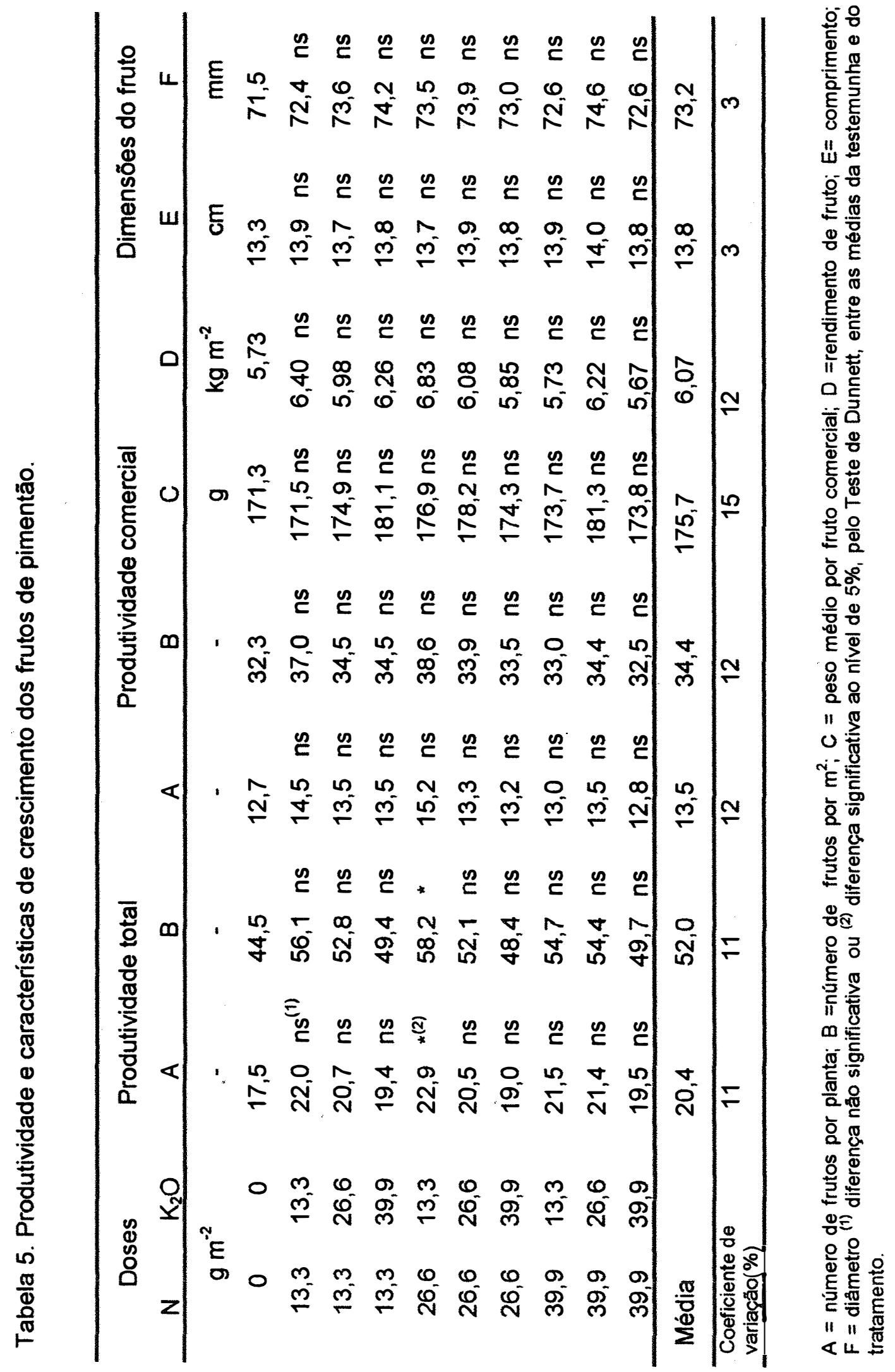


Quando foram comparadas entre si as doses dos nutrientes, não foi encontrado efeito favorável nas dimensōes dos frutos comerciais, bem como no seu número de frutos por planta, por área e peso médio dos frutos (tabela 6), entretanto o tratamento com a dose média de $\mathrm{N}$ e a menor dose de $\mathrm{K}_{2} \mathrm{O}$ foi o que deu a maior produtividade de frutos classificados como comercial. Por outro lado, $\mathrm{O} \mathrm{N}$ melhorou $\mathrm{O}$ número total de frutos por planta e por área (tabela 7).

$O$ efeito favorável do $\mathrm{N}$ no rendimento de frutos de pimentão foi relatado por muitos autores (Locascio et al., 1981; Locascio \& Alligood, 1992; Locascio et al., 1985). Os rendimentos chegaram até $26,4 \mathrm{tha}^{-1} \mathrm{com}$ a aplicação máxima de $224 \mathrm{~kg} \mathrm{ha}^{-1}$ de $\mathrm{N}$. Batal \& Smith (1981) e Hartz et al. (1993), referem-se a rendimentos semelhantes aos citados, com a aplicação de 110 e $152 \mathrm{~kg} \mathrm{ha}^{-1}$ de $\mathrm{N}$, respectivamente. Também há relatos na literatura onde não foram encontradas respostas no aumento de produtividade, devido ao nutriente, como os de 0 . Sullivan et al. (1979), na Flórida, durante três anos de experimentação, em solo franco arenoso com baixo teor de N. Da mesma forma, Srinivas \& Prabhakar (1982) não encontraram efeito do $\mathrm{N}$ no número de frutos e produção de pimentão.

Também encontram-se na literatura citaçōes que mostram o efeito favorável do $\mathrm{K}$ sobre 0 rendimento de frutos. Jeyaraman \& Balasubramanian (1988) obtiveram, em solo franco arenoso e média disponibilidade de $\mathrm{K}_{2} \mathrm{O}$, relação quadrática entre $\mathrm{o}$ rendimento de frutos e a aplicação de potássio. A melhor dose de $\mathrm{K}_{2} \mathrm{O}$ foi de $70 \mathrm{~kg} \mathrm{ha}^{-1}$, atribuindo o resultado a um efeito positivo em componentes do rendimento e também ao controle de incidência de pragas e moléstias.

Há alguns relatos na literatura onde $\mathrm{N}$ e $\mathrm{K}$ foram estudados conjuntamente, como Ozaki et al. (1955) e Olsen \& Lyons (1994), Khan \& Suryanarayana (1977). Os últimos autores encontraram efeito depressivo, quando aplicaram além de $45 \mathrm{~kg} \mathrm{ha}^{-1}$ de $\mathrm{K}_{2} \mathrm{O}$. Da mesma forma, Moreno et al. (1996), em ambiente protegido, obtiveram um máximo rendimento de frutos total e comercial, com doses maiores de $\mathrm{N}$ e baixa quantidade de $\mathrm{K}$ aplicado, atribuindo os resultados ao maior número de frutos por planta. Nesse caso também altas doses de $K$ tiveram um efeito depressivo na produtividade, resultando em maior produção de frutos de segunda classe. 


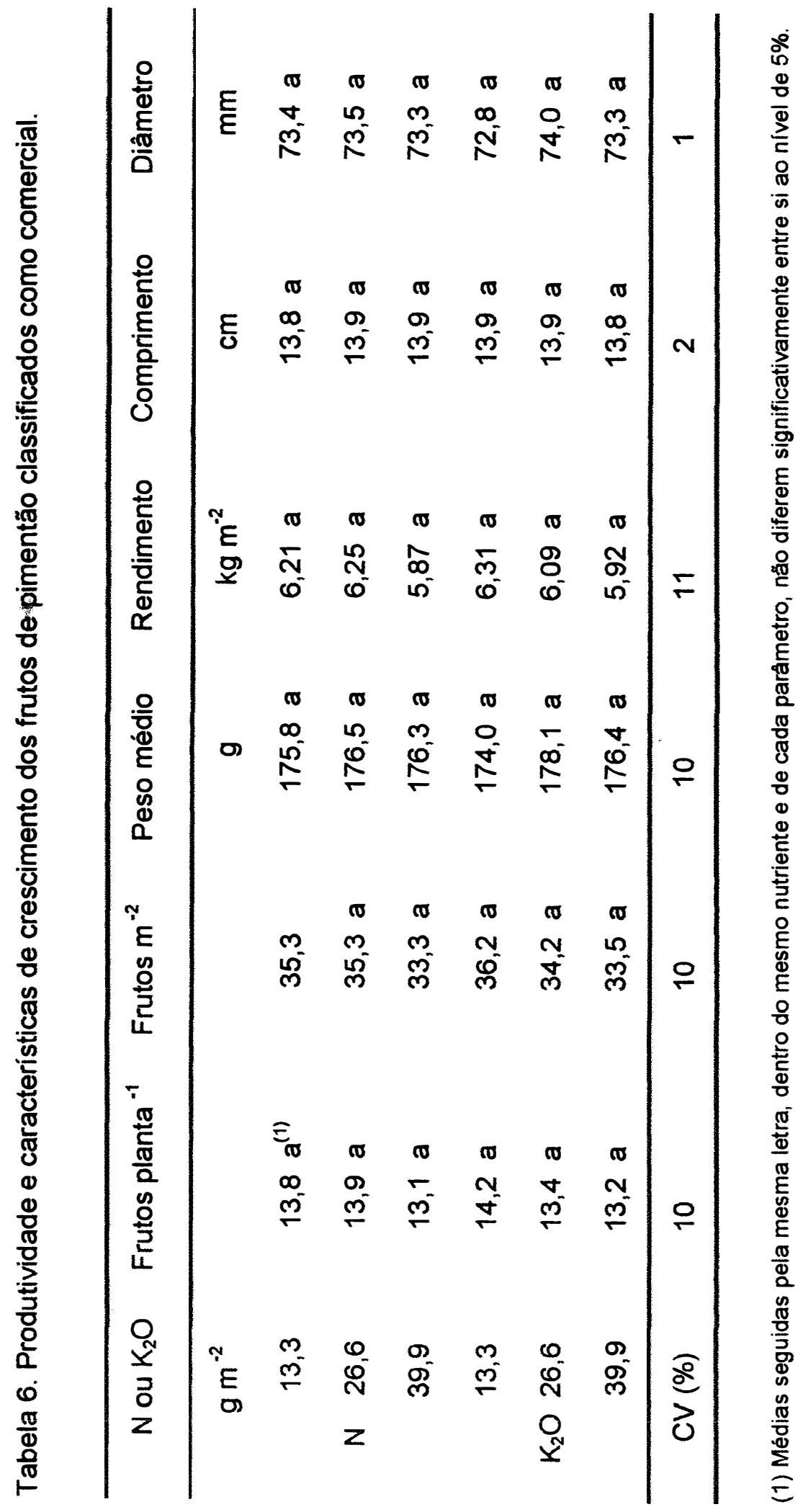


Tabela 7. Número total de frutos por planta.

\begin{tabular}{|c|c|c|c|c|c|c|c|}
\hline \multirow[b]{2}{*}{ Dose de $\mathrm{N}$} & \multicolumn{4}{|c|}{ Doses de $\mathrm{K}_{2} \mathrm{O}\left(\mathrm{g} \mathrm{m}^{-2}\right)$} & \multirow[b]{2}{*}{ F linear } & \multirow{3}{*}{$F$ quadrático } & \multirow[b]{2}{*}{$\mathrm{R}^{2}$} \\
\hline & 13,3 & 26,6 & 39,9 & Média & & & \\
\hline$\left(\mathrm{g} \mathrm{m}^{-2}\right)$ & \multicolumn{4}{|c|}{$g^{-2}$} & & & \\
\hline 13,3 & 22,0 & 20,7 & 19,4 & 20,7 & ns & ns & - \\
\hline 26,6 & 22,9 & 20,5 & 19,0 & 20,8 & $\star(1)$ & ns & 0,98 \\
\hline 39,9 & 21,5 & 21,4 & 19,5 & 20,8 & ns & ns & - \\
\hline Média & 22,1 & 20,9 & 19,3 & & & & \\
\hline$F$ linear & ns & ns & ns & & & & \\
\hline F quadrático & ns & ns & ns & & & & \\
\hline $\mathrm{R}^{2}$ & - & - & - & & & & \\
\hline
\end{tabular}

(1) : diferenças significativas a $5 \%$ de probabilidade, ns : diferenças não significativas.

Tabela 8. Número total de frutos por área.

\begin{tabular}{|c|c|c|c|c|c|c|c|}
\hline \multirow[b]{2}{*}{ Dose de $\mathrm{N}$} & \multicolumn{4}{|c|}{ Doses de $\mathrm{K}_{2} \mathrm{O}\left(\mathrm{g} \mathrm{m}^{-2}\right)$} & \multirow[b]{2}{*}{ F linear } & \multirow[b]{2}{*}{$F$ quadrático } & \multirow[b]{2}{*}{$\mathrm{R}^{2}$} \\
\hline & 13,3 & 26,6 & 39,9 & Média & & & \\
\hline$\left(g \mathrm{~m}^{-2}\right)$ & \multicolumn{4}{|c|}{$g \mathrm{~m}^{-2}$} & & & \\
\hline 13,3 & 56,1 & 52,8 & 49,4 & 52,8 & ns & ns & - \\
\hline 26,6 & 58,2 & 52,1 & 48,4 & 52,9 & $\star(1)$ & ns & 0,98 \\
\hline 39,9 & 54,7 & 54,4 & 49,7 & 52,9 & ns & ns & - \\
\hline Média & 56,3 & 53,1 & 49,2 & & & & \\
\hline$F$ linear & ns & ns & ns & & & & \\
\hline F quadrático & ns & ns & ns & & & & \\
\hline $\mathrm{R}^{2}$ & - & - & - & & & & \\
\hline
\end{tabular}

(1) : diferenças significativas a $5 \%$ de probabilidade, ns : diferenças não significativas. 
De acordo com Shukla et al. (1987), a produtividade de frutos de pimentão está intimamente relacionada ao maior número de frutos por planta ou por área.

Quanto a influência da adubação nitrogenada e potássica nas características dos frutos, os relatos da literatura divergem entre si. Hochmuth et al. (1987), em 4 locais da Flórida, não encontraram efeito do $\mathrm{N}$ sobre o peso médio dos frutos. Da mesma forma, Abdel Maksoud et al. (1975), não encontraram, durante dois anos de cultivo, efeito do $\mathrm{K}$ no comprimento dos frutos, enquanto que Khan \& Suryanarayana (1977), Subhiani et al. (1990) e Vanangamudi et al. (1990) referem-se a um efeito favorável dos nutrientes no comprimento e diâmetro dos frutos. Singh et al. (1988) obtiveram frutos com comprimento de $10,7 \mathrm{~cm}$ e diâmetro de $9,4 \mathrm{~cm}$, quando o solo recebeu $150 \mathrm{~kg} \mathrm{ha}^{-1}$ de N. Hassan \& Ramlan (1994) referem-se a um maior número de frutos devido a adubação potássica.

A diversidade de resultados dá-se por conta da diversidade de condições em que os experimentos relatados na literatura foram desenvolvidos.

Comparando-se a produtividade obtida no presente experimento, em média $6,1 \mathrm{~kg} \mathrm{~m}$, com a obtida pelos autores citados, verificou-se um ótimo rendimento de frutos, mesmo no tratamento testemunha. Isto quer dizer que o solo mesmo sem a adubação química, conseguiu suprir adequadamente as exigências das plantas de pimentão. As caracteristicas dos frutos variam conforme o cultivar utilizado, entretanto as obtidas no presente experimento estão compativeis com as citadas na literatura.

\subsection{Conclusões}

Para as condições que esse trabalho foi realizado, pode-se concluir que:

1. $\mathrm{O}$ aumentou a produção de matéria seca do caule, folhas, parte aérea e raízes, não tendo efeito na produção de matéria seca dos frutos. Comparativamente à testemunha, a melhor dose de $\mathrm{N}$ foi de $26,6 \mathrm{~g} \mathrm{~m}^{-2}$. 
2. A contribuição do peso da matéria seca do caule, folhas. caule + folhas e frutos foi de 31,$5 ; 15,7 ; 47,2$ e $53,1 \%$ em relação ao peso da matéria seca total da parte aérea.

3. O efeito favorável do $\mathrm{N}$ na produçāo de matéria seca total ocorreu somente em baixas concentraçōes de $\mathrm{K}$ no solo $\left(13,3 \mathrm{~g} \mathrm{~m}^{-2}\right)$.

4. $O N$ aumentou $~ O$ número total de frutos produzidos, embora não tenha afetado o número de frutos comerciais e as caracteristicas de crescimento dos frutos, como peso, comprimento e diâmetro e consequentemente não afetou também o rendimento de frutos comerciais.

5. $\mathrm{OK}$, aplicado como $\mathrm{KCl}$, em doses maiores que $13,3 \mathrm{~g} \mathrm{~m}^{-2}$, teve efeito depressivo no crescimento da planta, crescimento, produção e rendimento de frutos, como consequência de um menor crescimento das raizes. 
EFEITO DO NITROGÉNIO E POTÁSSIO NA NUTRIÇÃO DO PIMENTÃO CULTIVADO EM AMBIENTE PROTEGIDO 


\section{EFEITO DO NITROGÊNIO E POTÁSSIO NA NUTRIÇÃO DO PIMENTÃO CULTIVADO EM AMBIENTE PROTEGIDO}

\subsection{Resumo}

Os objetivos do trabalho foram avaliar o efeito da aplicação de $\mathrm{N}$ e $\mathrm{K}_{2} \mathrm{O}$ em cobertura, sobre a concentração foliar, no início do florescimento (aos 52 dias) e frutificação( aos 83 dias), e sobre o acúmulo de nutrientes, em plantas de pimentão cultivado em ambiente protegido, além de determinar a concentração de nutrientes e características químicas do solo, ao final do experimento. $O$ experimento foi conduzido no Centro experimental de Campinas do Instituto Agronômico (IAC), fazenda Santa Elisa, de novembro/96 a agosto/97 e constou dos seguintes tratamentos: controle e as combinações de três doses de $\mathrm{N}\left(13,3 ; 26,4\right.$ e $\left.39,9 \mathrm{~g} \mathrm{~m}^{-2}\right)$ e três doses de $\mathrm{K}_{2} \mathrm{O}\left(13,3 ; 26,4\right.$ e $\left.39,9 \mathrm{~g} \mathrm{~m}^{-2}\right)$. O delineamento experimental adotado foi o de blocos ao acaso, em esquema fatorial $(3 \times 3+1)$, com 4 repetições, totalizando 40 parcelas. Cada parcela foi composta de 11 plantas, num total de 444 plantas. Todas as plantas foram irrigadas por gotejamento. Foram avaliados na planta, a concentração de nutrientes nas folhas, aos 52 e 83 dias e o acúmulo de nutrientes na parte vegetativa (caules, folhas e frutos), ao final do experimento. No solo foram determinadas acidez ativa, acidez potencial e conteúdos de matéria orgânica, $\mathrm{N}$ total, amoniacal, nitrico, K, P Ca e Mg. Com base nos resultados, foram obtidas as seguintes conclusões :

1. As doses de $N$ não afetaram a concentração dos nutrientes presentes em folhas recém maduras, embora diminuiram a concentração de $S$, aos 83 dias do transplante, 
exceto na dose de $13,3 \mathrm{~g} \mathrm{~m}^{-2}$ de $\mathrm{K}_{2} \mathrm{O}$. A aplicação de maiores doses de $\mathrm{K}_{2} \mathrm{O}$, diminuiram a concentração de $\mathrm{P}$ e $\mathrm{S}$ nas folhas, nesse mesmo período.

2. $\mathrm{ON}$ aumentou o acúmulo de nutrientes no caule, folhas e parte aérea, ao final do ciclo de cultivo, quando aplicado na dose de $26,6 \mathrm{~g} \mathrm{~m}^{-2}$. $\mathrm{O} \mathrm{K}_{2} \mathrm{O}$ contribuiu somente quando presente em baixas concentrações no solo. Os nutrientes presentes nos frutos não foram influenciados pelos tratamentos.

3. Os nutrientes mais acumulados na planta foram $\mathrm{K}, \mathrm{N}$ e Ca e os nutrientes menos acumulados na planta foram $\mathrm{Mg}, \mathrm{P}$ e $\mathrm{S}$.

4. $\mathrm{O}$ caule acumulou maior quantidade de $\mathrm{S}, \mathrm{Mg}, \mathrm{K}$ e Ca $(51 ; 45 ; 42$ e $37 \%$, respectivamente); as folhas contribuiram mais com o $\mathrm{Ca}, \mathrm{Mg}, \mathrm{N}, \mathrm{K}$ e P $(62 ; 52 ; 51 ; 40$ e $40 \%$, respectivamente); os frutos continham mais $P, N, K$ e S $(37 ; 24 ; 18$ e $15 \%$, respectivamente).

5. Ao final do cultivo, comparativamente à testemunha, a concentração de $N$ total no solo foi significativamente maior conforme a dose de $\mathrm{N}$ aplicada, porém somente além de $20 \mathrm{~cm}$ de profundidade. $O \mathrm{~K}$ foi significativamente maior, de acordo com as quantidades aplicadas, independente da profundidade de amostragem.

6. $\mathrm{O} \mathrm{N}$ amoniacal concentrou-se mais a $20 \mathrm{~cm}$ de profundidade, independente da quantidade de $\mathrm{N}$ aplicada, enquanto o nitrato foi maior , nessa profundidade, quando o nutriente foi aplicado na doses máxima. Até $20 \mathrm{~cm}$, as quantidades de $\mathrm{N}_{-} \mathrm{NH}_{4}{ }^{+}$foram maiores que $\mathrm{N}-\mathrm{NO}_{3}{ }^{-}$.

7. A maior presença de amônio e nitrato de 20 a $40 \mathrm{~cm}$ no perfil do solo foi decorrente da movimentação dos ions, junto com a água, quando $\mathrm{O}$ foi aplicado no solo em quantidades mais altas. Nessa profundidade, as concentrações de nitrato foram maiores que amônio.

8. O deslocamento do $\mathrm{K}^{+}, \mathrm{Ca}^{2+}$ e $\mathrm{Mg}^{2+}$ pelo solo foi o mesmo da água, embora tenha havido maior concentração dos cátions até $20 \mathrm{~cm}$ de profundidade, exceto para o $\mathrm{P}$, que esteve em alta concentração até $40 \mathrm{~cm}$ no solo.

9. Doses de $\mathrm{K}_{2} \mathrm{O}$ maiores que $13,3 \mathrm{~g} \mathrm{~m}^{-2}$, correspondentes a $3,0 \mathrm{mmol}_{c} \mathrm{dm}^{-3}$ e $3,1 \%$ de saturação do nutriente no complexo de troca, prejudicaram o crescimento das raízes e absorção de nutrientes. 


\section{EFFECT OF NITROGEN AND POTASSIUM ON THE NUTRITION OF SWEET PEPPER GROWN AT A PROTECTED ENVIRONMENT}

\subsection{Summary}

The goals of this work were to evaluate the effect of the top application of $\mathrm{N}$ and $\mathrm{K}_{2} \mathrm{O}$ on the leaf concentration at the early blooming and fructification and on the accumulation of nutrients in sweet pepper plants grown at a protected environment, in addition to determining the concentration of nutrients and chemical characteristics of the soil towards the end of the experiment. The experiment was conducted at the Centro Experimental de Campinas, of the Instituto Agronômico (IAC), Santa Elisa farm, from November/96 through August/97, with the following treatments: control and combination of three rates of $\mathrm{N}\left(13.3 ; 26.4\right.$ and $\left.39.9 \mathrm{~g} \mathrm{~m}^{-2}\right)$ and three rates of $\mathrm{K}_{2} \mathrm{O}\left(13.3 ; 26.4\right.$ and $\left.39.9 \mathrm{~g} \mathrm{~m}^{-2}\right)$. The experimental block design was randomized, in a factorial scheme $(3 \times 3+1)$, with four replications in a total of 40 plots. Each plot comprised 11 plants in a total of 444 plants. All plants underwent trickle irrigation. The concentration of nutrients in leaves at 52 and 83 days, nutrient absorption at the vegetative part (stems, leaves and fruits) were evaluated towards the end of the experiment. Regarding the soil, organic matter, active acidity, potential acidity, and total $\mathrm{N}$, ammoniac, nitric, potassium, phosphorus, calcium and magnesium contents were evaluated. The results led to the following conclusions:

1. The nitrogen did not affect the concentration of nutrients in recently ripened leaves, except for sulfur, which was lower 83 days after transplantation to $13.3 \mathrm{~g} \mathrm{~m}^{-2}$ of $\mathrm{K}_{2} \mathrm{O}$; the potassium, however, decreases the concentration of phosphorus and sulphur at the same period. 
2. The nitrogen increased the absorption of nutrients in the stem, leaves, and top part at the end of the cultivation period when applied at the rate of $26.6 \mathrm{~g} \mathrm{~m}^{-2}$. The potassium contributed only at low concentrations in the soil. The nutrients absorbed by fruits were not influenced by the treatments.

3. The most absorbed nutrients were $\mathrm{K}, \mathrm{N}$, and $\mathrm{Ca}$, and the least absorbed ones were $\mathrm{Mg}, \mathrm{P}$, and $\mathrm{S}$.

4. The stem accumulated a higher amount of $\mathrm{S}, \mathrm{Mg}, \mathrm{K}$ and $\mathrm{Ca}(51 ; 45 ; 42 ; 37 \%)$; leaves contributed specially with $\mathrm{Ca}, \mathrm{Mg}, \mathrm{N}, \mathrm{K}$, and $\mathrm{P}(62 ; 52 ; 51 ; 40$ and $40 \%)$; fruits had more $P, N, K$ and $S(37 ; 24 ; 18 ; 15 \%)$.

5. Comparatively to the control plant, the total concentration of $\mathrm{N}$ in soil was significantly higher at the end of the cultivation according to the $\mathrm{N}$ rate applied, however, only at over $20-\mathrm{cm}$ depths. The potassium was significantly higher, according to the amounts applied, regardless of depth and sample.

6. The ammoniac $\mathrm{N}$ was more concentrated at $20-\mathrm{cm}$ depths, probably due to the high amount of organic matter, regardless of the amount of $\mathrm{N}$ applied, while the nitrate was higher at such depth when the nutrient was applied at maximum rates. The amounts of $\mathrm{N}-\mathrm{NH}_{4}{ }^{+}$were higher than those of $\mathrm{N}-\mathrm{NO}_{3}{ }^{-}$.

7. The highest amount of ammonium and nitrate at 20 to $40 \mathrm{~cm}$ into soil profile was due to the ions movement along with water at higher amounts in soil. At such depth the concentrations of nitrate were higher than those of ammonium.

8. The displacement of $\mathrm{K}^{+}, \mathrm{Ca}^{2+}$, and $\mathrm{Mg}^{2+}$ through the soil followed the movement of water although cations were more concentrated until a $20-\mathrm{cm}$ depth. The $P$ had a high concentration until $40 \mathrm{~cm}$ within the soil, probably due to the vertical movement of the organic matter.

9. Rate of $\mathrm{K}_{2} \mathrm{O}$ higher $13.3 \mathrm{~g} \mathrm{~m}^{-2}$ or $3.0 \mathrm{mmol}_{\mathrm{c}} \mathrm{dm}^{-3}$ and $3.1 \%$ changed, harmed the growth and nutrient uptake. 


\subsection{Introdução}

O pimentão (Capsicum annuum L.) pertence à familia solanaceae, e ao gênero Capsicum, sendo originário da América Central, em regiōes de clima mais tropical; requer temperaturas mais elevadas, para que não haja estiolamento das folhas maduras, murchamento das partes mais jovens e lentidão de crescimento. De acordo com Siviero \& Gallerani (1992), a faixa ideal de temperatura está entre minima de $16^{\circ} \mathrm{C}$ e máxima de $30^{\circ} \mathrm{C}$.

Em condições de cultivo protegido, há maior condição para o crescimento da planta, que pode atingir mais de 2,0 m de altura; o ciclo da cultura é bem maior e o pimentão é, por isso, mais exigente do ponto de vista nutricional, em comparação ao cultivo em campo. Entretanto, são raros os trabalhos com adubação nessas condições de cultivo, havendo por esse motivo aplicação excessiva de fertilizantes, principalmente porque os cultivos são sucessivos no mesmo local, levando a uma salinização do solo e problemas de absorção de água e nutrientes.

Sabe-se que existe uma relação entre teor de nutrientes no solo, teor nas folhas e produção. Nesse sentido, Thomas \& Heilman (1964) observaram, em cultivo protegido, que a aplicação de $\mathrm{N}$ aumentou o teor deste nutriente nos tecidos $\mathrm{e}$ diminuiu a concentração de $P$ nas folhas, associado a um maior crescimento do pimentão. Os mesmos autores estabeleceram 4,0 \% como nivel crítico de $\mathrm{N}$ nas folhas, no inicio do florescimento. Não foi possivel definir um nivel crítico de $P$, sendo que a concentração de 0,6 \% foi considerada adequada. De acordo com Swiader \& Morse (1982), folhas de pimentão com $0,46 \%$ de $P$ apresentavam sintomas visiveis de toxidez, enquanto que $0,28 \%$ de $P$ nas folhas relacionavam-se às mais altas produções. Já Lorenz \& Vittum (1980) citam que o nivel deficiente em P no peciolo de folhas completamente expandidas é de $0,20 \%$, e que o nivel suficiente é de $0,40 \%$. Os autores observaram que no florescimento, esses niveis podem estar entre $0,15 \mathrm{e}$ $0,25 \%$ do peso seco.

De acordo com Hassan \& Hamlan (1994) a aplicação de K resultou em maiores teores foliares desse nutriente, sem alterar as concentrações (\%) de $N, P, e$ $\mathrm{Ca}$, que foram, no inicio da frutificação, respectivamente de 4,05;0,69 e 0,31, 
para $132 \mathrm{~kg} \mathrm{ha}^{-1}$ de $\mathrm{K}_{2} \mathrm{O}$ aplicado. Os teores de $\mathrm{K}(\%)$ aumentaram de 3,74 para 4,06 e 4,32, respectivamente para doses de 0,66 e $132 \mathrm{~kg} \mathrm{ha}^{-1}$ do elemento aplicado ao solo.

As concentrações (\%) de nutrientes nas folhas e caules determinadas por Hegde (1989), após 67 dias do transplante, em plena frutificação foram:- N (5,23 e 2,02); $P(0,81$ e 0,46); $K(4,88$ e 3,07); Ca (3,81 e 1,62); $M g(2,38$ e 1,65).

O pimentão absorve nutrientes de forma diferenciada, havendo maior exigência nutricional nos estádios reprodutivos, concordando com os resultados referidos por Miller et al. (1979). Segundo os autores, um maior acúmulo de N, P, K, Ca e Mg ocorreu nos estádios iniciais do ciclo da planta até o aparecimento dos primeiros frutos.

A absorção dos nutrientes aumentou significativamente com o N aplicado, sendo que as quantidades encontradas na planta inteira ( $\mathrm{kg} \mathrm{ha}^{-1}$ ), ao final do ciclo de cultivo foram de N (55,5); P (13,2); K (73,1); Ca (22,3), Mg (20,9). De acordo com Hegde (1988) o máximo de absorção correspondeu a $180 \mathrm{~kg} \mathrm{ha}^{-1}$ de $\mathrm{N} \mathrm{e}$ resultou em um máximo de matéria seca produzida, assim como um máximo número, peso e rendimento de frutos. Os objetivos do presente trabalho foram :-

1- Determinar as concentrações dos nutrientes nas folhas, no início do florescimento, aos 50 após transplante e início da frutificação, aos 83 dias após transplante.

2- Avaliar o acúmulo e a distribuição dos nutrientes nos órgãos da planta, ao final do ciclo.

3- Determinar as quantidades de $\mathrm{N}$ total, $\mathrm{N}$ amoniacal, $\mathrm{N}$ nitrico e $\mathrm{K}$ no solo, assim como determinar a concentração de $\mathrm{P}, \mathrm{Ca}$ e $\mathrm{Mg}$ remanescentes no solo, ao final do ciclo de cultivo. 


\subsection{Material e Métodos}

Para avaliar a influência do $\mathrm{N}$ e do $\mathrm{K}_{2} \mathrm{O}$ na nutrição de plantas de pimentão, cultivar Mayata, desenvolveu-se o experimento em ambiente protegido, com área de $210 \mathrm{~m}^{-2}$, no Centro Experimental, Fazenda Santa Elisa, Instituto Agronômico de Campinas (IAC), em latossolo vermelho escuro distrófico.

A análise granulométrica apresentou, na camada de 0 a $20 \mathrm{~cm}: 333 \mathrm{~g}$ $\mathrm{kg}^{-1}$ de argila, $80 \mathrm{~g} \mathrm{~kg}^{-1}$ de silte e $590 \mathrm{~g} \mathrm{~kg}^{-1}$ de areia e densidade do solo de 1,12 g $\mathrm{cm}^{-3}$; na camada de 20 a $40 \mathrm{~cm}$, o solo apresentou $370 \mathrm{~g} \mathrm{~kg}^{-1}$ de argila, $100 \mathrm{~g} \mathrm{~kg}^{-1} \mathrm{de}$ silte, $530 \mathrm{~g} \mathrm{~kg}^{-1}$ de areia e densidade do solo de $1,37 \mathrm{~g} \mathrm{~cm}^{-3}$. A análise química do solo, amostrado em duas profundidades, apresentou os seguintes resultados (tabela 9).

Tabela 9. Características químicas do solo coletado antes e após calagem

\begin{tabular}{lccrr}
\hline Característica & \multicolumn{2}{c}{ Antes calagem } & \multicolumn{2}{c}{ Após calagem } \\
& $0-20 \mathrm{~cm}$ & $20-40 \mathrm{~cm}$ & $0-20 \mathrm{~cm}$ & $20-40 \mathrm{~cm}$ \\
\hline $\mathrm{pH}\left(\mathrm{CaCl}_{2}\right)$ & 5,3 & 5,4 & 5,7 & 4,8 \\
$\mathrm{M} . \mathrm{O} .\left(\mathrm{g} \mathrm{dm}^{-3}\right)$ & 25,0 & 21,0 & 24,0 & 24,0 \\
$\mathrm{P}\left(\mathrm{mg} \mathrm{dm}^{-3}\right)$ & 20,0 & 15,0 & 199,0 & 39,0 \\
$\mathrm{~S}-\mathrm{SO}_{4}\left(\mathrm{mg} \mathrm{dm}^{-3}\right)$ & 14,0 & 26,2 & 250,7 & 134,3 \\
$\mathrm{~N}\left(\mathrm{~g} \mathrm{~kg}^{-1}\right)$ & 0,18 & 0,17 & 0,18 & 0,17 \\
$\mathrm{~K}\left(\mathrm{mmol}_{\mathrm{c}} \mathrm{dm}^{-3}\right)$ & 3,5 & 2,8 & 3,2 & 3,5 \\
$\mathrm{Ca}\left(\mathrm{mmol}_{\mathrm{c}} \mathrm{dm}^{-3}\right)$ & 35,0 & 31,0 & 52,0 & 27,0 \\
$\mathrm{Mg}\left(\mathrm{mmol}_{\mathrm{c}} \mathrm{dm}^{-3}\right)$ & 16,0 & 14,0 & 19,0 & 14,0 \\
$\mathrm{H}+\mathrm{Al}\left(\mathrm{mmol}_{\mathrm{c}} \mathrm{dm}^{-3}\right)$ & 38,0 & 34,0 & 22,0 & 34,0 \\
$\mathrm{~S}\left(\mathrm{mmol}_{\mathrm{c}} \mathrm{dm}^{-3}\right)$ & 55,0 & 48,0 & 74,2 & 45,0 \\
$\mathrm{~T}\left(\mathrm{mmol}_{\mathrm{c}} \mathrm{dm}^{-3}\right)$ & 93,0 & 82,0 & 96,2 & 79,0 \\
$\mathrm{~V}(\%)$ & 59 & 59 & 77 & 57 \\
\hline
\end{tabular}

(1) Os resultados das análises referem-se a amostragem de solo feita após a adição de adubação orgànica e fosfatada. 
Após preparo do solo através de aração e uso de enxada rotativa, foram aplicadas 2,0 tha ${ }^{-1}$ de calcánio dolomítico, para correção da acidez e elevar o teor de magnésio para $9 \mathrm{mmol}_{c} \mathrm{dm}^{-3}$. Os cálculos foram feitos de acordo com os resultados das análises quimicas de solo. Incorporou-se também 1 tha ${ }^{-1}$ de esterco curtido (Nagai et al., 1995), cujos resultados com base em umidade natural foram $\left(\mathrm{g} \mathrm{kg}^{-1}\right): \mathrm{pH}\left(\mathrm{CaCl}_{2}\right)=6,5$; umidade total $=410$; matéria orgânica total= 256; matéria orgânica compostavel $=216$; matéria orgânica resistente a compostagem $=40,1$; carbono total (orgânico e mineral) $=142$; carbono orgânico $=120$; residuo mineral total $=334 ; \mathrm{N}$ total $=5,0 ; \mathrm{P}_{2} \mathrm{O}_{5}$ total $=5,1 ; \mathrm{K}_{2} \mathrm{O}=6,0 ; \mathrm{Ca}$ total $=2,8 ; \mathrm{Mg}$ total $=1,9 ; \mathrm{S}$ total $=1,7$; relação $\mathrm{C} / \mathrm{N}(\mathrm{C}$ total e $\mathrm{N}$ total $)=28 / 1$.

A adubação mineral foi feita 7 dias antes do transplante das mudas, colocando-se $60 \mathrm{~g} \mathrm{~m}^{-2}$ de $\mathrm{P}_{2} \mathrm{O}_{5}, 100 \mathrm{mg} \mathrm{m}^{-2}$ B e $240 \mathrm{mg} \mathrm{m}^{-2}$ de $\mathrm{Zn}$, nas formas de superfosfato simples, bórax e sulfato de zinco. Os fertilizantes foram aplicados no sulco de plantio, de acordo com recomendaçōes de Boaretto (1986) e Raij et al. (1996).

As mudas, que se desenvolveram em substrato constituido por casca de pinus, vermiculita, turfa e nutrientes, foram transplantadas para os locais definitivos em 01/11/96, após 50 dias da semeadura. As adubações nitrogenada (uréia) e potássica (cloreto de potássio) iniciaram-se 13 dias após o transplantio, aplicadas em cobertura e parceladas em seis vezes, entre o período de 13/11/96 a 24/01/97. Os tratamentos compreenderam uma testemunha geral e as combinaçöes de três doses de $\mathrm{N}\left(4,8\right.$, e $12 \mathrm{~g}_{\text {planta- }}{ }^{-1}$ ou 13,$3 ; 26,6$ e $\left.39,9 \mathrm{~g} \mathrm{~m}^{-2}\right)$, e très doses de $\mathrm{K}_{2} \mathrm{O}(4,8$ e $12 \mathrm{~g}$ planta ${ }^{-1}$ ou 13,$3 ; 26,6$ e 39,9 $\mathrm{g} \mathrm{m}^{-2}$ ). Os niveis de $\mathrm{N}$ e $\mathrm{K}_{2} \mathrm{O}$ foram escolhidos de acordo com resultados da análise do solo, seguindo recomendação de Boaretto (1986) e Raij et al. (1996). Os adubos foram aplicados ao lado das plantas, nas duas linhas de cada canteiro, logo abaixo dos gotejadores.

O delineamento experimental adotado foi o de blocos ao acaso, em esquema fatorial $(3 \times 3+1)$, com 4 repetições, totalizando 40 parcelas. Cada parcela experimental foi composta de 11 plantas, dispostas em duas linhas num total de 444 plantas. Foram consideradas úteis as sete plantas em posição central, ocupando, cada planta, uma área de $2,75 \mathrm{~m}^{2}$, para $0,50 \mathrm{~m}$ entre plantas e $0,60 \mathrm{~m}$ entre linhas. 
No inicio do florescimento, 50 dias após transplante e início da frutificação, 83 dias após transplante, retiraram-se folhas recém maduras, considerando a terceira ou quarta folha a partir do ápice, para a determinação do teor de nutrientes. Foram retiradas de 4 a 5 folhas por planta e 5 a 6 plantas por parcela.

A água foi colocada através de gotejadores, num volume que esteve entre a umidade, dentro da faixa minima necessária para o pimentão e a umidade na capacidade de campo, considerando a área da parcela e a profundidade do sistema radicular. O volume de água minimo limitante para o pimentão, correspondeu a um potencial matricial $(\psi)$ igual a $11 \mathrm{kPa}$ e foi calculado em função da curva de retenção de água pelo solo (Wosten \& van Genuchten, 1988). Da mesma forma, foi calculado o potencial matricial correspondente a umidade na capacidade de campo. A capacidade máxima de retenção de água foi obtida experimentalmente, de acordo com Pereira (1995). O tempo de irrigação foi calculado em função da vazão dos gotejadores por parcela e do volume de água necessário. O potencial matricial, correspondente às umidades, foi lido em tensiômetros instalados no inicio, meio e final do túnel plástico, às profundidades de 20 e $40 \mathrm{~cm}$.

As podas e desbrotas dos ramos foram mensais; o tutoramento dependeu do crescimento das plantas e no tratamento fitossanitário utilizou-se inseticidas, fungicidas e acaricidas especificos.

No final do experimento, foram colhidas 7 plantas úteis, localizadas no centro da parcela, separando-se caule, folhas e frutos remanescentes. Os frutos foram separados e contados; os caules e folhas foram lavados com água deionizada e uma parte foi separada e seca em estufa a $65^{\circ} \mathrm{C}$ até peso constante.

As amostras de folhas, caules e frutos, recém maduros, após secagem em estufa, foram moidas e analisadas para a determinação dos teores de macronutrientes de acordo com método descrito por em Bataglia et al. (1983).

As amostras compostas de solo, por parcela, foram coletadas às profundidades de 0-20 e 20-40 cm, em cinco tratamentos. Os locais de coleta basearam-se na área umidecida, sendo as amostras recolhidas no centro e nas duas laterais da linha de gotejo. Os tratamentos amostrados foram aqueles onde o menor nivel de $\mathrm{N}\left(13,2 \mathrm{~g} \mathrm{~m}^{-2}\right)$ estava combinado a o menor e maior nivel de $\mathrm{K}_{2} \mathrm{O}$ (13,2 e 39,9 $\mathrm{g} \mathrm{m}^{-2}$ ), com o mesmo procedimento em relação ao potássio, além do controle, sem 
aplicação dos nutrientes. Para a determinação de amônio e nitrato, as amostras de solo foram coletadas em 3 tratamentos: controle e nas parcelas que receberam as doses minimas e máximas de $\mathrm{N}$ e $\mathrm{K}_{2} \mathrm{O}$. $\mathrm{O}$ solo foi seco ao ar e moido. Foram analisadas acidez ativa, acidez potencial, matéria orgânica, $\mathrm{P}, \mathrm{K}, \mathrm{Ca}$ e $\mathrm{Mg}$, conforme método proposto por Raij et al. (1987). $\mathrm{O} N$ total, $\mathrm{N}$ amoniacal e nitrico foram analisados segundo Bremner (1965) e Bremner \& Mulvaney (1982).

Utilizou-se 0 teste de Dunnett bilateral ao nivel de $5 \%$ de probabilidade para comparar a testemunha com os demais tratamentos. Para a análise dos nutrientes no solo utilizou-se fatorial $2 \times 2$ e para a análise dos teores de amônio e nitrato no solo, devido ao número menor de tratamentos amostrados, foi usado o teste de Tukey, a nível de $5 \%$. Para a análise da concentração e acúmulo de nutriente utilizou-se fatorial $3 \times 3$. Os graus de liberdade referentes aos niveis de $\mathrm{Ne}$ $\mathrm{K}_{2} \mathrm{O}$ foram decompostos em polinômios ortogonais para obtenção da melhor equação de ajuste dos dados (Gomes, 1987).

\subsection{Resultados e Discussão}

\subsubsection{Nutrição mineral do pimentão}

\subsubsection{Teor de nutrientes nas folhas}

A análise química de órgãos de plantas para fins de diagnóstico do estado nutricional, tem por base a suposição de que existe uma relação causal entre o teor do nutriente no órgão amostrado para diagnóstico e a produtividade (Marschner, 1997) . O valor considerado adequado depende de uma série de fatores tais como, a produtividade a ser obtida, o órgão escolhido para análise, idade da planta, clima, além de outros. No caso das plantas de pimentão são as folhas recém maduras que têm sido usadas para diagnóstico, através da análise quimica, mas ainda não ha resultados que correlacionem niveis na planta e produtividade. 
Há citações na literatura dos valores considerados adequados ou suficientes, para pimentão, como por exemplo os teores indicados abaixo.

Tabela 10. Teores de nutrientes em folhas recém maduras de pimentão em diferentes estádios de desenvolvimento.

\begin{tabular}{cccc}
\hline Nutriente & $\begin{array}{c}\text { Plantas jovens, } \\
\text { primeiras flores (1) }\end{array}$ & $\begin{array}{c}\text { Plantas produzindo } \\
\text { frutos (1) }\end{array}$ & $\begin{array}{c}\text { Plantas jovens, com } \\
\text { flores e frutos (2) }\end{array}$ \\
\hline $\mathrm{g} \mathrm{kg}$ & $\mathrm{g} \mathrm{kg}^{-1}$ & $\mathrm{~g} \mathrm{~kg}^{-1}$ \\
$\mathrm{~N}$ & $40,0-60,0$ & $35,0-50,0$ & $30,0-60,0$ \\
$\mathrm{~K}$ & $3,5-10,0$ & $2,2-7,0$ & $3,0-7,0$ \\
$\mathrm{Ca}$ & $40,0-60,0$ & $35,0-45,0$ & $40,0-60,0$ \\
$\mathrm{Mg}$ & $10,0-25,0$ & $13,0-28,0$ & $10,0-35,0$ \\
$\mathrm{~S}$ & $3,0-10,0$ & $2,5-12,0$ & $3,0-12,0$ \\
& Não há dados & Não há dados & não há dados \\
\hline
\end{tabular}

(1) MILLS \& JONES (1996)

(2) REUTER \& ROBINSON (1997)

(3) Raij et al. (1996).

Tabela 11. Teores de nutrientes em folhas e caules de pimentão.

\begin{tabular}{lllllll}
\hline Autor & Órgão amostrado & N & P & K & Ca & Mg \\
& & $\%$ & $\%$ & $\%$ & $\%$ & $\%$ \\
Miller et al. (1979) & Folhas + peciolos $^{(1)}$ & 4,9 & 0,88 & 4,7 & 1,6 & 0,9 \\
Miller et al. (1979) & Caule $^{(1)}$ & 3,0 & 0,29 & 4,3 & 0,8 & 0,8 \\
Salinas et al. (1982) & Folhas $^{(2)}$ & 4,3 & 0,47 & 8,9 & 3,2 & 1,1 \\
\hline
\end{tabular}

(1) plantas no início da frutificação ${ }^{(2)}$ plantas no florescimento, cultivada em solução nutritiva. 
Comparando-se os teores foliares considerados adequados pelos diferentes autores e os teores determinados nas folhas do pimentão, em dois estádios de desenvolvimento, pode-se afirmar que a cultura esteve adequadamente nutrida em macronutrientes (tabela 12). As plantas do tratamento testemunha, que não receberam adubação nitrogenada e potássica mineral, também apresentaram teores foliares de macronutrientes considerados adequados. Isto indica que o solo, que recebeu esterco de curral antes do plantio da cultura, foi capaz de suprir as exigências nutricionais da cultura de pimentão em $N$ e $K$, até 83 dias após o transplante. É necessário considerar que o teor de nutrientes nas folhas submetidas aos tratamentos com $\mathrm{N}$ e $\mathrm{K}_{2} \mathrm{O}$, aos 50 e 83 dias do transplante, ou seja, em pleno florescimento e plena frutificação, não difeririu significativamente da testemunha (tabela 12). Tal fato pode ser justificado, levando-se em conta que a maior parte do $\mathrm{N}$ e $\mathrm{K}_{2} \mathrm{O}$ foi aplicada após a primeira coleta de folhas e a última aplicação foi feita um dia após a segunda coleta das folhas.

Verifica-se que a aplicação de $\mathrm{K}_{2} \mathrm{O}$ diminuiu a concentração de $\mathrm{P}$ nas folhas, quando a amostragem foi realizada após 83 dias do transplante (tabela 13). Provavelmente doses de $\mathrm{K}_{2} \mathrm{O}$, aplicado como $\mathrm{KCl}$, maiores que $13,3 \mathrm{~g} \mathrm{~m}^{-2}$, dificultaram a absorção de $\mathrm{P}$, como consequência da menor produção de raízes. De acordo com Marschner (1985), altas concentraçōes de sais em solução aumentam a pressão osmótica e diminuem o potencial de água do solo. Nesse caso, há prejuizos no desenvolvimento das raízes. O $\mathrm{P}$ é principalmente absorvido por difusão, caminhando no solo a curtas distâncias e necessitando, por isso, de uma maior extensão do sistema radicular para haver maior proximidade do nutriente e melhor absorção pelas raízes. Malavolta et al. (1984) e Gomes et al. (1996) obtiveram redução no teor foliar de $P$, devido a presença de cloreto em solução. Nesse mesmo trabalho, o cloreto também diminuiu a concentração de $\mathrm{N}, \mathrm{K}, \mathrm{Ca}$ e $\mathrm{Mg}$ nas plantas de pimentão; tal fato foi atribuído à inibição competitiva entre cloreto e nitrato e a redução do sistema radicular devido a salinidade do ânion.

Aos 83 dias, observou-se maior concentração foliar dos nutrientes, como consequência do maior desenvolvimento da planta, a medida que os frutos se formam. Haag et al. (1970) trabalhando em solução nutritiva observaram que a 


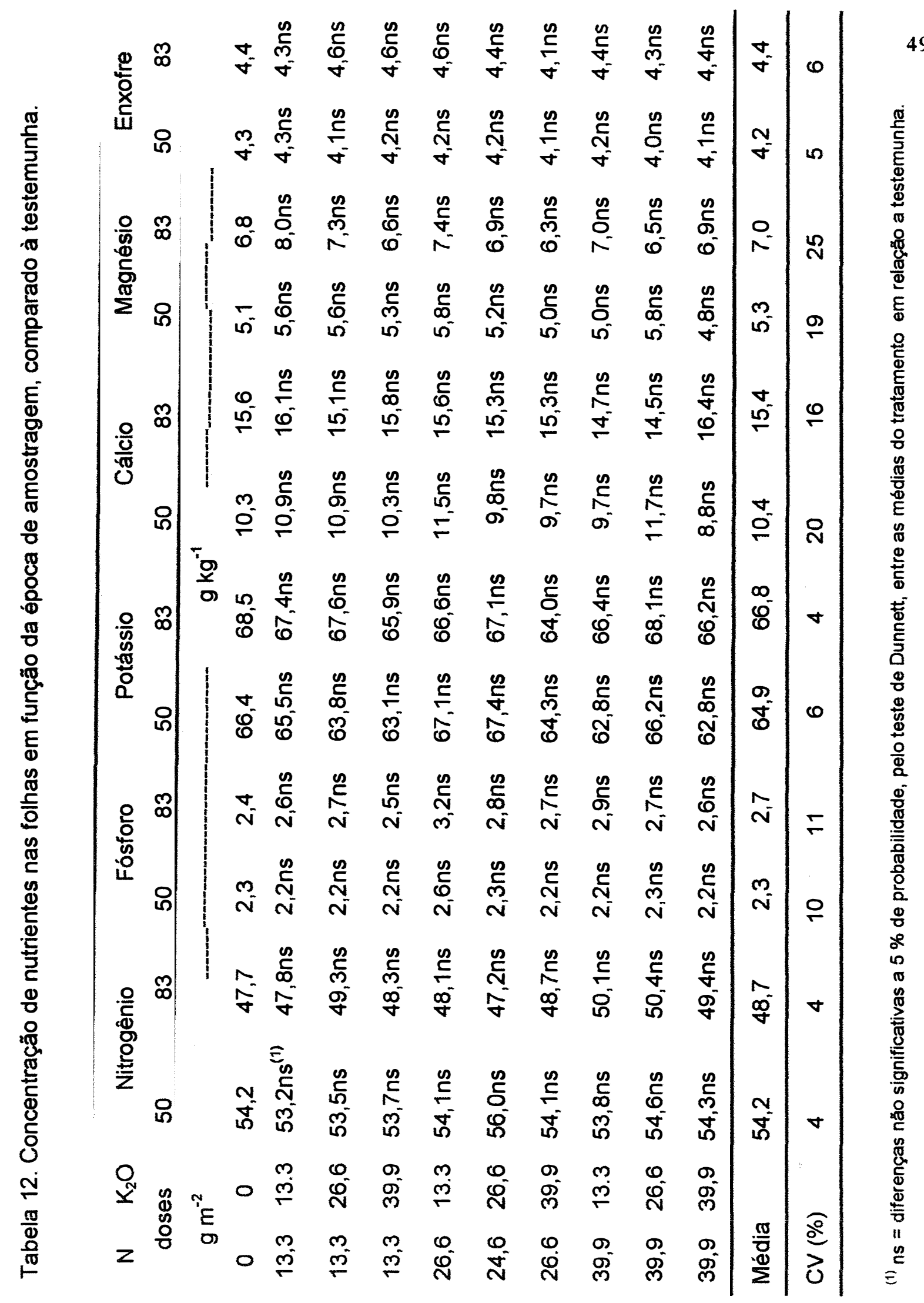




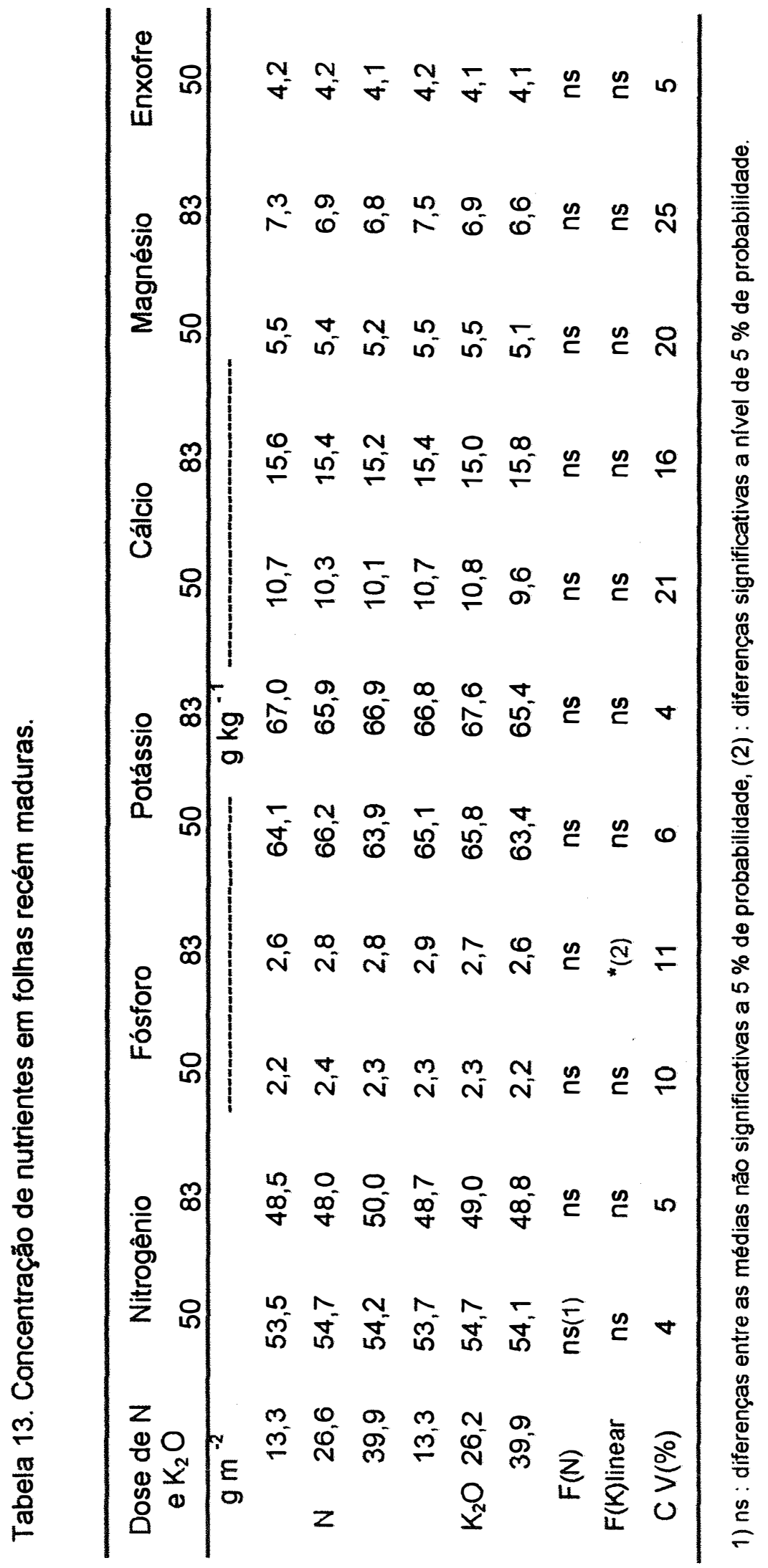


concentração de $\mathrm{N}$ e K aumentou até 81 dias do transplante, estabilizando-se até 95 dias e decrescendo a partir desse período. A concentração de $P$ decresceu, enquanto - Ca aumentou, de acordo com o ciclo da planta. O Mg sofreu pequena oscilação percentual, comparado ao $\mathrm{S}$, que elevou-se na parte vegetativa até 95 dias, estabilizando-se em seguida. Hochmuth (1994) observou que os teores de $\mathrm{N}$ e $\mathrm{K}$ diminuiram nas folhas, do início da formação dos botões florais até o início da colheita dos frutos.

O N diminuiu a concentração de $S$ foliar, aos 83 dias, porém somente em altas quantidades de $\mathrm{K}_{2} \mathrm{O}$ (tabela 14). Alguns trabalhos, porém, evidenciaram um efeito sinérgico entre N e S, como Fagéria \& Singh (1982); Zhao et al. (1993); Sharma et al. (1994); Plessis \& Agenbag (1994). Doses maiores de $\mathrm{K}_{2} \mathrm{O}$, diminuíram o teor de $\mathrm{S}$ nas folhas, principalmente na dose intermediária de $\mathrm{N}$.

Tabela 14. Concentração de enxofre nas folhas, aos 83 dias, após transplante.

\begin{tabular}{|c|c|c|c|c|c|c|c|}
\hline \multirow[b]{2}{*}{ Dose de $N$} & \multicolumn{4}{|c|}{ Doses de $\mathrm{K}_{2} \mathrm{O}\left(\mathrm{g} \mathrm{m}^{-2}\right)$} & \multirow[b]{2}{*}{ F linear } & \multirow[b]{2}{*}{$F$ quadrático } & \multirow[b]{2}{*}{$\mathrm{R}^{2}$} \\
\hline & 13,3 & 26,6 & 39,9 & Média & & & \\
\hline$\left(g^{-2}\right)$ & \multicolumn{4}{|c|}{$\mathrm{g} \mathrm{m}^{-2}$} & & & \\
\hline 13.3 & 4,30 & 4,58 & 4,61 & 4,50 & ns & ns & - \\
\hline 26.6 & 4,60 & 4,43 & 4,05 & 4,36 & $\star \star(1)$ & ns & 0,96 \\
\hline 39.9 & 4,42 & 4,42 & 4,36 & 4,34 & ns & ns & - \\
\hline Média & 4,44 & 4,42 & 4,34 & & & & \\
\hline F linear & $n s^{(2)}$ & ns & ns & & & & \\
\hline F quadrático & ns & ns & $\star \star$ & & & & \\
\hline $\mathrm{R}^{2}$ & - & - & 1,00 & & & & \\
\hline
\end{tabular}

(1) : Diferenças significativas a $1 \%$ de probabilidade (2): diferenças não significativas. 
O efeito da aplicação de $N$ e $K$ sobre a concentração foliar de nutrientes encontra-se na literatura, relatado por Russo (1991) e Knavel (1977), sendo que este último, em cultivo protegido, não encontrou até 87 dias, efeito significativo da aplicação da adubação nitrogenada, no teor deste nutriente nas folhas. Somente a partir dessa época é que as concentrações do nutriente diferiram com os tratamentos, utilizando doses crescentes de N. Por outro lado, Hassan et al. (1993), Locascio \& Alligood (1992) e Locascio \& Stall (1994) verificaram que os teores de $\mathrm{N}$ nas folhas variaram de acordo com a aplicação do nutriente no solo.

Locascio \& Fiskell (1979) relacionaram as concentrações de NPK nas folhas, em plena frutificação, à aplicação de $\mathrm{N}$. A concentração de $\mathrm{N}$ aumentou linearmente de 3,29 para $4,24 \%$, enquanto a concentração de $K$ diminuiu linearmente de 4,25 para 4,02\% e a concentração de $P$ permaneceu praticamente constante entre 0,37 e $0,39 \%$. Maiores concentrações de $N$ e $K$ nas folhas, com a aplicação dos nutrientes, são referidos por Roychoudhury et al. (1990).

Hochmuth et al. (1988), em Martin e Palm Beach, Flórida, encontraram em folhas recém maduras de pimentão, no início do florescimento, teores de $K$ variando entre 57 e 62 e 60 e $72 \mathrm{~g} \mathrm{~kg}^{-1}$, respectivamente para os dois locais. Porém, somente depois de um mês das primeiras amostragens é que foram verificadas diferenças significativas nas concentrações foliares de $K$, devido à aplicação do nutriente no solo. A aplicação de $K$ não influenciou os teores deste nutriente nas folhas, no inicio do florescimento, em outros dois locais estudados.

Persaud et al. (1977) observaram um aumento linear na concentração de $\mathrm{N}$ e $\mathrm{K}$, no início do florescimento e final da frutificação, em folhas de tomate, quando os nutrientes foram aplicados de forma crescente no solo; a concentração de $P$ manteve-se constate, nas duas épocas de amostragem.

Thomas \& Heilman (1964), em cultivo protegido, encontraram menor teor de P em folhas de pimentão, no inicio do florescimento e frutificação, quando os niveis de nitrogênio no solo eram mais altos, atribuindo os resultados a um maior crescimento da planta e ao efeito de diluição. 
4.5.1.2 Acúmulo de nutrientes nos órgãos da planta de pimentão.

Como já se discutiu anteriormente, as adubações nitrogenada e potássica tiveram pouca influência nos teores de nutrientes nas folhas. Porém, quanto ao acúmulo de nutrientes, após 39 semanas de cultivo, verificou-se que as doses de $\mathrm{N}$ e $\mathrm{K}$ aplicadas no solo influenciaram de maneira significativa os nutrientes acumulados na planta durante o todo o ciclo de cultivo. Analisando os resultados da tabela 15, comparativamente à testemunha, pode-se afirmar que as doses intermediárias e máxima de $\mathrm{N}$ propiciaram o maior acúmulo de nutrientes pelo pimentão. O K contribuiu somente quando aplicado na menor dose.

Os nutrientes acumulados pelos frutos não foram influenciados pelos tratamentos, embora Widders \& Lorez (1982) afirmam que o K no frutos é extremamente dependente do $K$ do solo, uma vez que a redistribuição a partir dos órgãos vegetativos é de apenas $12 \%$.

O N favorece o acúmulo de nutrientes, porque aumenta a produção de biomassa do pimentão, uma vez que estimula o crescimento vegetativo, como já demonstrado por muitos autores (Srinivas \& Prabhakar, 1982; Grainfenberg et al., 1985; Hegde , 1987; Magnífico, 1987; Shukla et al., 1987; Manchanda \& Singh, 1988; Bar-Tal et al., 1990; Hassan et al., 1993; Mishriky \& Alphonse, 1994).

Doses de $\mathrm{K}_{2} \mathrm{O}$ acima de $13,2 \mathrm{~g} \mathrm{~m}^{-2}$, aplicado como $\mathrm{KCl}$, diminuiram o crescimento das raizes e parte aérea e consequentemente diminuiram a absorção e acúmulo de nutrientes. De acordo com Cruciani (1980), o pimentão é uma cultura moderadamente sensivel à salinidade. Altas concentrações de cloreto em solução prejudicam a absorção de nutrientes, principalmente o $\mathrm{N}$, devido a inibição competitiva entre os ânions cloreto e nitrato (Pessarakli \& Turner, 1988).

Um fato importante a ressaltar é que as quantidades de nutrientes acumuladas na parte aérea são as quantidades exportadas pela cultura do pimentão, pois no final do cultivo toda a planta é arrancada e levada para fora do tunel plástico.

Como pode se verificar na tabela 16, há grandes variações nos resultados encontrados na literatura. São muitos os fatores responsáveis pelas 
variaçōes, como a produtividade, associada ao número de semanas de cultivo, 0 cultivar empregado e as condiçōes de ambiente de cultivo.

Tabela 15. Acúmulo de nutrientes pelo pimentão ao final do ciclo, após 39 semanas.

\begin{tabular}{|c|c|c|c|c|c|c|c|c|}
\hline & \multicolumn{4}{|c|}{ CAULES + FOLHAS } & \multicolumn{4}{|c|}{ PARTE AÉREA } \\
\hline & Controle & mínimo & médio & máximo & Controle & minimo & médio & máximo \\
\hline & & $g \mathrm{~m}^{-2}$ & & & & $g \mathrm{~m}^{-2}$ & 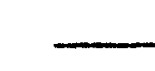 & \\
\hline$N$ & 5,79 & $6,24 \mathrm{~ns}$ & 9,96 * & $11,23^{*}$ & 8,00 & $8,96 n s$ & $12,38^{\star}$ & $13,90 *$ \\
\hline$P$ & 0,43 & $0,40 \mathrm{~ns}$ & $0,63^{*}$ & $0,79 *$ & 0,70 & $0,73 \mathrm{~ns}$ & $0,94^{\star}$ & $1,14^{*}$ \\
\hline$K$ & 12.18 & $12,78 \mathrm{~ns}$ & $18,77^{\star}$ & 21,71 * & 15,30 & $16,77 \mathrm{~ns}$ & $22,19 \star$ & $25,35 *$ \\
\hline $\mathrm{Ca}$ & 4,82 & $5,40 n s$ & $8,01 \star$ & $8,71^{\star}$ & 4,90 & $5,50 \mathrm{~ns}$ & $8,10^{*}$ & $8,68 *$ \\
\hline $\mathrm{Mg}$ & 1,95 & $2,31 \mathrm{~ns}$ & 3,63 * & $4,20^{\star}$ & 2,01 & $2,37 \mathrm{~ns}$ & $3,70^{\star}$ & $4,27^{\star}$ \\
\hline$S$ & 1,20 & $1,26 \mathrm{~ns}$ & $1,97^{\star}$ & $2,28 *$ & 1,44 & $1,55 \mathrm{~ns}$ & $2,23^{\star}$ & 2,57 * \\
\hline
\end{tabular}

(1): Diferenças significativas a nivel de $5 \%$ pelo teste Dunnett; $n s$ : diferenças não significativas; mínimo: doses de $\mathrm{N}=13,32 \mathrm{~g} \mathrm{~m}^{-2}$ e $\mathrm{K}_{2} \mathrm{O}=39,9 \mathrm{~g} \mathrm{~m}^{-2} ;$ médio : doses de $\mathrm{N}=39,9 \mathrm{~g} \mathrm{~m}^{-2}$ e $\mathrm{K}_{2} \mathrm{O}=13,3 \mathrm{~g} \mathrm{~m}^{-2}$; máximo: doses de $\mathrm{N}=26,6 \mathrm{~g} \mathrm{~m}^{-2}$ e $\mathrm{K}_{2} \mathrm{O}=13,3 \mathrm{~g} \mathrm{~m}^{-2}$.

Quando os tratamentos foram comparados entre si, não se observou influência no acúmulo de nutrientes pelos frutos (figuras 1 e 3), o que concorda, no que diz respeito ao K, com os resultados de Hochmuth et al. (1994), embora Locascio et al. (1985), Crespo Ruiz et al. (1988) e Olsen et al. (1993) demonstraram o contrário, confirmando a influência do $\mathrm{N}$ nos nutrientes presentes nos frutos. $\mathrm{OK}, \mathrm{N}$ (figuras 1 e 3 , segundo eixo), assim como $P$ e $S$ (figuras 1 e 3 ) estiveram mais presentes nos frutos (figuras 1 e 3 , segundo eixo). Quando se considera a parte aérea (caule+folhas e frutos), observou-se maior acúmulo de $\mathrm{K}$ (figura 2, segundo eixo), $\mathrm{Ne}$ $\mathrm{Ca}$ (figura 2 ). A absorção dos nutrientes obedeceu uma relação quadrática, com o aumento das doses de $\mathrm{N}$ aplicadas, exceto para o $\mathrm{Ca}$. O aumento das doses de $\mathrm{K}_{2} \mathrm{O}$ aplicado como $\mathrm{KCl}$ ao solo, diminuiu, de forma linear os nutrientes acumulados na planta (figura 4), podendo estar relacionado ao efeito salino do cloreto. 
Tabela 16. Quantidades de nutrientes acumulados por plantas de pimentão, citadas na literatura.

\begin{tabular}{ccccccc}
\hline Nutriente & 1 & 2 & 3 & 4 & 5 & 6 \\
\hline & $\mathrm{kg} \mathrm{ha} \mathrm{h}^{-1}$ & $\mathrm{~kg} \mathrm{ha}^{-1}$ & $\mathrm{~kg} \mathrm{ha}^{-1}$ & $\mathrm{~kg} \mathrm{ha}^{-1}$ & $9 \mathrm{~m} \mathrm{-2}$ & 9 planta $^{-1}$ \\
$\mathrm{~N}$ & $195 / 189$ & 153 & 201 & 31 e 34 & 30 & $6,7 / 10,0$ \\
$\mathrm{P}$ & $20 / 22$ & 30 & 56 & 6 e 6 & 3 & $0,9 / 1,3$ \\
$\mathrm{~K}$ & $210 / 205$ & 241 & 269 & 42 e 49 & 38 & $8,3 / 12,5$ \\
$\mathrm{Ca}$ & $78 / 76$ & 148 & 160 & 2 e 5 & 12 & $6,2 / 9,0$ \\
$\mathrm{Mg}$ & $46 / 34$ & 31 & 91 & 2 e 3 & 6 & $0,2 / 1,2$ \\
$\mathrm{~S}$ & $34 / 27$ & - & - & 4 e 4 & - & -
\end{tabular}

1- Olsen et al. (1993), cultivo de primavera e outono; resultados relativos ao máximo rendimento e a dose de 280 e $200 \mathrm{~kg} \mathrm{há}^{-1}$ de $\mathrm{N}$ e K no solo.

2- Subbiah et al. (1982), aplicando $120 \mathrm{~kg} \mathrm{há}^{-1}$ de $\mathrm{N}$

3- Lopez (1988) ${ }^{1}$, produtividade de frutos de $54 \mathrm{t} \mathrm{hă}^{-1}$ (citado por Nigri, 1990), em ambiente protegido.

4- Haag et al. (1970), 17 semanas de cultivo em solução nutritiva, planta inteira e frutos, em ambiente protegido.

5- Rincon et al. (1995), com 35 e $43 \mathrm{~g} \mathrm{~m}^{-2}$ de $\mathrm{N}$ e K aplicados ao solo e densidade de $2,5 \mathrm{pl} \mathrm{m}^{-2}$, em ambiente protegido.

6- Graifenberg et al. (1985). Os números referem se a cultivares diferentes; e a aplicação de 160,5 e 110,5 kg há - 1 de $\mathrm{N}$ e K no solo , em ambiente protegido.

1. LOPES, C.C. Fertilizacíon en riego por goteo de cultivos hortícolas, S.1. Delegacíon de Agricultura Almería Rafael Gimenes Mejías, 1988. 213 p. 


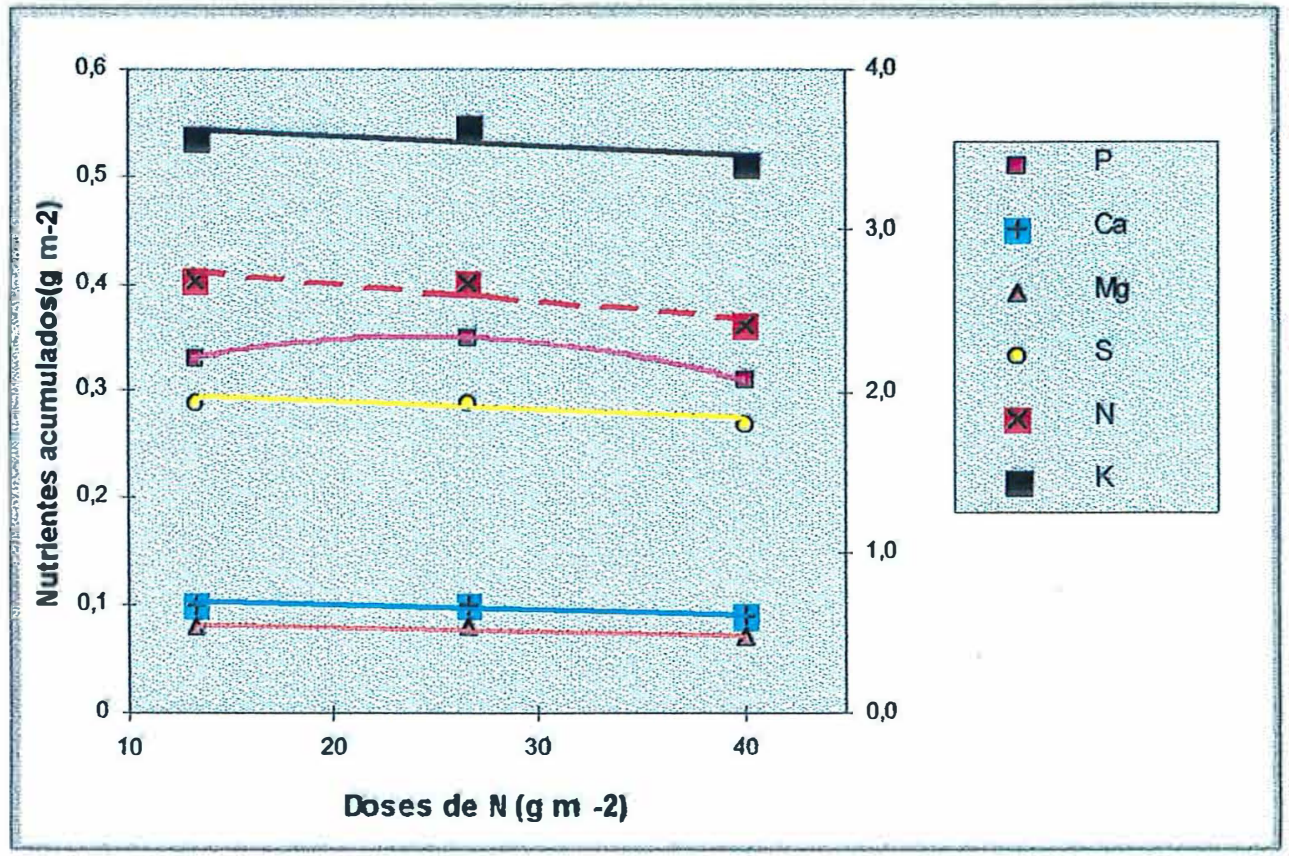

Figura 1. Acúmulo de nutrientes pelos frutos de pimentão, em função da aplicação de $\mathrm{N}$ no solo, na dose de $\mathrm{K}_{2} \mathrm{O}$ de $13,3 \mathrm{~g} \mathrm{~m}^{2}$.

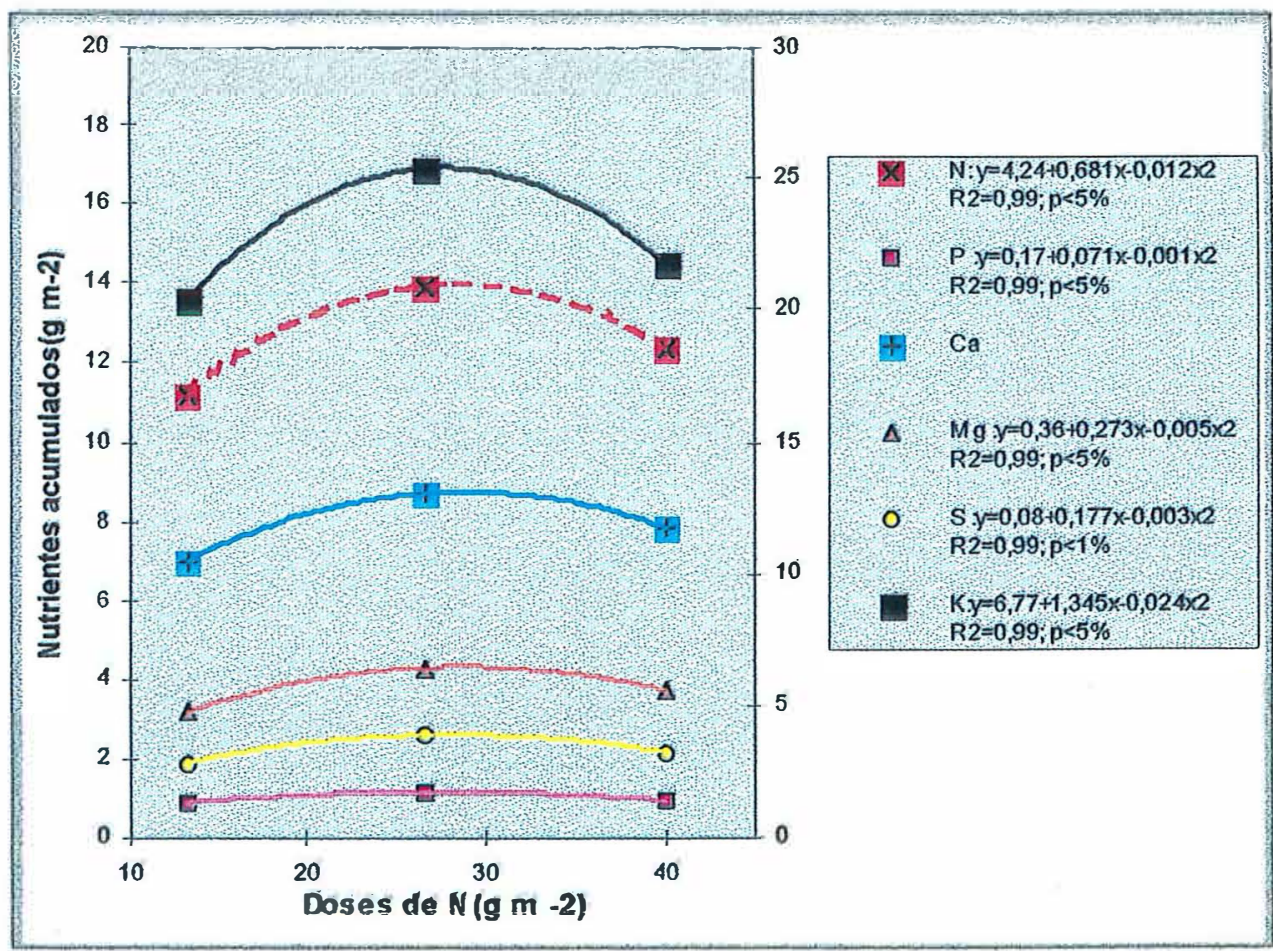

Figura 2. Acúmulo de nutrientes pela parte aérea do pimentão, em função da aplicação do $\mathrm{N}$ no solo, na dose de $\mathrm{K}_{2} \mathrm{O}$ de $13,3 \mathrm{~g} \mathrm{~m}^{-2}$. 


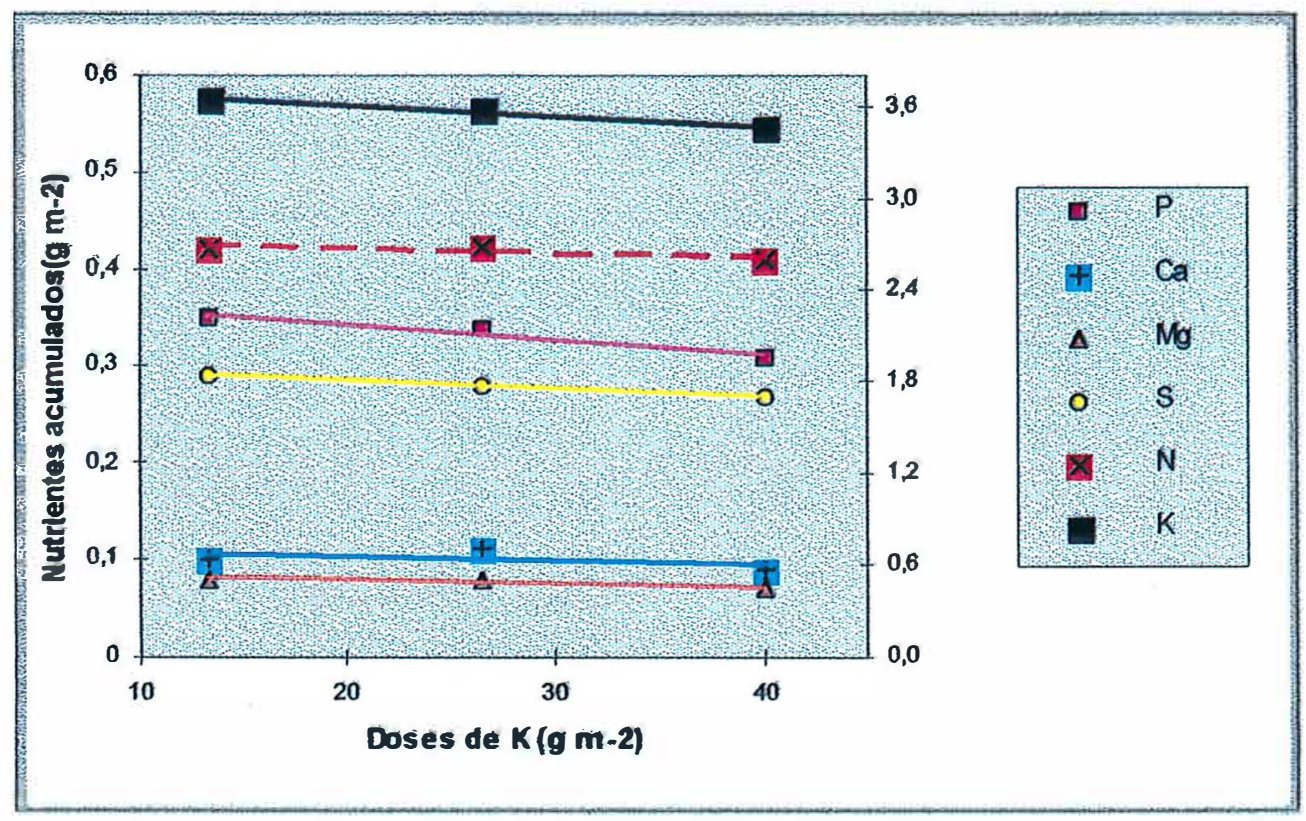

Figura 3. Acúmulo de nutrientes pelos frutos de pimentão, em função da aplicação de $\mathrm{K}_{2} \mathrm{O}$ no solo, na dose de $\mathrm{N}$ de $26,6 \mathrm{~g} \mathrm{~m}^{-2}$.

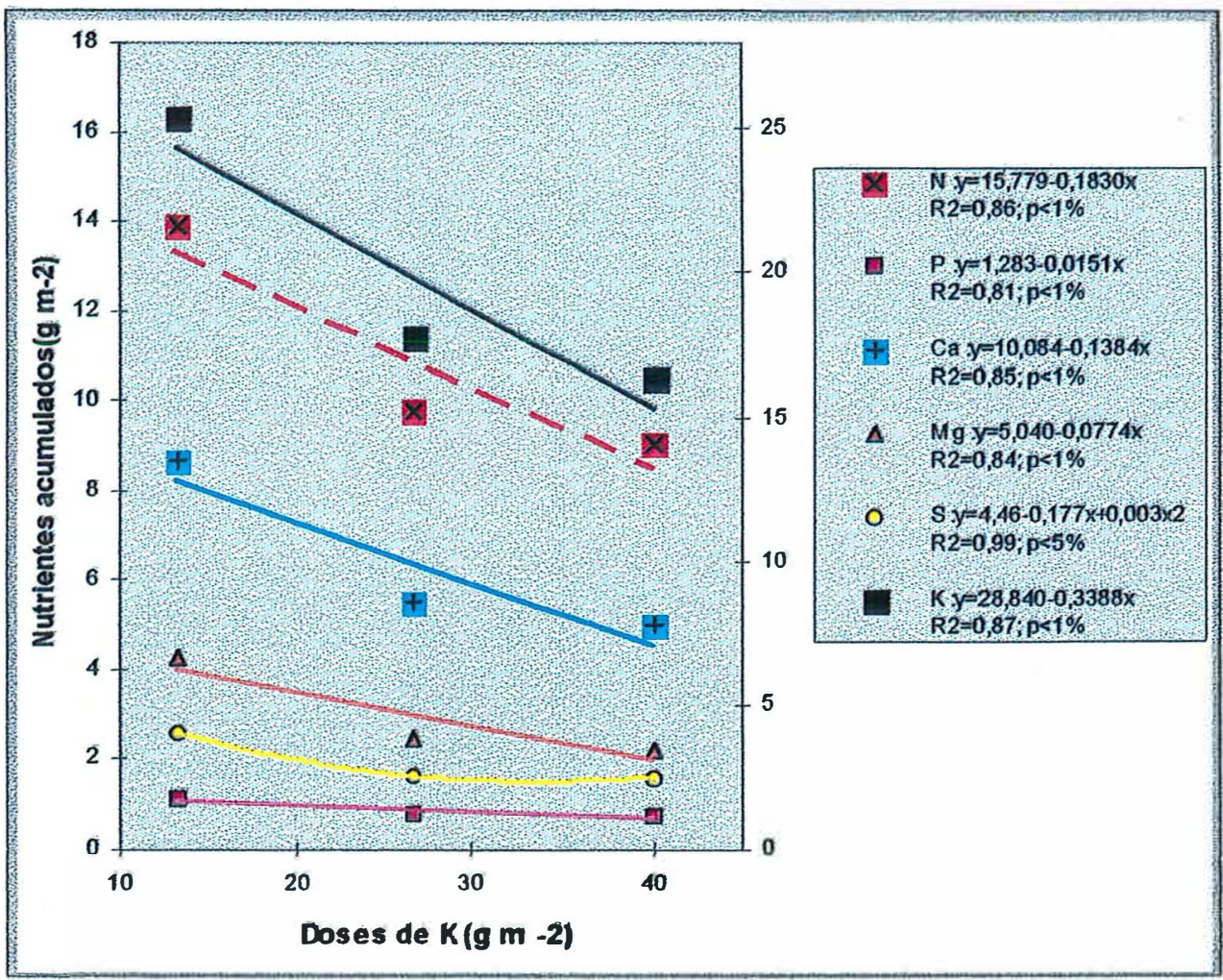

Figura 4. Acúmulo de nutrientes na parte aérea do pimentão, em função da aplicação de $\mathrm{K}_{2} \mathrm{O}$ no solo, na dose de $\mathrm{N}$ de $26,6 \mathrm{~g} \mathrm{~m}^{-2}$. 
Em todas as figuras, os maiores acúmulos na planta e frutos, relacionaram-se a um $\mathrm{N}$ máximo de $26,6 \mathrm{~g} \mathrm{~m}^{-2}$ e $\mathrm{K}_{2} \mathrm{O}$ máximo de $13,3 \mathrm{~g} \mathrm{~m}^{-2}$. De acordo com Thomas \& Heilman (1967), Hegde (1988), Locascio et al. (1985), Crespo Ruiz et al. (1988), doses de $\mathrm{N}$ maiores que 120, 180, 224 e $300 \mathrm{~kg} \mathrm{ha}^{-1}$, também não influenciaram a quantidade de nutrientes acumulados pelo pimentão, ao final do ciclo de cultivo, que variou de 9 a 14 semanas. Segundo os autores, diferentes respostas ao $\mathrm{N}$ estiveram relacionadas principalmente ao crescimento, produção de matéria seca e ao ciclo de cultivo. Da mesma forma, Olsen et al. (1993) encontraram após 14 semanas do transplante, um máximo de nutrientes absorvidos, relacionados a $280 \mathrm{e}$ $200 \mathrm{~kg} \mathrm{ha}^{-1}$ de $\mathrm{N}$ e $\mathrm{K}$ aplicados ao solo.

Em termos percentuais, em relação ao total, o caule acumulou maior quantidade de $\mathrm{S}, \mathrm{Mg}, \mathrm{K}$ e Ca $(51 ; 45 ; 42$ e $37 \%$, respectivamente); as folhas contribuíram mais com o $\mathrm{Ca}, \mathrm{Mg}, \mathrm{N}, \mathrm{K}$ e P $(62 ; 52 ; 51 ; 40$ e 40\%, respectivamente); os frutos contiveram mais $\mathrm{P}, \mathrm{N}, \mathrm{K}$ e S $(38 ; 24 ; 18$ e $15 \%$, respectivamente), como está ilustrado na Figura 5.

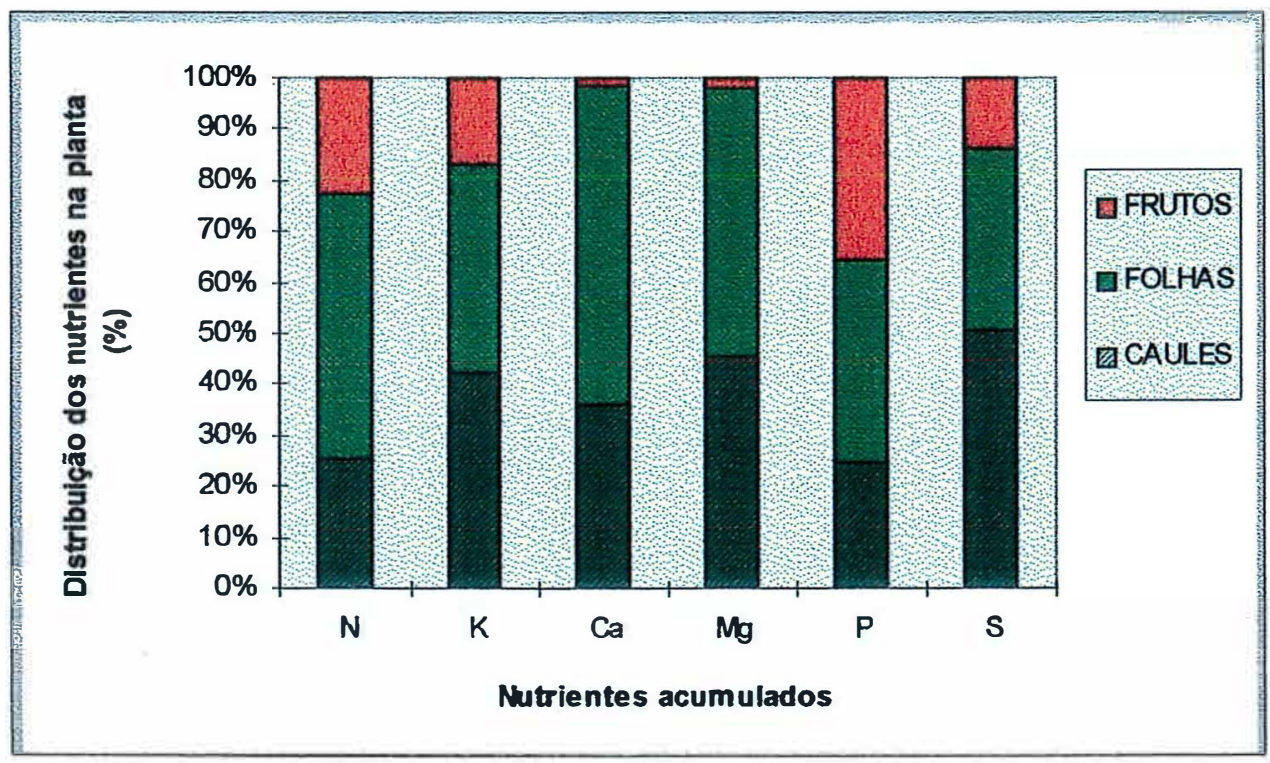

Figura 5. Distribuição pecentual dos nutrientes na planta 
A distribuição dos nutrientes encontrada por Miller et al. (1979) é a seguinte : N (21, 36 e $44 \%) ; K(25,35$ e $40 \%) ; P(38,21$ e $41 \%) ; C a(29,64$ e $6 \%), M g$ $(34,50$ e $16 \%)$, respectivamente para caules, folhas e frutos. As folhas apresentaram maior percentagem de $\mathrm{Ca}$ e $\mathrm{Mg}$, enquanto que os frutos continham mais $\mathrm{NP}$ e K. O K distribuiu-se em partes iguais nos frutos e demais órgãos vegetativos. A distribuição dos nutrientes nos frutos concorda com Olsen et al. (1993).

Considerando-se as variaçöes que ocorreram em trabalhos citados por outros autores, pode-se dizer que, de forma geral, os resultados de distribuição percentual de nutrientes nos diferentes órgãos da planta de pimentão encontrados no presente trabalho concordam com os dados de literatura.

\subsubsection{Efeito da adubação nitrogenada e potássica nas características químicas do solo, ao final do cultivo.}

A aplicação de adubos no solo pode causar efeitos desejáveis e indesejáveis nas propriedades químicas do solo. A alteração desejável é aumentar o teor no solo do nutriente aplicado na adubação, quando este limita o crescimento do vegetal cultivado, possibilitando que a cultura manifeste todo o seu potencial genético de produtividade, se nenhum outro fator estiver limitando o seu crescimento.

No presente experimento, a produtividade de $6,83 \mathrm{~kg} \mathrm{~m}^{-2}$ de frutos comerciáveis, apresentados anteriormente na tabela 5 , obtida com a adubação com 26,6 e $13,3 \mathrm{~g} \mathrm{~m}^{-2}$ de $\mathrm{N}$ e $\mathrm{K}_{2} \mathrm{O}$, respectivamente, é considerada alta se comparada às mencionadas na literatura. Isto quer dizer que o máximo do efeito desejável foi obtido com as mencionadas doses de $\mathrm{N}$ e $\mathrm{K}_{2} \mathrm{O}$ e que doses acima destas podem ser desnecessárias e mesmo causarem efeitos indesejáveis. Os efeitos indesejáveis que eventualmente a adubação pode causar dependem da fonte do nutriente e da dose empregada, como também das características do solo.

Para a uréia, o principal efeito de sua aplicação ao solo é aumentar a acidez do solo, diminuindo o $\mathrm{pH}$ e aumentando a acidez potencial. No presente experimento, o efeito da aplicação da uréia na acidez do solo foi mínimo, pois o pH que era em média, antes do início do cultivo de pimentão, de 5,7 e 4,8 nas camadas de 0-20 e 0-40 cm, respectivamente, passou para 5,6 e 5,2 nas mesmas camadas 
(tabela 17). Por outro lado, pode-se verificar que não houveram diferenças significativas entre as médias de acidez potencial da testemunha e dos tratamentos que receberam adubação nitrogenada e mesmo entre as médias dos tratamentos que receberam as doses de $N$ (tabela 18). Deve-se considerar que o solo usado tem textura argila até a profundidade de $40 \mathrm{~cm}$, o que deve ter evitado que alteraçōes mais drásticas ocorressem.

As doses de $\mathrm{N}$ aplicadas tiveram uma influência pequena sobre o teor de $\mathrm{N}$ total do solo, embora foram constatados efeitos significativos dos tratamentos em relação à testemunha, nos teores da camada de solo entre 20 e $40 \mathrm{~cm}$ de profundidade (tabela 17). Isto ocorre porque a quantidade aplicada, mesmo na maior dose empregada, é muito pequena em relação a quantidade de $\mathrm{N}$ já existente no solo, principalmente na forma orgânica. Entretanto, se considerado o teor de $\mathrm{N}$ inorgânico, verifica-se pela tabela 19, que tanto o teor de amônio como de nitrato foram aumentados, em relação à testemunha, pela adubação nitrogenada, embora tais teores sejam considerados baixos, de acordo com a interpretação de Fassbender (1975). Segundo o autor, nos solos da América Latina, os teores médios de nitrogênio estão entre: $\mathrm{N}$ total $\left(1,2\right.$ a $\left.7,0 \mathrm{~g} \mathrm{~kg}^{-1}\right) ; \mathrm{N}^{-N_{4}}{ }_{4}^{+}$total (30 a $140 \mathrm{mg} \mathrm{kg}^{-1}$ ); $\mathrm{N}-\mathrm{NH}_{4}^{+}$trocável (8-75 mg kg-1); ${\mathrm{N}-\mathrm{NO}_{3}}^{-1}\left(1-25 \mathrm{mg} \mathrm{kg}^{-1}\right)$. Segundo Malavolta et al. (1997) solos de cerrado apresentam teores médios de $\mathrm{N}$ total de 0,8 a $1,4 \mathrm{~g} \mathrm{dm}^{-3}$. Outros autores como Locascio \& Fiskell (1977), Locascio \& Alliggod (1992), Locascio et al. (1981), Hochmuth et al. (1987) e Hochmuth et al. (1994) encontraram variações nos teores de nitrato e amônio do solo, motivadas pela adubação nitrogenada, muito maiores que as encontradas no presente trabalho.

Foi possivel calcular pelo método indireto o aproveitamento do $\mathrm{N}$ aplicado ao solo (*). Estimou-se que as plantas de pimentão aproveitaram apenas 24,22 e $11 \%$ do $\mathrm{N}$ aplicado, considerando a dose menor, média e maior de $\mathrm{N}$ aplicado.

$\left(^{\star}\right) \%$ aproveitamento $=(100)^{\star}($ tratamento - testemunha $) /($ dose aplicada $)$.

Ex: testemunha $=8,00 \mathrm{~g} \mathrm{~m}^{-2}$ (tabela 15)

Tratamento com $39,96 \mathrm{~g} \mathrm{~m}^{-2}=\left(12,38 \mathrm{~g} \mathrm{~m}^{-2}\right.$ média da dose, tabela 15)

$\%$ aproveitamento $=(100)(12,38-8,00) /(39,96)=11,0 \%$ 
O $\mathrm{N}$ amoniacal concentrou-se mais à profundidade de $20 \mathrm{~cm}$, provavelmente mais adsorvido a matéria orgânica. A maior presença de amônio e nitrato de 20 a $40 \mathrm{~cm}$ pode ter sido decorrente da movimentação dos ions no solo, quando em quantidades mais altas (tabela 19). $\mathrm{O}$ teor de $\mathrm{N}$ nítrico na profundidade além de $20 \mathrm{~cm}$ foi maior, seguindo as quantidades do nutriente no solo. Goldberg et al. (1971) verificaram que o nitrato movimentou-se no solo, junto com a água aplicada pelos gotejadores, assim como Kafkafi \& Bar-Yosef (1980) determinaram alta concentração de nitrato (100 ppm) a profundidade de 20 a $40 \mathrm{~cm}$ do gotejador.

O $\mathrm{K}$ foi significativamente maior conforme sua aplicação ao solo, comparado à testemunha e aos tratamentos, nas duas profundidades amostradas (tabelas 17 e 18), confirmando a sua permanência no solo, principalmente adsonvido aos colóides orgânicos e inorgânicos.

Teores menores de $\mathrm{K}$ foram encontrados por Hortenstine (1962), Fiskell et al. (1978), estes referem-se a $84 \mathrm{ug} \mathrm{g}^{-1}$ de $\mathrm{K}$ no solo, extraído por duplo ácido, após 17 semanas de cultivo e Hochmuth et al. (1994) encontraram encontraram teores de $\mathrm{K}$ na linha de plantio até 23 ppm e até 128 ppm na entre linha.

$O$ aumento do $K$ no solo é confirmado pela saturação do nutriente no solo, em função da sua CTC . Ao final do experimento, a saturação de $\mathrm{K}$, na camada de 0-20 cm de solo, que era de 2,2\%, na testemunha, subiu para $3,4 \%$ e $5,6 \%$, quando as maiores doses do nutriente foram aplicadas. No início do experimento a saturação de $K$, para a camada mencionada, foi de 3,3\%. Efeitos semelhantes a estes também ocorreram na camada de 20 a $40 \mathrm{~cm}$ de solo. Estes aumentos devem ter sido os responsáveis pela diminuição da matéria seca do sistema radicular, como foi comentado anteriormente. Destes resultados, pode-se deduzir que o teor de $\mathrm{K}$ no solo ao redor de $3,0 \mathrm{mmol}_{\mathrm{c}} \mathrm{cm}^{-3}$ de solo, correspondendo a uma saturação de $K$ de 3,0\% não devem ser ultrapassados quando se deseja cultivar pimentão no solo a ser adubado, pois pode causar efeitos deletérios na cultura e ao mesmo tempo possibilitar que ocorra a salinização do solo. como vem acontecendo com freqüência nos solos sob cultivo em ambiente protegido. 


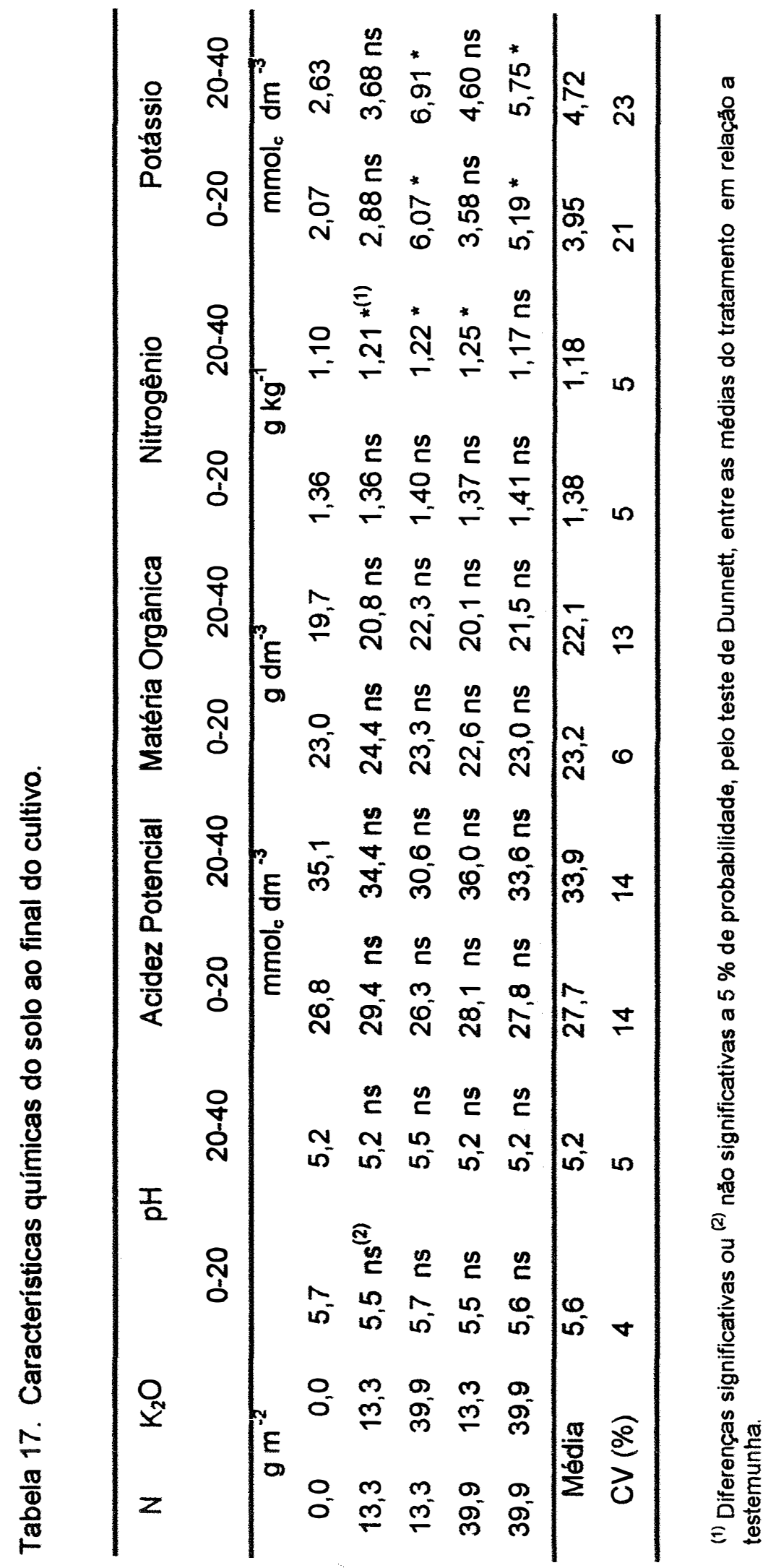




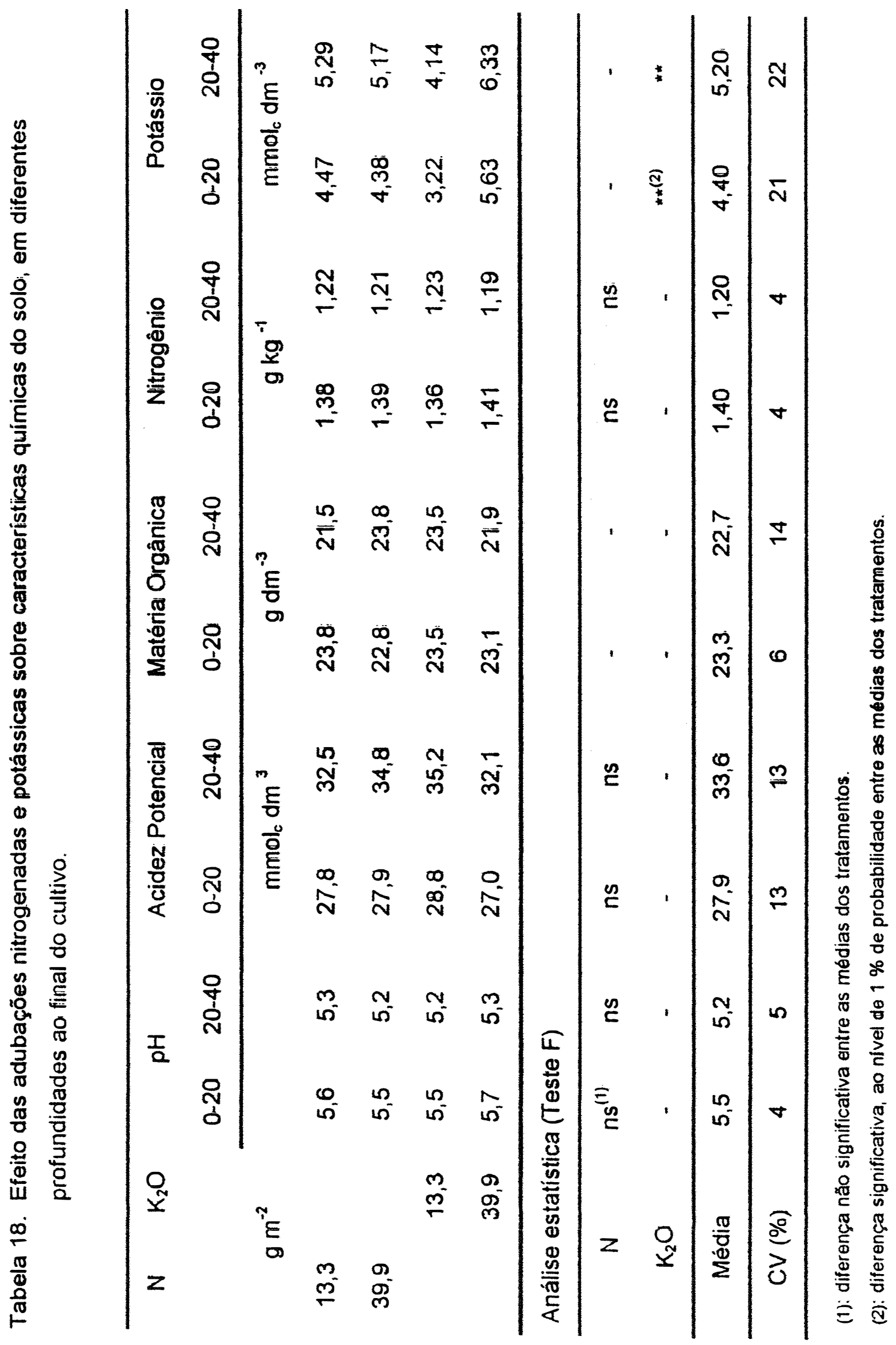


Tabela 19. Concentração de nitrogênio em duas profundidades do solo $(\mathrm{cm})$ ao final do cicio de cultivo.

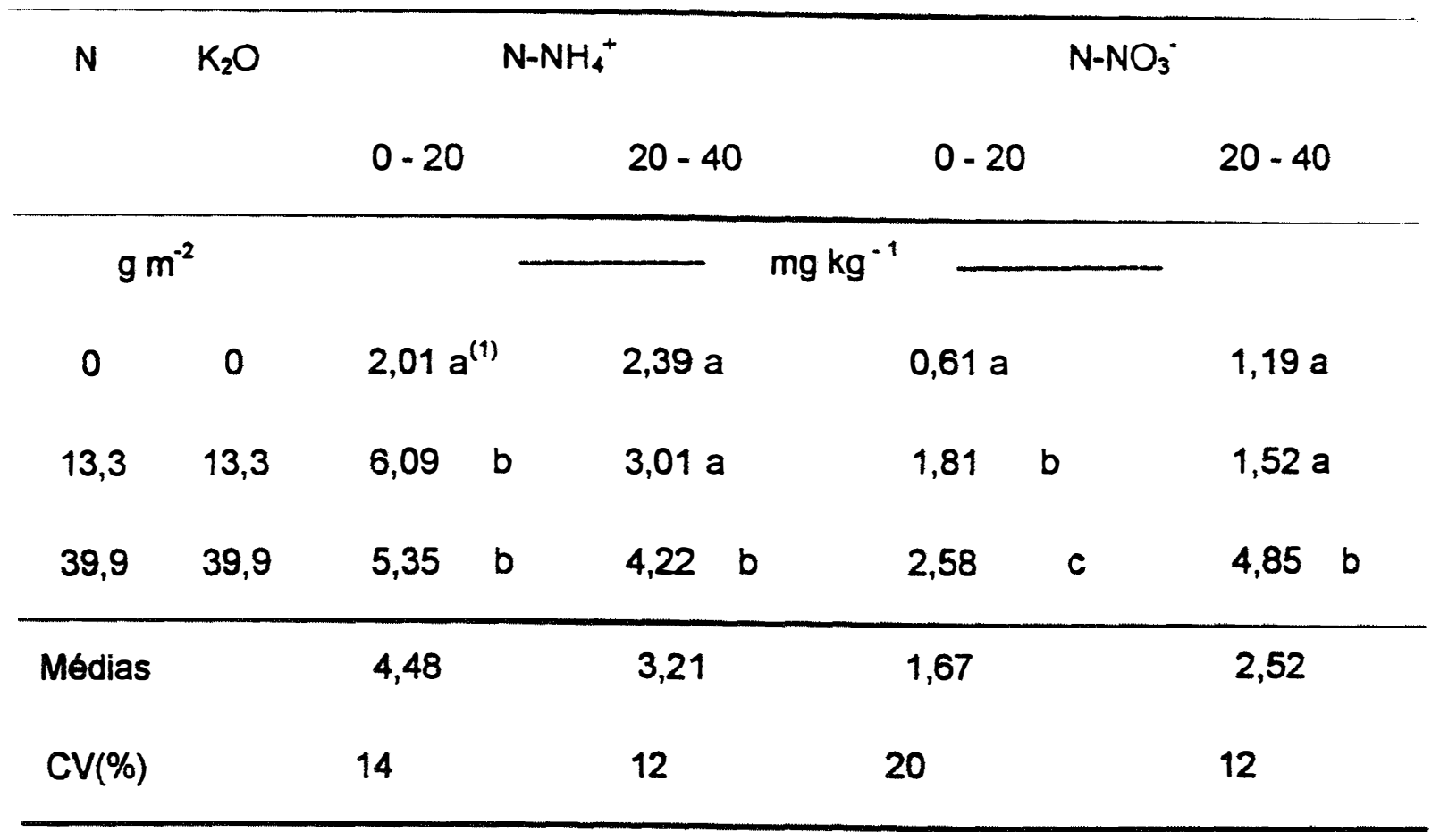

(1) Médias seguidas da mesma letra, na vertical, nảo diferem estatisticamente entre si pelo teste de Tukey ao nivel de $5 \%$.

O baixo aproveitamento do $\mathrm{N}$ pela cultura deveria resultar em maior acúmulo de $\mathrm{N}$ no solo, já que não deve ter havido perda por lixiviação de nitrato, pois a irrigação foi controlada para fornecer água aos primeiros $40 \mathrm{~cm}$ de solo. Deve então ter ocorrido volatilização de $\mathrm{N}$ da uréia que foi aplicada na superficie do solo, pois as condiçōes de solo no tunel plástico eram favoráveis, ou seja, alta temperatura do ar e alta umidade do solo. Há vários trabalhos na literatura referentes a volatilização da uréia, em condiçōes de alta umidade do ar e temperatura do solo (Lara Cabezas et al., 1992; Ernst \& Massey, 1960; Vlek \& Carter, 1983; Bouwmeester et al., 1985).

As maiores doses de $\mathrm{K}_{2} \mathrm{O}$ aplicadas, fez com que houvesse também maiores teores de $\mathrm{P}, \mathrm{Ca}$ e $\mathrm{Mg}$ no solo, nas duas profundidades amostradas, principalmente na menor dose de $\mathrm{N}$ (tabelas 20 e 21); tal fato ocorreu porque $\circ \mathrm{K}$ afetou 0 desenvolvimento das raizes e consequentemente afetou também o crescimento da planta e absorção de nutrientes, já discutidos anteriormente. 


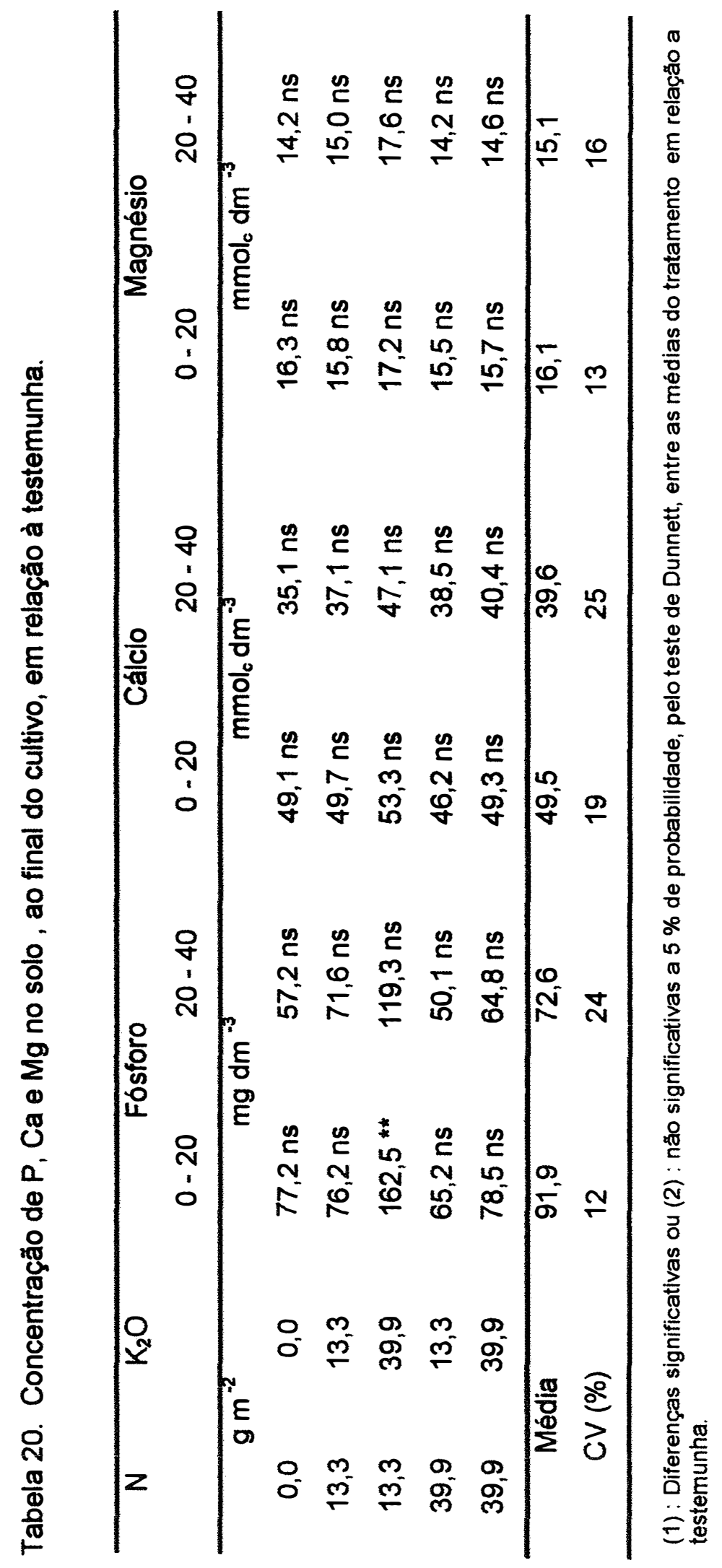




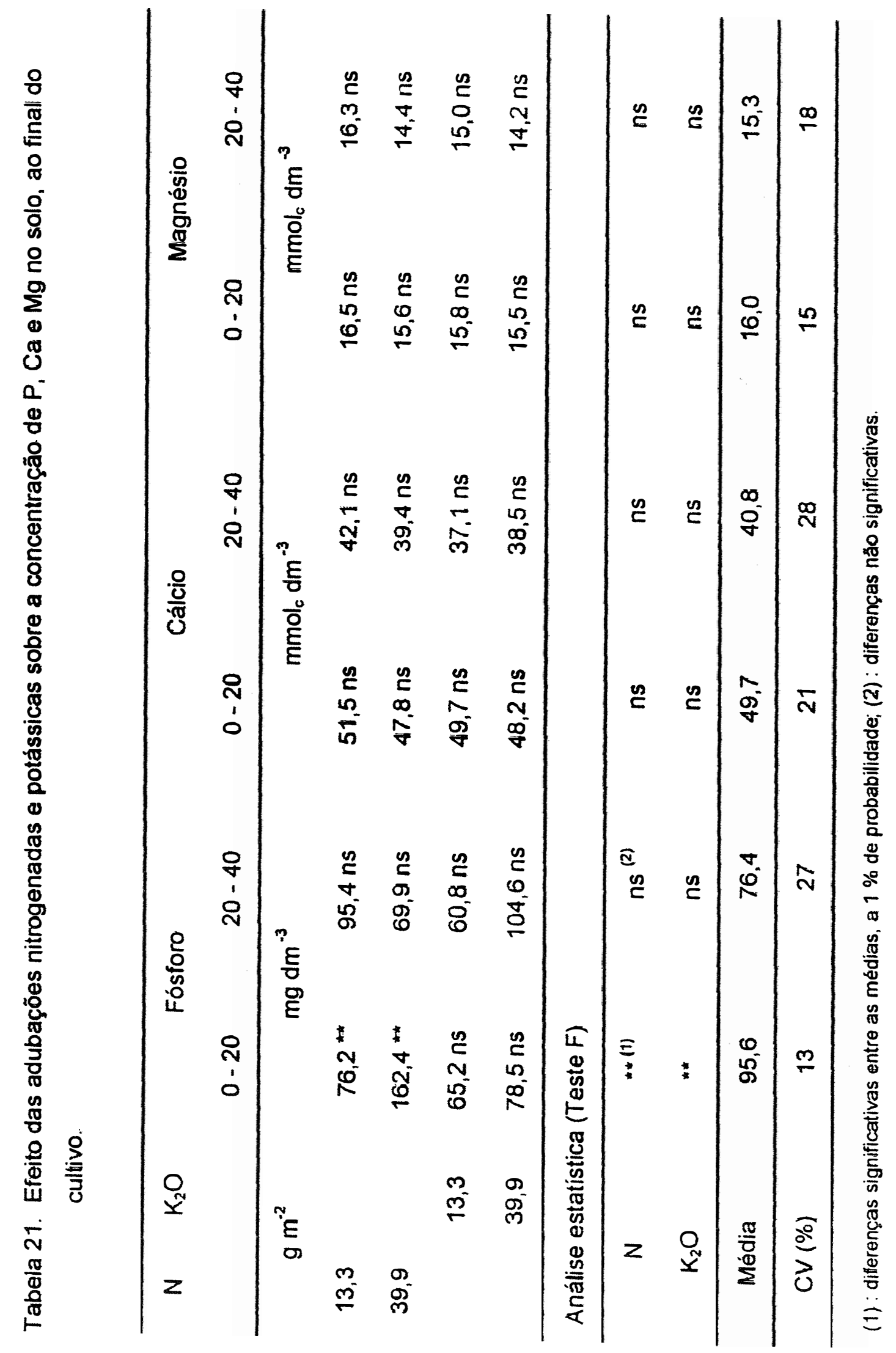


Kafkafi \& Bar-Yosef (1980) encontraram maior concentração de P a $20 \mathrm{~cm}$ dos gotejadores, enquanto que o $\mathrm{K}$ estava distribuído mais uniformemente na zona umidecida. Goldberg et al. (1971) encontraram movimentação do $P$ vertical e horizontalmente a $20 \mathrm{~cm}$ do gotejador, em solos arenosos. Santiago \& Goyal (1985) após cultivo de pimentão irrigado, relatam que a concentração de $P$ foi mais alta logo abaixo dos gotejadores, enquanto que o $\mathrm{K}, \mathrm{Ca}$ e $\mathrm{Mg}$ diminuíram de 15 a $45 \mathrm{~cm}$ no solo, devido a maior presença de raízes nessa área.

\subsection{Conclusões}

Para as condições que esse trabalho foi realizado, pode-se concluir que:

1. As doses de $\mathrm{N}$ não afetaram a concentração dos nutrientes presentes em folhas recém maduras, embora diminuíram a concentração de $S$, aos 83 dias do transplante, exceto na dose de $\mathrm{K}_{2} \mathrm{O}$ de $13,3 \mathrm{~g} \mathrm{~m}^{-2}$. Doses maiores de $\mathrm{K}_{2} \mathrm{O}$, diminuiram a concentração de $\mathrm{P}$ e $\mathrm{S}$, nesse mesmo período.

2. $\mathrm{ON}$ aumentou o acúmulo de nutrientes no caule, folhas e parte aérea, ao final do ciclo de cultivo, quando aplicado na doses de $26,6 \mathrm{~kg} \mathrm{há-1}$. O $\mathrm{K}_{2} \mathrm{O}$ contribuiu somente quando presente em baixas concentrações no solo. Os nutrientes acumulados pelos frutos não foram influenciados pelos tratamentos.

3. Os nutrientes mais acumulados na planta foram $\mathrm{K}, \mathrm{N}$ e $\mathrm{Ca}$ e os nutrientes menos acumulados na planta foram $\mathrm{Mg}, \mathrm{P}$ e $\mathrm{S}$.

4. O caule acumulou maior quantidade de $\mathrm{S}, \mathrm{Mg}, \mathrm{K}$ e $\mathrm{Ca}(51 ; 45 ; 42,37 \%$, respectivamente); as folhas contribuiram mais com o $\mathrm{Ca}, \mathrm{Mg}, \mathrm{N}, \mathrm{K}$ e P $(62 ; 52 ; 51$, 40 e $40 \%$, respectivamente); os frutos continham mais $\mathrm{P}, \mathrm{N}, \mathrm{K}$ e S $(37 ; 24 ; 18$ e 15 $\%$, respectivamente).

5. Ao final do cultivo, comparativamente à testemunha, a concentração de $N$ total no 
solo foi significativamente maior conforme a dose de $\mathrm{N}$ aplicada, porém somente além de $20 \mathrm{~cm}$ de profundidade. O potássio foi significativamente maior, de acordo com as quantidades aplicadas, independente da profundidade de amostragem.

6. O N amoniacal concentrou-se mais a $20 \mathrm{~cm}$ de profundidade, independente da quantidade de $\mathrm{N}$ aplicada, enquanto o nitrato foi maior, nessa profundidade, na maior dose de $\mathrm{N}$. As concentrações de amônio foram maiores que as concentrações de nitrato.

7. A maior presença de amônio e nitrato de 20 a $40 \mathrm{~cm}$ no perfil do solo foi decorrente da movimentação dos ions, junto com a água, quando em quantidades mais altas no solo. Nessa profundidade, as concentrações de nitrato foram maiores que amônio.

8. O deslocamento do $\mathrm{K}, \mathrm{Ca}$ e $\mathrm{Mg}$ pelo solo seguiu a movimentação da água, embora tenha havido maior concentração dos cátions até $20 \mathrm{~cm}$ de profundidade. $O P$ esteve em alta concentração até $40 \mathrm{~cm}$ no solo.

9. Doses de $\mathrm{K}_{2} \mathrm{O}$, aplicadas como $\mathrm{KCl}$, maiores que $13,3 \mathrm{~g} \mathrm{~m}^{-2}$, correspondentes a $3,0 \mathrm{mmol}_{c} \mathrm{dm}^{-3}$ e $3,1 \%$ de saturação no complexo de troca, prejudicaram o crescimento das raizes e absorção de nutrientes. 


\section{REFERÊNCIAS BIBLIOGRÁFICAS}

ABDEL-MAKSOUD, M.; EL OKSH, I.I.; EL BEHIEDI, M.; EL SAWAH, M.H. Effect of potassium and stable manure on growth, chemical composition, yield and fruit quality of sweet pepper. Egyptian Journal of Soil Science, p.367-380, 1975. Special issue

AL RAWAHY, S.A.; STROEHLEIN, J.L.; PESSARAKLI, M. Dry-matter yield and nitrogen-15, $\mathrm{Na}^{+}, \mathrm{Cl}^{-}$and $\mathrm{K}^{+}$content of tomatoes under sodium chloride stress. Joumal of Plant Nutrition, v. 15, n. 3, p. 341-358, 1992.

ALBREGTS, E.E. Effect of nitrogen and potassium on bell pepper grown under paper mulch. Soil and Crop Science Society of Florida Annual Proceedings, v. 31, p. 116-118, 1971.

BAR-TAL, A.; BAR-YOSEF, B.; KAFKAFI, V. Pepper transplant response to root volumes and nutrition in the nursery. Agronomy Journal, v. 82, n.5, p. 989-995, 1990.

BAR-YOSEF, B.; STAMMERS, C.; SAGIV, B. Growth of trickle irrigated tomato as related to rooting volume and uptake of $\mathrm{N}$ and water. Agronomy Journal, v. 72, p. 815-822, 1980.

BATAGLIA, O.C.; FURLANI, A.M.C.; TEIXEIRA, J.P.F.; FURLANI, P.R.; GALLO, J.R. Métodos de análise química de plantas. Campinas: Instituto Agronômico, 1983. 48 p. (Boletim Técnico, 78). 
BATAL, K.M.; SMITTLE, D. A . Response of bell pepper to irrigation, nitrogen and plant population. Journal American Society for Horticultural Science, v. 106, n.3, p.259-262, 1981.

BOARETTO, A.E. Análise química de terra e recomendação de calagem e adubação para as principais culturas do Estado de São Paulo. Botucatu: Fundação de Estudos Agrícolas e Florestais, 1986. 50 p. (Boletim Didático, 2).

BOHN, W. Methods of studying root systems. Berlin: Springer-Velag, 1979. 189p.

BOUWMEESTER, R.J.B.; VLEK, P.L.G.; STUMPE, J.M. Effect of environmental factors on ammonia volatilization from a urea-fertilizer soil. Soil Science Society of American Journal, v.49, p. 376-381, 1985.

BREMNER, J.M. Inorganic forms of nitrogen. In: BLACK, C.A. (Ed.). Methods of soil analysis. Madison: American Society of Agronomy, 1965. pt.2, p. 1179-1237.

BREMNER, J.M.; MULVANEY, C.S. Nitrogen total. In: PAGE, A.L.; MILLER, R.H.; KEENEY, D.R. (Ed.). Methods of soil analisys. Chemical and microbiological properties. 2 (Ed.). Madison, ASA, 1982. V. 2, cap.31, p. 595-624, (Agronomy; a series of monographs, 9).

CARBALLO, S.J.; BLANKENSHIP, S.M.; SANDERS, D.C. Drip fertigation with nitrogen and potassium and post harvest susceptibility to bacterial soft rot of bell peppers. Journal of Plant Nutrition, v.17, n. 7, p.1175-1191, 1994.

CHOUGULE, A B.; MAHAJAN, P.R. Effects of varying levels of plant population, nitrogen, phosphorus and potash on growth and yield of chilli (Capsicum annuum L.). Vegetable Science, v.6, n.2, p. 73-80, 1979. 
COVARELLI, G. L'influenza della concimazione sulla resa quantitativa e qualitativa del peperone. Rivista di Agronomia, v. 10, n.3, p. 178-186, 1974.

CRESPO RUIZ, M.; GOYAL, M.; BAEZ, C.C. de; RIVIERA, L.E. Nutrient uptake and growth characteristics of nitrogen fertigated sweet peppers under drip irrigation and plastic mulch. Joumal of Agriculture of the University of Puerto Rico, v. 72, n. 4, p. $575-585,1988$.

CRUCIANI, D.E. A drenagem na agricultura. São Paulo: Nobel, 1980. 333 p.

EI SAIED, H.M. Chemical composition of sweet and hot pepper fruits grown under plastic house conditions. Egyptian Journal of Horticulture, v.22, n.1, p. 11-18, 1995.

ERNST, J.W.; MASSEY, H.F. The effects of several factors on volatilization of ammonia formed from ureia in the soil. Soil Science Society of American Joumal, v.24, p. 87-90, 1960.

EVERETT, P.H. Effect of nitrogen and potassium rates on fruit yield and size of mulch grown staked tomatoes. Proceedings Florida State of Horticultural Society, v. 89, p. 159-162, 1976.

EVERETT, P.H.; SUBRAMANYA, R. Pepper production as influenced by plant spacing and nitrogen-potassium rates. Proceedings Florida State of Horticultural Society, v.96, p.79-82, 1983.

FAGERIA, N.K.; SINGH, H. Response of wheat to soil application of nitrogen and sulphum. Pesquisa Agropecuária Brasileira, v. 17, n. 8, p. 1121-1126, 1982.

FASSBENDER, H.W. Química de suelos. Costa Rica: Matilde de La Cruz, 1975. $397 \mathrm{p}$. 
FEIGIN, A.; RYLSKI, I.; MEIRI, A.; SHALHEVET, J. Response of melon and tomato plants to chloride-nitrate ration in saline nutrient solutions. Journal of Plant Nutrition, v. 10, n. 9-16, p. 1787-1794, 1987.

FISKELL, J.G.A.; LOCASCIO, S.J.; SINGHOLKA, S.; MARTIN, F.G. Effects of fertilization $\mathrm{N}$ sources, rates and placement on soil test values for bedded peppers with and without mulch. Soil and Crop Science Society of Florida Annual Proceedings, v. 37, p. 183-188, 1978.

FONSECA, A.F.A. da. Avaliação do comportamento de cultivares de pimentão (Capsicum annuum L.) em Rondônia. Porto Velho: EMBRAPA, 1986. 6 p.

FUJIMURA, M.; KURACHI, S.A.H.; ARRUDA, F.B.; PIRES, R.C. de M. A técnica de estudo de raízes pelo método do trado. Campinas: IAC, 1994. 10p. (Boletim Técnico, 153).

GUINES, A.; INAL, A.; ALPASLAN, M. Effect of salinity on stomatal resistance, proline and mineral composition of pepper. Journal of Plant Nutrition, v. 19, n. 2, p. 389396, 1996.

GOLDBERG, D.; GORNAT, B.; BAR-YOSEF, B. The distribution of roots, water and minerals as a result of trickle irrigation. Journal American Society for Horticultural Science, v. 96, p. 645-648, 1971.

GOLLIFER, D.E. Effect of aplications of potassium on annual crops grown on soils of the Dala Series in Malaita, British Solomon Islands. Tropical Agriculture, v. 49, n. 3, p. 261-268, 1972.

GOLLIFER, D.E. Effects of applications of mulch and potassium on Capsicum annuum. Papua New Guinea Journal of Agriculture, Forestry and Fisheries, v. 36, n.1, p. 22-29, 1993. 
GOMES, F.P. A estatística moderna na pesquisa agropecuária. 2. ed. Piracicaba: Potafos, 1987. $162 \mathrm{p}$.

GOMES, I.; PEDRENÕ, J.N.; MORAL, R. ; IBORRA, M.R.; PALACIOS, G.; MATRIX, J. Salinity and nitrogen fertilization affecting the macronutrient content and yield of sweet pepper plants. Journal of Plant Nutrition, v. 19, n. 2, p. 353-359, 1996.

GONZÁLEZ, A.; BEALE, A. N and P fertilizers and growth and yield of sweet pepper. Journal of Agriculture of the University of Puerto Rico, v. 71, n. 2, p. 209-215, 1987.

GOYAL, M.R.; CRESPO RUIZ, M.; RIVERA, LE. Root distribution of nitrogen fertigated sweet peppers under drip irrigation. Joumal of Agriculture of the University of Puerto Rico, v. 72, n. 1, p. 51-55, 1988.

GOYAL, M.R.; LUNA, R. G.; HERNÁNDEZ, E.R. de; BÁEZ, C.C. de. Pos-harvest evaluation of nitrogen fertigated sweet peppers under drip irrigation and plastic mulch. Journal of Agriculture of University of Puerto Rico, v. 73, n. 2, p. 109-115, 1989.

GRAIFENBERG, A.; PETSAS, S.; LENZI, I. Crescita e asportazione degli elementi nutritivi nel peperone allevato in serra fredda. Colture Protette, v. 12, p. 33-38, 1985.

GUILLEN, M.G.; FERNANDEZ, F.G.; CARO, M. Experiencias de fertilizacion con pimiento, tomate y algodon en suelos pardo calizos del campo de Cartagena (Murcia). Anales de Edafologia y Agrobiologia, v. 25, p. 589-598, 1966.

HAAG, H.P.; HOMA, P.; KIMOTO, T. Nutrição mineral de hortaliça. V - Absorção de nutrientes pela cultura do pimentão. O Solo, v. 62, n.2, p. 7-11, 1970. 
HARTZ, T.K.; LeSTRANGE, M.; MAY, D.M. Nitrogen requirements of drip-irrigated peppers. HortScience, v.28, n.11, p.1097-1099, 1993.

HASSAN S.A.; RAMLAN, Z. A. Influence of potassium fertilizer and mulching on growth and yield of chilli (Capsicum annuum L.). Acta Horticulture, v. 369, p.311318, 1994.

HASSAN, S.A.; GERBER, J.M. SPLITTSTOESSER, W.E. Growth and yield potential of green pepper as affected by nitrogen at transplanting. Pertanika Journal Tropical Agricultural Science, v. 16, n. 2, p. 101-105, 1993.

HEGDE, D.M. Irrigation and nitrogen requirement of bell pepper (Capsicum annuum). Indian Journal of Agricultural Sciences, v.58, n.9, p.668-672, 1988.

HEGDE, D.M. Effect of soil moisture and nitrogen on plant water relations, mineral composition and productivity of bell pepper (Capsicum annuum L.). Indian Journal of Agronomy, v. 34, n.1, p.30-34, 1989.

HEGDE, D.M. Growth analysis of bell pepper (Capsicum annuum L.) in relation to soil moisture and nitrogen fertilization. Scientia Horticulturae, v.33, p.179-187, 1987.

HOCHMUTH, G.J. Efficiency ranges for nitrate-nitrogen and potassium for vegetable petiole sap quick tests. Hort Tecnology, v. 4, n. 3, p. 218-222, 1994.

HOCHMUTH, G.J.; SHULER, K.; HANLON, E.; ROE, N. Pepper response to fertilization with soluble and controlled release potassium fertilizers. Proceedings Florida State of Horticultural Society, v. 107, p. 132-139, 1994.

HOCHMUTH, G.J.; SHULER, K.D.; MITCHELL, R.L.; GILREATH, P.R. Nitrogen crop nutrient requirement demonstrations for mulched pepper in Florida. Proceedings Florida State of Horticultural Society, v.100, p.205-209, 1987. 
HOCHMUTH, J.G.; SHULER, K.D.; GILREATH, P.R.; MITCHELL, R.L. Field testing of revised Mehlichl predicted potassium fertilizer recommendation for mulched pepper. Soil and Crop Science Society of Florida Annual Proceedings, v. 47, p. 30-35, 1988.

HORTENSTINE, C.C. The response of sweet peppers in everglades organic soils to $P$ and $\mathrm{K}$ fertilization. Proceedings Florida State of Horticultural Society, v. 75, p. 146-152, 1962.

HULUGALLE, N.R.; WILLATT, S.T. Patterns of water uptake and root distribution of chilli peppers grown in soil columns. Canadian Journal of Plant Science, v. 67, p. $531-535,1987$.

ILEY, J.R.; OZAKI, H.Y. Nitrogen-potash ratio study with plastic mulched pepper. Proceedings Florida State of Horticulture Society, v.79, p.211-216, 1966.

JAWORSKI, C. A.; KAYS, S.J.; SMITLE, D.A . Effects of nitrogen and potassium fertilization in trickle irrigation on yield of pepper and polebean. Hortscience, v.13, p.477-478, 1978.

JEYARAMAN, S.; BALASUBRAMANIAN, R. Role of potassium treatment on yield and incidence of pests and diseases in chilli. Journal of Potassium Research, v.4, n.2, p.67-70, 1988.

JOHNSON, C.D.; DECOTEAU, D.R. Nitrogen and potassium fertility affects jalapeño pepper plant growth, pod yield, and pungency. Hortscience, v.31, n.7, p.11191123, 1996.

JONES, R.D.; SCHWAB, A.P. Nitrate leaching and nitrate occurrence in a fine texture soil. Soil Science, v. 155, n. 4, p. 272-282, 1993. 
JOSEPH, P.A.; PILLAI, P.B. Effect of N, P and $K$ on the growth and yield of chilli, variety pant $C_{1}$. Agricultural Research Journal of Kerala, v. 23, n. 1 , p. 75-82, 1985.

KAFKAFI, V.; BAR-YOSEF, B. Trickle irrigation and fertilization of tomatoes in hight calcareous soils. Agronomy Journal, v. 72, p. 873-897, 1980.

KHAN, M.A.R.; SURYANARAYANA, V. Effect of N P and K on flowering, fruit size and yield of chilli. Vegetable Science, v. 4, n. 1, p. 53-60, 1977.

KNAVEL, D.E. The influences of nitrogen on pepper transplant growth and yielding of plants grown with different levels of soil nitrogen. Journal American Society for Horticultural Science, v. 102, n. 5, p. 533-535, 1977.

NATHU LAL.; PUNDRIK, K.C. Effect of nitrogen, phosphorus and potassium on the growth and yield of chilli (Capsicum annuum L.). Punjab Horticulture Joumal, v.11, n.1-2, p.22-26, 1971.

LARA CABEZAS, W.A.R.; TRIVELIN, P.C.O.; BOARETTO, A.E. Efeito do tamanho de grânula e relação N/S da uréia aplicada em superfície na volatilização de amônia sob diferentes umidades iniciais do solo. Revista Brasileira da Ciência do Solo, v. 16, p. 409-413, 1992.

LESKOVAR, D.I.; CANTLIFFE, D.J.; STOFFELLA, P.J. Pepper (Capsicum annuum L.) root growth and its relation to shoot growth in response to nitrogen. Journal of Horticultural Science, v. 64, n. 6, p. 711-716, 1989.

LOCASCIO, S. J.; FISKELL, J.G.A. Pepper response to sulphur-coated urea, mulch and nitrogen rate. Proceedings Florida State of Horticultural Society, v. 92, p.112-115, 1979. 
LOCASCIO, S.J.; ALLIGOOD, M.R. Nitrogen and potassium source and N-rate for drip-irrigated pepper. Proceedings Florida State of Horticultural Society, v.105, p.323-325, 1992.

LOCASCIO, S.J.; FISKELL, J.G.A. Pepper production as influenced by mulch, fertilizer placement and nitrogen rate. Soil and Crop Science Society of Florida Annual Proceedings, v. 36, p. 113-117, 1977.

LOCASCIO, S.J.; FISKELL, J.G.A.; MARTIN, F.G. Responses of bell pepper to nitrogen sources. Journal of the American Society for Horticultural Science, v. 106, p.628-632, 1981.

LOCASCIO, S.J.; FISKELL, J.G.A.; GRAETZ, P.A.; HAUCK, R.D. Nitrogen accumulation by pepper as influenced by mulch and time of fertilizer application. Journal American Society for Horticultural Science, v.110, p.315-318, 1985.

LOCASCIO, S.J.; STALL, W.M. Bell pepper yield as influenced by plant spacing and row arrangement. Joumal American Society for Horticultural Science, v. 119, n. 5, p. 899-902, 1994.

LORENZ, O . A .; VITTUM, M.T. Phosphorus nutrition of vegetables crops and sugar beets. In: KHASAWNEH, F.E.; SAMPLE, E.C.; KAMPRATH, E.J.(Ed.). The role of phosphorus in agriculture. Madison: ASA, 1980. p.737-762.

MAGNíFICO, V. La fertilizzazione delle colture orticole in funzione dei ritmi di accrescimento e di asportazione dei principali elementi nutritivi. Colture Protette, v. 16, n.3, p. $71-79,1987$. 
MALAVOLTA, E.; SANTOS, A.J.R. do; FRANÇA, A.F. de; FACHINELLO, J.C.; BARBOSA FILHO, M.P. Estudo sobre a nutrição mineral do arroz. XXVII. Fatores que influenciam a absorção radicular do fósforo pela variedade IAC-164. Anais da Escola Superior de Agricultura "Luiz de Queiroz", v. 41, p. 307-332, 1984.

MALAVOLTA, E.; VITTI, G.C.; OLIVEIRA, S.A. de. Avaliação do estado nutricional de plantas: princípios e aplicações. 2. ed. Piracicaba: Potafos, 1997. 319 p.

MANCHANDA, A.K.; SINGH, B. Effect on plant density and nitrogen on yield and quality of bell pepper (Capsicum annuum L.). Indian Journal of Horticulture, v. 44, n. 3-4, p. 250-252, 1987.

MANCHANDA, A.K.; SINGH, B. Effect of plant density and nitrogen on growth and fruit yield of bell pepper (Capsicum annuum L.). Indian Journal of Agronomy, v. 33, n. 4, p. 445-447, 1988.

MARSCHNER, H. Mineral nutrition of higher plants. 2. ed. San Diego: Academic Press, 1997. $889 \mathrm{p}$.

MARSCHNER, H. Mineral nutrition of higher plants. London: Academic Press, 1985.

MAYNARD, D.N.; LACHMAN, W.H.; CHECK, R.M.; VERNELL, H.F. The influence of nitrogen levels on flowering and fruit set of peppers. Proceedings American Society for Horticultural Science, v.81, p.385-389, 1962.

MILLER, C.H. Some effect of different levels of five nutrient elements on bell peppers. Proceedings American Society for Horticultural Science, v.77, p. 440-449, 1961. 
MILLER, C.H.; MCCOLLUM, R.E.; CLAIMON, S. Relationships between growth of bell peppers (Capsicum annuum L.) and nutrient accumulation during ontogeny in field environments. Journal American Society of Horticultural Science, v.104, n.6, p.852-857, 1979.

MILLS, H.A.; BENTON JONES JR. Plant analysis handbook. II: A practical sampling, preparation, analysis and interpretation guide. Athens: MicroMacro Publishing, 1996. 422 p.

MISHRIKY, J.F.; ALPHONSE, M. Effect of nitrogen and plant spacing on growth, yield and fruit mineral composition of pepper (Capsicum annuum L.). Bulletin of Faculty of Agriculture University of Cairo, v. 45, n. 2, p. 413-431, 1994.

MORENO, D.A.; PULGAR, G.; VÍLLORA, G.; ROMERO, L. Effect of $N$ and $K$ on fruit production and leaf levels of $\mathrm{Fe}, \mathrm{Mn}, \mathrm{Zn}, \mathrm{Cu}$ and $\mathrm{B}$ and their biochemical indicator in capsicum plants. Phyton, v. 59, n. 1-2, p. 1-12, 1996.

NAGAI, H. Pimentão. In: Fahl, J.I.; Camargo, M.B.P. de; Pizzinatto, M.A.; Furlani, A.M.C.; Betti, J.A.; Mello, A.M.T. de; Maria, I.C. de; (Ed.). Instruções agrícolas para o Estado de São Paulo. 6. ed. Campinas: Instituto Agronômico, 1995. p. 335337. (Boletim, 200).

NASCIMENTO, W. N.; BOITEAUX, L.S. Produção de sementes de pimentão em Brasília. Horticultura Brasileira, v.10, n.2, 125-126, 1992.

NIGRI, F.M. Fertilizacion del pimiento (Capsicum annuum) em cultivo bajo cobertura plastica. Corrientes: Universidad Nacional del Nordeste, Faculdad de Ciências Agrarias, 1990. 41 p.

O'SULLIVAN, J. Response of peppers to irrigation and nitrogen. Canadian Journal of Plant Science, v.59, p.1085-1091, 1979. 
OLSEN, J.K.; LYONS, P.J.; KELLY, M. Nitrogen uptake and utilization by bell pepper in subtropical Australia. Joumal of Plant Nutrition, v.16, n.1, p.177-193, 1993.

OLSEN, J.K.; LYONS, P.J. Petiole sap nitrate is better than total nitrogen in dried leaf for indicating nitrogen status and yield responsiveness of capsicum in subtropical Australia. Australian Joumal of Experimental Agriculture, v.34, p.835-843, 1994.

OZAKI, H.Y.; OZAKI, C.T.; HAMILTON, M.G. The effects of applied nitrogen, phosphorus and potash on yield and growth of peppers. Proceedings Florida State of Horticultural Society, v. 68, p. 230-233, 1955.

PAYERO, J.O. ;BHANGOO, M.S. Nitrogen fertilizer management practices to enhance seed production by by 'Anaheim Chili' peppers. Journal American Society for Horticultural Science, v. 115, n. 2, p. 245-251, 1990.

PEREIRA, E.C. Avaliação do crescimento e produtividade de pimentão matriciais de água no solo, em condições de casa de vegetação. Botucatu, 1995. 64 p. Dissertação (Mestrado) - Faculdade de Ciências Agronômicas, Universidade Estadual Paulista.

PERSAUD, N.; LOCASCIO, S.J.; GERALSON, C.M. Influence of fertilizer rate and placement and irrigation method on plant nutrient status, soil soluble salt and root distribution of mulched tomatoes. Soil and Crop Science Society of Florida Annual Proceedings, v. 36, n. 1, p. 121-125, 1977.

PESSARAKLI, M.; TUCKER, T.C. Dry matter yield and nitrogen 15 uptabke by tomatoes under sodium chloride stress. Soil Science Society of American Journal, v. 52, p. 698-700, 1988. 
PLESSIS, J.P.; AGENBAG, G.A . Reaction of two wheat cultivars to nitrogen and sulphur fertilizer in the Swartland I. Vegetative growth, nitrogen and sulphur uptake and concentration in the plant. South African Journal of Plant and Soil, v.11, n.4, p.163-169, 1994.

POBLETE, E.R. El cultivo de las chiles dulces: Novedades Horticolas, v. 16, n. 1-4, p. 21-27, 1971.

PRINCE, C.A.; SANDERS, D.C.; CAMPBELL, C.R. Response of pepper to $\mathbf{N}$ fertilizer and N/K rations. In: INTERNATIONAL MICRO-IRRIGATION CONGRESS, 4, Albury - Wodonga, 1988. Proceedings. v.2

RAIJ, B. van; CANTARELLA, H.; QUAGGIO, J.A.; FURLANI, A.M.C. Recomendação de adubação e calagem para o Estado de São Paulo. Campinas: IAC , 1996. $285 p$.

RAIJ, B. van; QUAGGIO, J.A.; CANTARELLA, H.; FERREIRA, M.E.; LOPEZ, A.S.; BATAGLIA, O.C. Análise química do solo para fins de fertilidade. Campinas: Fundação Cargill, 1987. 170 p.

RAMANATHAN, N. Apply NPK fertilizers for bigger chilli yield. Fertilizer News, v. 10, n. 9, p. $7-12,1965$.

REUTER, D.J.; ROBINSON, J.B. Plant analysis: a interpretation manual, and 2. (Ed.). Callingwood: CSIRO, 1997. 572 p.

RICHTER, R.; SVOBOVA, J.; CHMELA, V. The effect of graduated rates of $\mathrm{K}_{2} \mathrm{O}$ on the yield and quality of sweet peppers. The effect of graduated rates of $\mathrm{K}_{2} \mathrm{O}$ on the nutrient content of sweet peppers. Bull. vyzk. Úst. Zelin., Olomouc, v. 12/13, p. 93104; 105-116, 1968-1969. Resumo 6829 em Horticulture abstracts v.41. 
RINCON, L.; SAEZ, J.; BALSALOBRE, E.; PELLICER, C. Crecimiento y absorcion de nutrientes del pimiento grueso en cultivo bajo invemadero. Investigation Agraria: Produccion y Proteccion Vegetale, v.10, n.1, p.47-49, 1995.

ROYCHOUDHURY, A.; CHATTERJEE, R.; MITRA, S.K. Effect of different doses of nitrogen, phosphorus, potassium, calcium, magnesium and iron on growth and development in chilli. Indian Cocoa - Areconut and Spices Journal, v. 13, $n^{\circ} 3$, p. 96-99, 1990.

RUSSO, V.M. Effects of fertilizer rate, application timing and plant spacing on yield and nutrient content of bell pepper. Journal of Plant Nutrition, v.14, p.1047-1056, 1991.

SALINAS, R.M.; CERDA, A.A.; FERNANDEZ, F.G. Efecto del boro sobre la composicion mineral de guisante y pimiento. Anales de Edafologia y Agrobiologia, v. 41, n. 5-6, p. 991-1001, 1982.

SANTIAGO, C.L.; GOYAL, M.R. Nutrient uptake and solute movement in drip irrigated summer peppers. Joumal Agriculture of the University of Puerto Rico, v. 69, n. 1, p. 63-68, 1985.

SHARMA, R.N.; PRASAD, R. Studies on the fertilizer requirement of chilli. Indian Cocoa - Areconut and Spices Journal, v. 16, n. 2, p. 47-51, 1992.

SHARMA, A. K.; SHARMA, A . M.; SHARMA, Y.M. Effect of irrigation, nitrogen and sulphur application on seed yield, quality and sulphur uptake by Indian mustard (Brassica juncea). Agriculture Science Digest, v.14, n.1, p.63-67, 1994.

SHUKLA, V.; SRINIVAS, K.; PRABHAKAR, B.S. Response of bell pepper to nitrogen, phosphorus and potassium fertilization. Indian Journal of Horticulture, v. 44, n. 1-2, p. 81-84, 1987. 
SILVESTRE, G.; SIVIERO, P. Effetti del sistema irriguo della pacciamatura delle fertilizzazione sulla produzione del peperone. Informatore Agrario, v. 50, n. 27 , p. 41-52, 1994.

SILVA, M.R.L. Efeito de diferentes substrato na formação de mudas de pimentão (Capsicum annuum L.) em bandejas de polietireno expandido. Jaboticabal, 1994. 68p. Monografia (Graduação) - Faculdade de Ciências Agrárias e Veterinária, Universidade Estadual Paulista.

SINGH, K.; SRIVASTAVA, B.K. Effect of various levels of nitrogen and phosphorus on growth and yield of chilli (Capsicum annuum L.). Indian Joumal of Horticulture, v. 45, p. $319-324,1988$.

SINGH, V.; SHARMA, D.K.; BHAGWAN, B.V.K. Effect of level of nitrogen and time of its application on growth, yield and net-profit of chilli. Progressive Horticulture, v. 20, n. $1-2$, p. $80-86,1988$.

SIVIERO, P.; GALLERANI, M. La cultivazione del pepperone. Verona : Edizioni. L'informatore Agrario, 1992. 217 p.

SRINIVAS, K.; PRABHAKAR, B.S. Response of capsicum to nitrogen fertilization. Vegetable Science, v. 9, p. 71-74, 1982.

STROEHLEIN, J.L.; OEBKER, N.F. Effects of nitrogen and phosphorus on yields and tissue analyses of chili peppers. Communications in Soil Science and Plant Analysis, v.10, n.3, p.551-563, 1979.

SUBBIAH, K.; HELKIAH, J.; RAVIKUMAR, Y.; RAJAGOPAL, C.K. Effect of combined application of organic and inorganic fertilizers on the yield and nutriente uptake of MDU.1 chilli. South Indian Horticulture, v. 30, p. 45-47, 1982. 
SUBHANI, P.M.; RAVISANKAR, C.; NARAYANA, N. Effect of graded levels and time of application of $\mathrm{N}$ and $\mathrm{K}_{2} \mathrm{O}$ on flowering, fruiting and yield of irrigated chilli. Indian Cocoa - Arecanut and Spices Journal, v. 14, n. 2, p. 70-73, 1990.

SUNDSTROM, F.J.; THOMAS, C.H.; EDWARDS, R.L.; BASKIN, G.R. Influence of N and plant spacing on mechanically harvested tabasco pepper. Journal American Society for Horticultural Science, v.109, n.5, p.642-645, 1984.

SWIADER, J.M.; MORSE, R.D. Phosphorus solution concentration for production of tomate, pepper and eggplant in minesoils. Journal American Society for Horticultural Science, v. 107, n. 6, p. 1149-1153, 1982.

THOMAS, J.R.; HEILMAN, M.D. Nitrogen and phosphorus content of leaf tissue in relation to sweet pepper yields. Proceedings American Society for Horticultural Society, v.85, p.419-425, 1964.

THOMAS, J.R.; HEILMAN, M.D. Influence of moisture and fertilizer on growth and $N$ and $\mathrm{P}$ uptake by sweet peppers. Agronomy Journal, v.59, p.27-30, 1967.

VANANGAMUDI, K.; SUBRAMANIAN, K.S.; BASKARAN, M. Influence of irrigation and nitrogen on the yield and quality of chilli fruit and seed. Seed Research, v. 18, n. 2, p. 114-116, 1990.

VARGAS-RAMíREZ, L.G.; LORIA-MARTINEZ, W.; PEREZ-ARGUEDAS, O.A. Efecto de nitrogeno, fosforo, potasio y sus interacciones en la produccion de chile dulce (Capsicum annuum). Boletin Tecnico, Universidad de Costa Rica, v. 9, n. 1, p. 1-17, 1976.

VLEK, P.L.G.; CARTER, M.F. The effects of soil environments and fertilizers modifications on the rate of urea hydrolisys . Soil Science, v. 136, p. 56-63, 1983. 
WIDDERS, I.E.; LORENZ, O.A.. Potassium nutrition during tomato plant development. Journal American Society for Horticultural Science, v. 107, n. 6, p. 960-964, 1982.

WIEDENFELD, R.P. Rate, timing, and slow-release nitrogen fertilizers on bell peppers and muskmelon. Hortscience, v.21, n.2, p.233-235, 1986.

WOSTEN, J.H.M.; GENUCHTEN, M. TH. van. Using texture and other soil properties to predict the unsaturated soil hydraulic functions. Soil Science Society of American Journal, v.52, p.1762-1770, 1988.

ZHAO, F.J.; EVANS, E.J.; BILSBORROW, P.E.; SYERS, J.K. Sulphur uptake and distribution in double and single low varieties of oilseed rape (Brassica napus L.). Plant and Soil, v. 150, p. 69-76, 1993.

ZORNOZA, P.; AROZARENA. B. Estudio de la composicion quimica de plantas de pimiento a lo largo del ciclo de cultivo. Anales de Edafologia y Agrobiologia, v. 45, n. 1-2, p. 163-172, 1986. 


\section{APÊNDICE}

APÊNDICE I. Temperatura e umidade no interior do túnel plástico, durante o crescimento da cultura do pimentão.

\begin{tabular}{|c|c|c|c|c|c|c|}
\hline \multirow[t]{3}{*}{ Mês/ano } & \multirow{2}{*}{\multicolumn{3}{|c|}{ Temperatura }} & \multicolumn{3}{|c|}{ Umidade } \\
\hline & & & & & $(\%)$ & \\
\hline & máxima & mínima & média & máxima & mínima & média \\
\hline Novembro/96 & 43,3 & 14,9 & 29,1 & 99 & 26 & 63 \\
\hline Dezembro & 47,5 & 17,0 & 32,3 & 99 & 25 & 62 \\
\hline Janeiro/97 & 49,0 & 19,1 & 34,1 & 99 & 18 & 59 \\
\hline Fevereiro & 47,0 & 18,0 & 32,5 & 99 & 25 & 62 \\
\hline Março & 55,2 & 15,3 & 35,3 & 99 & 13 & 56 \\
\hline Abril & 38,9 & 14,5 & 26,7 & 99 & 33 & 66 \\
\hline Maio & 34,4 & 11,9 & 23,2 & 99 & 31 & 65 \\
\hline Junho & 35,1 & 4,4 & 19,8 & 99 & 26 & 63 \\
\hline Julho & 35,0 & 10,9 & 23,0 & 99 & 28 & 64 \\
\hline Agosto & 40 & 2,4 & 21,4 & 99 & 18 & 59 \\
\hline
\end{tabular}

Dados medidos diariamente no interior do túnel plástico. 